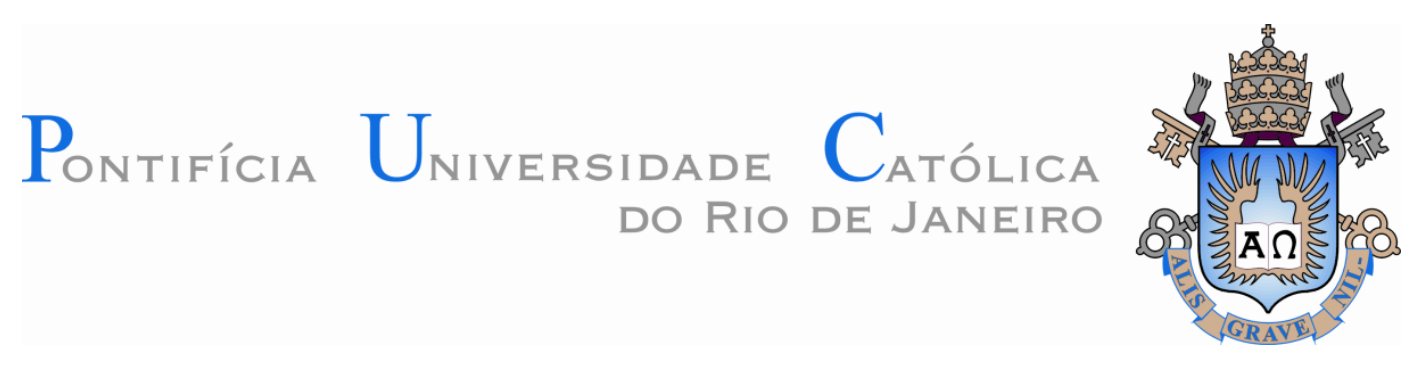

Marcelo Sampaio De Simone Teixeira

\title{
Análise termomecânica das tensões em poços de petróleo utilizando abordagens analítica e numérica
}

\section{Dissertação de Mestrado}

Dissertação apresentada como requisito parcial para obtenção do grau de Mestre pelo Programa de Pósgraduação em Engenharia Civil do Departamento de Engenharia Civil da PUC-Rio.

Orientadora: Profa. Deane de Mesquita Roehl Coorientadora: Dra. Fernanda Lins Gonçalves Pereira 


\title{
Marcelo Sampaio De Simone Teixeira
}

\section{Análise termomecânica das tensões em poços de petróleo utilizando abordagens analítica e numérica}

Dissertação apresentada como requisito parcial para obtenção do grau de Mestre pelo Programa de PósGraduação em Engenharia Civil do Departamento de Engenharia Civil do Centro Técnico Científico da PUCRio. Aprovada pela Comissão Examinadora abaixo assinada.

\author{
Profa. Deane de Mesquita Roehl \\ Orientadora \\ Departamento de Engenharia Civil - PUC-Rio \\ Dra. Fernanda Lins Gonçalves Pereira \\ Co-Orientadora \\ Departamento de Engenharia Civil - PUC-Rio \\ Prof. Raul Rosas e Silva \\ Departamento de Engenharia Civil - PUC-Rio \\ Prof. Edgard Poiate Júnior \\ Universidade do Estado do Rio de Janeiro e \\ CENPES/PETROBRAS \\ Prof. Márcio da Silveira Carvalho \\ Coordenador Setorial do Centro \\ Técnico Científico - PUC-Rio
}

Rio de Janeiro, 22 de junho de 2016 
Todos os direitos reservados. É proibida a reprodução total ou parcial do trabalho sem autorização da universidade, do autor e do orientador.

\section{Marcelo Sampaio De Simone Teixeira}

Graduou-se em Engenharia Civil pela Pontifícia Universidade Católica do Rio de Janeiro (PUC-Rio) em 2013. Em 2014, ingressou no curso de mestrado em engenharia civil, da PUC-Rio, na área de estruturas, onde vem desenvolvendo investigações na linha de pesquisa em geomecânica computacional. Participou de um evento científico internacional (Cilamce 2015) e submeteu um artigo no International Journal of Rock Mechanics and Mining Sciences.

Ficha Catalográfica

Teixeira, Marcelo Sampaio De Simone

Análise termomecânica das tensões em poços de petróleo utilizando abordagens analítica e numérica / Marcelo Sampaio De Simone Teixeira; orientadora: Deane de Mesquita Roehl; Fernanda Lins Gonçalves Pereira Rio de Janeiro: PUC, Departamento de Engenharia Civil, 2016.

$$
\text { v., } 115 \text { f.: il.; } 29,7 \mathrm{~cm} \text {. }
$$

1. Dissertação (mestrado) - Pontifícia Universidade Católica de Rio de Janeiro, Departamento de Engenharia Civil.

Inclui referências bibliográficas

1. Engenharia Civil - Teses. 2. Método dos elementos finitos. 3. Poços de petróleo. 4. Solução analítica. 5. Processo construtivo. I. Roehl, Deane de Mesquita. II. Pereira, Fernanda Lins Gonçalves. III. Pontifícia Universidade Católica do rio de Janeiro. Departamento de Engenharia Civil. IV. Título. 
Aos meus pais Celia Regina e Evandro. Aos meus irmãos Gustavo, Fernando e Felipe e à minha esposa Yasmin. 


\section{Agradecimentos}

Agradeço minha família pela paciência e pelo apoio e incentivo dados durante toda minha vida acadêmica. Em especial ao meu pai Evandro, minha mãe Celia Regina, meus irmãos Gustavo, Fernando e Felipe, e à minha esposa Yasmin.

À Professora Deane Roehl, pela orientação e pela oportunidade de fazer parte do grupo de Geomecânica Computacional do Tecgraf. Agradeço ainda por toda a disponibilidade da Professora e pela amizade criada ao longo de minha vida acadêmica.

À engenheira do Tecgraf, Dra. Fernanda Pereira, pela orientação e auxílio ao longo da dissertação. Além disso, a todo o grupo de geomecânica computacional do Tecgraf, pelo suporte dado ao longo do mestrado.

Ao Professor Raul Rosas e Silva da PUC-Rio e ao engenheiro Dr. Edgard Poiate Jr. pela contribuição dada ao trabalho.

A todos os professores do Departamento de Engenharia Civil da PUC-Rio pelos ensinamentos ao longo da graduação e do mestrado.

Ao CNPq e à PUC-Rio, pelos auxílios concedidos, sem os quais este trabalho não poderia ter sido realizado. 


\section{Resumo}

Teixeira, Marcelo Sampaio De Simone; Roehl, Deane de Mesquita; Pereira, Fernanda Lins Gonçalves. Análise termomecânica das tensões em poços de petróleo utilizando abordagens analítica e numérica. Rio de Janeiro, 2016. 115p. Dissertação de Mestrado - Departamento de Engenharia Civil, Pontifícia Universidade Católica do Rio de Janeiro.

A análise das tensões em poços de petróleo é de extrema importância para a prevenção de acidentes durante as fases de construção e produção. As simulações devem aproximar-se ao máximo da realidade, representando da melhor forma as operações ao longo da vida útil do poço e, consequentemente, aumentando sua confiabilidade. Com esse objetivo, uma solução analítica é desenvolvida utilizando uma metodologia que simula a vida útil do poço. Nessa metodologia, consideram-se os efeitos das variações de temperatura em todo modelo e de poropressão na formação. Além disso, adotam-se os materiais em regime elástico, utilizando a hipótese de poço perfeitamente circular, vertical e com cargas uniformes. A solução analítica é calculada a partir das equações de Bradley para a perfuração, e de Lamé para as fases de descida do revestimento, cimento endurecido e produção. Nessa solução é feita uma compatibilidade de deslocamentos radiais entre as superfícies em contato, possibilitando o cálculo dos incrementos de tensão ao final de cada fase. Essa mesma metodologia é utilizada na modelagem por elementos finitos. A partir de dois estudos de caso, os resultados obtidos através das abordagens numérica e analítica são comparados. O primeiro estudo de caso representa um poço no Mar do Norte, e o segundo, um poço em um campo na Bacia de Santos, Brasil. Nos dois estudos de caso, são apresentadas as tensões radiais e tangenciais ao longo do revestimento, do cimento e da rocha, e também os índices de plastificação para o revestimento e para o cimento. No segundo estudo de caso, duas profundidades são avaliadas: no reservatório, considerando um revestimento, e em uma camada mais rasa, com dois revestimentos. Em ambos os estudos de caso, os resultados encontrados pela solução analítica são iguais aos obtidos pela solução numérica, validando, portanto, a solução analítica apresentada como uma alternativa para avaliação de tensões em condições ideais.

\section{Palavras-chave}

Solução analítica; Processo construtivo; Poços de petróleo; Método dos elementos finitos. 


\section{Abstract}

Teixeira, Marcelo Sampaio De Simone; Roehl, Deane de Mesquita (Advisor); Pereira, Fernanda Lins Gonçalves (Co-advisor). Thermo-mechanical stress analyses in wellbore considering analytical and numerical approaches. Rio de Janeiro, 2016. 115p. MSc. Dissertation - Departamento de Engenharia Civil, Pontifícia Universidade Católica do Rio de Janeiro.

The assessment of the wellbore stress state is extremely important in order to prevent accidents during construction and production phases. The methodology used in the models must be closer to reality, representing the wellbore lifespan operations, and consequently, enhancing the reliability of the wellbore. Thus, an analytical solution is developed using a methodology capable of simulating some of the main steps of the wellbore operations. In this methodology, the temperature and the pore pressure variations are considered. Besides that, it is used the assumption of circular and vertical wellbore under uniform loads, considering the elastic behavior of the materials. The analytical solution is developed using Bradley equation during the drilling step and Lamé equation during the construction and production steps. Therefore, the stresses after each step are calculated using the radial displacement compatibility between the surfaces in contact. This same methodology is used in the finite element model. Based on two case studies, the results obtained by the analytical and numerical solutions are compared. The first case study represents a wellbore in the North Sea while the second, a wellbore in a field in Santos Basin, Brazil. In both case studies, the radial and tangential stresses are presented for the casings, the cements and the formation, as well as the yield index in the casings and the cements. In the second case study, two depths are assessed: in the reservoir, considering one casing, and in a shallow depth, with two casings. In these two case studies, the results from the analytical and the numerical solutions are equal. Therefore, the analytical solution is validated as an alternative to assess the stresses in ideal wellbores.

\section{Keywords}

Analytical solution; Construction process; Wellbore; Finite element method. 


\section{Sumário}

1 Introdução 18

1.1. Motivação 19

1.2. Objetivo 21

1.3. Descrição dos capítulos 21

2 Processos ao longo da vida útil do poço 23

3 Solução analítica para o cálculo de tensões em poços 27

3.1. Introdução 27

3.2. Hipóteses adotadas 30

3.3. Solução para um revestimento 32

3.3.1. Perfuração 32

3.3.2. Descida do revestimento 34

3.3.3. Cimento endurecido 38

3.3.4. Produção (efeito mecânico e temperatura em regime permanente no revestimento e cimento) 40

3.3.5. Produção (efeito térmico - transiente) 43

3.3.6. Superposição de efeitos 45

3.4. Solução analítica com dois revestimentos 45

3.4.1. Descida do revestimento interno 46

3.4.2. Cimento interno endurecido 49

3.4.3. Produção (efeitos mecânico e térmico) 50

3.4.4. Superposição dos efeitos 55

3.5. Critério de plastificação 56

3.5.1. Aço 57

$\begin{array}{lr}\text { 3.5.2. Cimento } & 57\end{array}$

4 Modelagem numérica dos processos ao longo da vida útil dos $\begin{array}{ll}\text { poços } & 59\end{array}$

4.1. Introdução 59 
4.2. Hipóteses adotadas 64

4.3. Fases modeladas 64

4.3.1. Perfuração 64

4.3.2. Descida do revestimento e cimentação 65

$\begin{array}{ll}\text { 4.3.3. Produção } & 67\end{array}$

4.4. Modelos para simulação de poços 68

$\begin{array}{ll}\text { 4.5. Critério de plastificação } & 69\end{array}$

5 Estudos de caso $\quad 70$

5.1. Estudo de caso A - Campo do Mar do Norte 71

5.1.1. Parâmetros utilizados (Shearwater em -4765 m) 71

5.1.2. Metodologia alternativa $\quad 74$

5.1.3. Resultados (Shearwater em -4765 m) 77

5.2. Estudo de caso B - Campo da Bacia de Santos, Brasil 87

5.2.1. Parâmetros utilizados (Santos em $-5130 \mathrm{~m}$ ) 87

5.2.2. Resultados (Santos em $-5130 \mathrm{~m}$ ) 89

5.2.3. Parâmetros utilizados (Santos em -3640 m) 96

5.2.4. Resultados (Santos em -3640 m) 97

6 Considerações finais 106

$\begin{array}{ll}\text { 6.1. Conclusões } & 106\end{array}$

$\begin{array}{ll}\text { 6.2. Sugestões para trabalhos futuros } & 108\end{array}$

$\begin{array}{ll}\text { Referências bibliográficas } & 110\end{array}$ 


\section{Lista de figuras}

Figura 2.1 - Projeto de poços de petróleo na Bacia de Santos, Brasil. (Fonte: Adaptada de Carrizo et al., 2011).

Figura 2.2 - Vista da seção longitudinal durante o deslocamento do cimento.

Figura 2.3 - Vista da seção longitudinal após o cimento endurecido no anular.

Figura 3.1 - Distribuição da pressão de poros no poço quando adotado fluido não penetrante. (Fonte: Adaptada de Rocha \& de Azevedo, 2009)

Figura 3.2 - Nomenclatura utilizada para os raios de cada material no caso de um poço com dois revestimentos.

Figura 3.3 - Esquema com o estado inicial de tensão da rocha e a pressão do fluido de perfuração.

Figura 3.4 - Fase de descida do revestimento com pressão interna do fluido de perfuração e pressão devida ao cimento fluido no anular.

Figura 3.5 - Pressões atuando no revestimento na fase de descida do revestimento.

Figura 3.6 - Pressão atuando na formação durante a fase de descida do revestimento.

Figura 3.7 - Representação do poço com as pressões na fase em que o cimento está endurecido.

Figura 3.8 - Pressões atuando nos materiais durante a produção.

Figura 3.9 - Variação da poropressão na formação durante a produção.

Figura 3.10 - Fase de produção considerando somente o efeito térmico.

Figura 3.11 - Pressões atuando nos revestimentos, cimento externo e na formação após a descida do revestimento interno.

Figura 3.12 - Pressões atuando na fase de cimento interno endurecido.

Figura 3.13 - Representação do poço com as pressões e com a variação de temperatura durante a produção.

Figura 3.14 - Temperatura nas interfaces entre materiais.

Figura 4.1 - Curva de fluência considerada para o cálculo da deformação do sal ao longo do tempo. (Fonte: Firme, 2013).

Figura 4.2 - Representação do estado inicial do modelo e da perfuração do poço (seção transversal). 
Figura 4.3 - Esquema com os passos de modelagem durante a descida do revestimento e a cimentação do poço (seção longitudinal).

Figura 4.4 - Configuração da fase de produção de hidrocarboneto (seção longitudinal do poço).

Figura 5.1 - Malha de elementos finitos para o caso de um poço com dois revestimentos.

Figura 5.2 - Tensão radial para o revestimento e cimento para as duas metodologias apresentadas.

Figura 5.3 - Tensão tangencial para o revestimento e cimento para as duas metodologias apresentadas.

Figura 5.4 - Índice de plastificação no revestimento e no cimento utilizando diferentes metodologias.

Figura 5.5 - Tensão radial ao longo do raio na rocha após a perfuração do poço.

Figura 5.6 - Tensão tangencial ao longo do raio da formação após a perfuração do poço.

Figura 5.7 - Tensão radial ao longo do raio do modelo após a construção do poço.

Figura 5.8 - Tensão radial ao longo da espessura do revestimento e do cimento após a construção do poço.

Figura 5.9 - Tensão tangencial ao longo do raio após a construção do poço.

Figura 5.10 - Tensão tangencial ao longo da espessura do revestimento e do cimento após a construção do poço.

Figura 5.11 - Índice de plastificação no revestimento e no cimento após a construção do poço.

Figura 5.12 - Variação de temperatura ao longo do raio do poço para os modelos numérico e analítico, com variação de temperatura prescrita de $56^{\circ} \mathrm{C}$.

Figura 5.13 - Variação de temperatura no revestimento de $97 / 8^{\prime \prime}$ e no cimento utilizando os modelos numérico e analítico, com variação de temperatura prescrita de $56^{\circ} \mathrm{C}$.

Figura 5.14 - Tensão radial ao longo do raio do poço ao final da análise.

Figura 5.15 - Tensão radial ao longo da espessura do revestimento e do cimento após 20 anos de análise. 
Figura 5.16 - Tensão tangencial ao longo do raio do poço após 20 anos de análise.

Figura 5.17 - Tensão tangencial no revestimento e no cimento ao final da análise.

Figura 5.18 - Índice de plastificação no revestimento e no cimento ao final da análise.

Figura 5.19 - Tensão radial no poço ao longo do raio após o final da análise.

Figura 5.20 - Tensão radial no revestimento (10 3/4") e no cimento ao longo do raio após o final da análise.

Figura 5.21 - Tensão tangencial no poço ao longo do raio durante a produção.

Figura 5.22 - Tensão tangencial no revestimento de 10 3/4" e no cimento ao longo do raio ao final da análise.

Figura 5.23 - Índice de plastificação no revestimento de 10 3/4" e no cimento ao longo do raio após o final da análise.

Figura 5.24 - Índice de plastificação na superfície interna do revestimento de 10 3/4" com diferentes cenários de variação da poropressão.

Figura 5.25 - Índice de plastificação na superfície interna do revestimento de 10 3/4" em relação a variação da poropressão da rocha, considerando um cenário de injeção.

Figura 5.26 - Comparativo do índice de plastificação no revestimento de 10 3/4" entre os cenários de variação de poropressão e de variação de temperatura simulados.

Figura 5.27 - Perfil de variação de temperatura no poço, ao longo do raio, com variação de temperatura de $55^{\circ} \mathrm{C}$ na parede do revestimento após 20 anos.

Figura 5.28 - Perfil de variação de temperatura no revestimento e no cimento, com variação de temperatura de $55^{\circ} \mathrm{C}$ na parede do revestimento após 20 anos.

Figura 5.29 - Tensão radial no poço ao longo do raio ao final da análise em poço com dois revestimentos.

Figura 5.30 - Tensão radial ao longo das espessuras dos revestimentos de 14 " e de $103 / 4$ ", e dos cimentos após 20 anos de análise.

Figura 5.31 - Tensão tangencial no poço ao longo do raio após o final da análise em poço com dois revestimentos. 
Figura 5.32 - Tensão tangencial nos revestimentos de 14" e de 10 3/4", e nos cimentos após 20 anos de análise.

Figura 5.33 - Índice de plastificação ao longo das espessuras dos revestimentos de 14" e de 10 3/4", e dos cimentos após 20 anos de análise.

Figura 5.34 - Perfil de temperatura ao longo do modelo após 20 anos de simulação.

Figura 5.35 - Perfil de temperatura nos revestimentos de 14" e de 10 3/4", e nos cimentos após 20 anos de análise.

Figura 5.36 - Índice de plastificação nos revestimentos de 14" e 10 3/4", e cimentos após 20 anos de simulação. 


\section{Lista de tabelas}

Tabela 5.1 - Parâmetros do poço. 72

$\begin{array}{ll}\text { Tabela } 5.2 \text { - Propriedades da rocha. } & 73\end{array}$

$\begin{array}{ll}\text { Tabela } 5.3 \text { - Propriedades do aço. } & 73\end{array}$

$\begin{array}{ll}\text { Tabela } 5.4 \text { - Propriedades do cimento. } & 73\end{array}$

Tabela 5.5 - Parâmetros do poço. 88

$\begin{array}{ll}\text { Tabela } 5.6 \text { - Propriedades da rocha. } & 88\end{array}$

Tabela 5.7 - Propriedades do aço. $\quad 89$

Tabela 5.8 - Propriedades do cimento. $\quad 89$

$\begin{array}{ll}\text { Tabela } 5.9 \text { - Parâmetros do poço. } & 97\end{array}$ 


\section{Lista de símbolos}

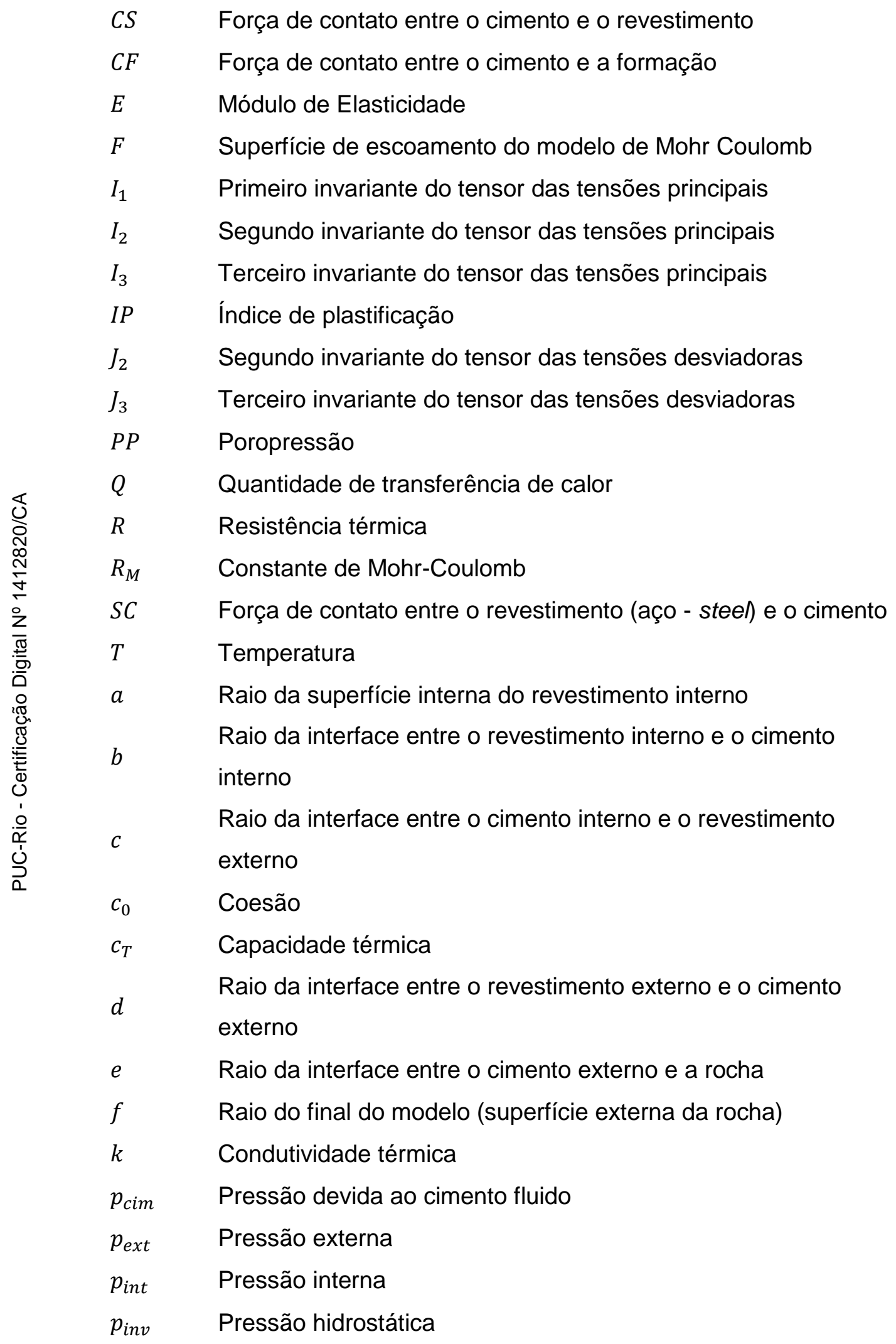




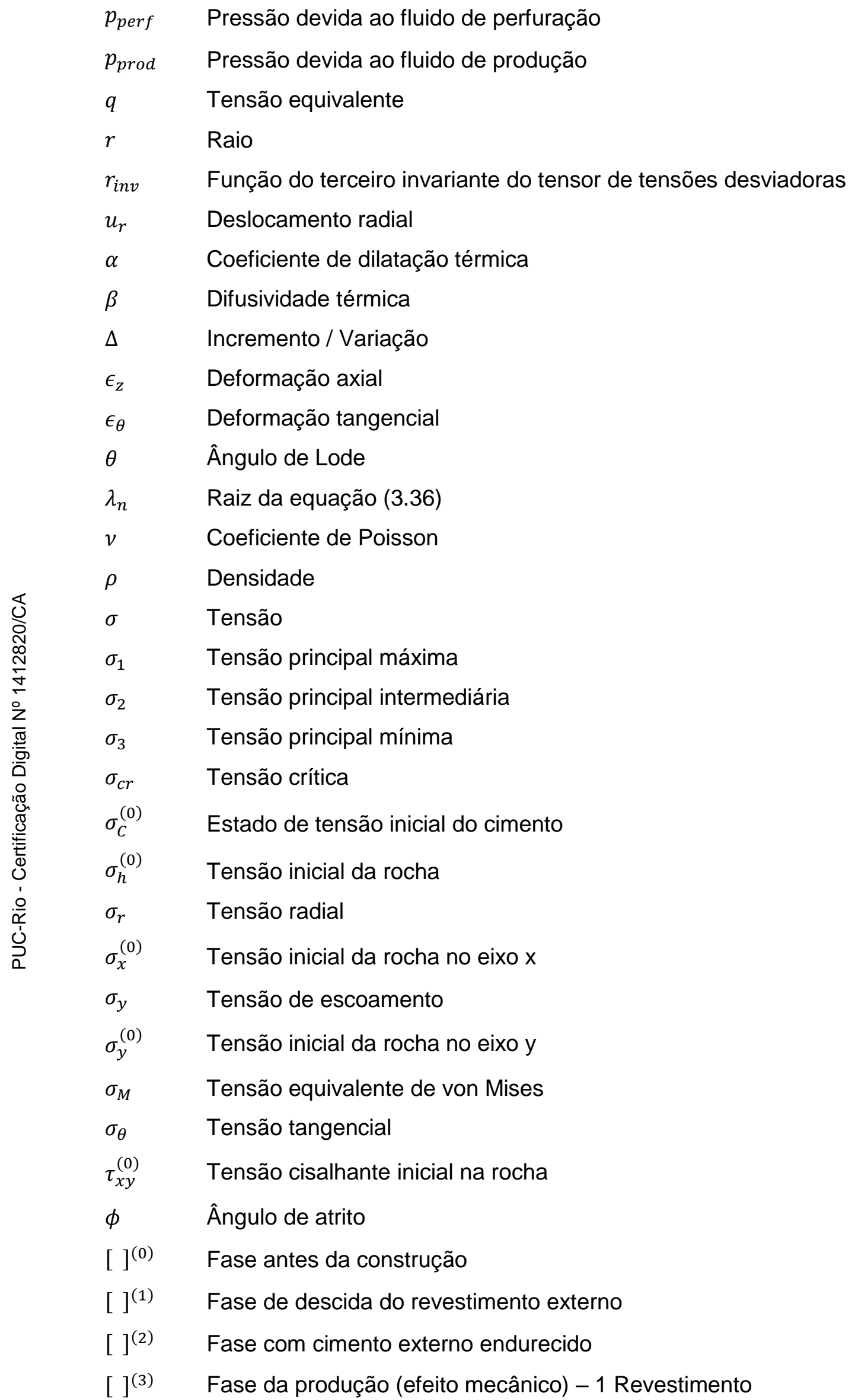


[ ] ${ }^{(3 T)}$ Fase de produção (efeito térmico) - 1 Revestimento

[ ] ${ }^{(4)} \quad$ Fase de descida do revestimento interno

[ ] ${ }^{(5)}$ Fase com cimento interno endurecido

[ ] ${ }^{(6)}$ Fase de produção (efeito mecânico) - 2 Revestimentos

[ ] ${ }^{(6 T)}$ Fase de produção (efeito térmico) - 2 Revestimentos

[ ] Referência ao cimento e revestimento internos

[ ] $]_{C}$ Cimento

[]$_{F} \quad$ Formação

[]$_{S} \quad$ Revestimento (aço - steel)

[]$_{e} \quad$ Externo

[]$_{i} \quad$ Interno 


\section{Introdução}

Devido às grandes áreas exploradas, diferentes cenários são encontrados em cada região. Algumas dessas regiões possuem poços que estão sujeitos a condições de altas temperaturas e altas pressões (HPHT - high temperature / high pressure) ou que são perfurados até as camadas abaixo do sal (pré-sal), apresentando desafios, tanto na fase de desenvolvimento do projeto, quanto nas fases de construção e produção.

Altas temperaturas, acima de $300^{\circ} \mathrm{F}\left(149^{\circ} \mathrm{C}\right)$ e altas pressões, acima de 10000 psi $(68947,57 \mathrm{kPa})$ de acordo com os limites apresentados por Teodoriu et al. (2010), tornam o processo de construção dos poços mais complexo. Algumas regiões, como a do campo de Shearwater, situado no Mar do Norte (Ravi et al., 2003), estão submetidas a altas temperaturas e altas pressões, tornando importante o estudo de estabilidade do poço e de integridade do revestimento. Assim, durante o cálculo das tensões nos poços de petróleo, os efeitos mecânicos e térmicos devem ser levados em consideração, de modo que sejam obtidas respostas mais próximas da realidade.

No caso de reservatórios abaixo da camada de sal, além da grande profundidade e, consequentemente, as altas pressões, deve-se ainda levar em conta o comportamento do sal. Poços em reservatórios na Bacia de Santos, Brasil, apresentados por Poiate Jr. et al. (2006), estão sob forte ação da fluência (deformação ao longo do tempo) do sal e, portanto, esse efeito deve ser incluído na simulação. Assim, as avaliações da estabilidade e da integridade do poço devem ser realizadas para garantir o bom desempenho do sistema.

Apesar do avanço da tecnologia, o custo de construção de poços de petróleo ainda é alto, atingindo valores na ordem de 50 milhões de dólares por poço (Lao et al., 2012). Assim, é necessária uma avaliação mais criteriosa das tensões no poço, para que não seja preciso refazer alguma fase por causa de falhas na parede do poço ou do revestimento. 
Martins et al. (1997) apresentam um problema de migração de gás no poço 4-RJS-466 e o custo da remediação desse problema para a Petrobras. Problemas relacionados a poços de petróleo também são frequentes fora do Brasil. No final da década de 90, segundo Ravi et al. (2006), apenas no Golfo do México, houve mais de 11493 revestimentos em 8122 poços de petróleo com problema de migração de gás. Falhas durante a construção de poços podem gerar problemas mais sérios durante as operações de exploração, como apresentado por Wilson (2012), que analisa as ocorrências de blowouts durante a perfuração de poços de petróleo.

Para que não seja necessário realizar investimentos financeiros para a remediação de problemas em poços, as simulações e os estudos devem englobar o maior número de efeitos e fenômenos possíveis. Considerar as variações de temperatura, poropressão e pressões atuantes podem levar a uma simulação mais realista. Por outro lado, o acesso a essas informações não é simples, além desses dados apresentarem um caráter incerto. Para aumentar a confiabilidade do projeto, diversas simulações, considerando diferentes possíveis cenários, devem ser realizadas. A solução analítica facilita esse processo, pois além de possuir como característica o rápido processamento, ainda possibilita uma análise paramétrica contínua, fixando a solução em função de uma variável específica.

Com o desenvolvimento de uma metodologia mais realista e de uma solução analítica, é possível simular as tensões em poços com mais facilidade. Assim, os cálculos tornam-se mais eficientes, ajudando na prevenção de acidentes e na redução de riscos.

Para casos mais específicos, as soluções analíticas tornam-se muito complexas ou até mesmo impossíveis, e por isso, a adoção de outras ferramentas, como o método dos elementos finitos, faz-se necessária. Problemas não uniformes e/ou que necessitem de modelos constitutivos que não são puramente elásticos, devem ser avaliados utilizando uma análise numérica. Essa análise pode ser modelada utilizando abordagens bi ou tridimensionais, dependendo das características do poço.

\section{1.}

\section{Motivação}

$\mathrm{Na}$ área de construção de poços de petróleo é importante a busca por aprimoramento das técnicas de construção com pesquisas voltadas para essa área, 
de forma a reduzir o custo financeiro e aumentar a eficiência. A perfuração de poços em grandes profundidades e em áreas de maiores desafios construtivos aumenta o risco de acidentes. Exemplos são enunciados em alguns trabalhos, como em Henderson \& Hainsworth (2014) e Heathman \& Beck (2006), que mostram diversos exemplos de ruína de poços com consequências ambientais e financeiras catastróficas. O comportamento de um poço durante sua construção é analisado em diversos estudos, como os de Mackay \& Fontoura (2014) e Brandão (2016). O trabalho de Gray et al. (2007) apresenta uma análise de tensões em poços de petróleo durante a construção e produção, demonstrando a importância de se levar em conta as diferentes fases da vida útil do poço. Além destes, o trabalho de Firme (2013) apresenta um estudo voltado para a análise probabilística de poços de petróleo em zonas de sal, auxiliando no aumento da confiabilidade durante a vida útil do poço e na redução do risco de insucessos operacionais e ambientais.

Com o avanço da tecnologia, um número cada vez maior de reservatórios têm sido explorados, e consequentemente, mais poços perfurados. Assim, soluções para avaliação da integridade e da estabilidade de poços tornam-se cada vez mais necessárias. Dessa forma, há o interesse de desenvolver ferramentas que possam ser usadas de forma cotidiana, com um rápido processamento e resultados confiáveis. Esse é o caso das soluções analíticas.

Por outro lado, em diversos trabalhos apresentados na literatura, o comportamento do poço é simulado através do método dos elementos finitos e as tensões no revestimento, no cimento e na rocha são apresentadas, como nos trabalhos de Gray et al. (2007) e Costa et al. (2010). Uma metodologia que considere a perfuração, a descida do revestimento, a cimentação e a produção mostra-se mais realista e mais próxima de representar o histórico de tensões em um poço de petróleo ao longo de sua vida útil.

Além dos efeitos mecânicos presentes nas distintas fases do poço, há também a influência da temperatura no estado de tensão final do poço. A temperatura em conjunto com as pressões no poço e a variação da poropressão na formação, podem levar a cenários mais críticos, sendo então um assunto interessante para pesquisa. 


\section{2. \\ Objetivo}

Um dos principais objetivos deste trabalho é o desenvolvimento de soluções analíticas para o cálculo das tensões nos poços levando em conta o efeito térmico e o efeito mecânico da variação da poropressão na formação rochosa. Essa solução pode ser utilizada para o pré-dimensionamento de poços e para análises de poços convencionais, sem a necessidade de utilizar programas mais sofisticados, como os de elementos finitos.

Outro objetivo é apresentar uma metodologia de modelagem de poços durante a construção do poço, e a produção de hidrocarboneto, que é utilizada nas abordagens analítica e por elementos finitos. Essa nova metodologia procura reproduzir os processos que ocorrem ao longo da vida útil do poço. Nela é incluída uma análise termomecânico considerando o efeito mecânico da variação da poropressão da rocha.

A partir das soluções analíticas e da metodologia apresentadas, tem-se ainda como objetivo avaliar a influência de cada fenômeno no estado de tensão final do poço.

\section{3. \\ Descrição dos capítulos}

No capítulo 2 uma breve introdução sobre os poços de petróleo é feita e algumas fases da sua vida útil são discutidas e explicadas.

Soluções analíticas desenvolvidas em outros trabalhos e as hipóteses adotadas por cada autor são apresentadas no capítulo 3. Bem como, informações sobre a solução analítica desenvolvida neste trabalho são discutidas e as formulações para um e dois revestimentos são apresentadas. As fases da vida útil do poço são consideradas nas formulações, levando em conta todo o histórico de tensão do poço. É feita ainda uma avaliação térmica, e as tensões resultantes do efeito da variação da temperatura são somadas às tensões mecânicas. Adiciona-se ainda o efeito mecânico da variação da poropressão, simulando a depleção ou a injeção durante a produção.

No capítulo 4, uma revisão bibliográfica dos modelos numéricos de poços de petróleo é realizada. A partir dessa coleta de informações, a metodologia de modelagem numérica (elementos finitos) de poços de petróleo é apresentada, assim 
como as hipóteses adotadas e como cada fase foi simulada. A metodologia utilizada nos estudos de caso é comparada com uma metodologia retirada da literatura.

No capítulo 5, dois estudos de caso são simulados. O primeiro é baseado em um poço no campo de Shearwater, Mar do Norte, enquanto o segundo estudo de caso, em um poço no campo da Bacia de Santos, no Brasil. Em ambos os casos, o revestimento suporta os carregamentos aplicados e os fenômenos presentes, sem plastificar. No estudo de caso do Brasil, duas profundidades são simuladas: uma no reservatório e outra em uma camada menos profunda, utilizando dois revestimentos. Em seguida, o resultado da solução analítica é comparado com o da solução numérica para todos os casos.

Por fim, no capítulo 6 as considerações finais do trabalho são apresentadas e, posteriormente são discutidas algumas sugestões para trabalhos futuros. 


\section{2 \\ Processos ao longo da vida útil do poço}

Neste capítulo, informações sobre poços de petróleo e sobre as fases que se desenvolvem ao longo da vida útil do poço são apresentadas. Nessas fases, pressões e condições de contorno são modificadas, alterando assim o estado de tensão do poço.

Inicialmente, antes da perfuração do poço, a rocha está sob um estado de tensão inicial, que depende basicamente do peso das camadas acima da profundidade analisada, do perfil de poropressão da formação e das características geológicas do campo. A perfuração é feita através de uma broca, que ao mesmo tempo que perfura a rocha, injeta um fluido (lama) de perfuração. Esse fluido possui diversas funções para a construção do poço, entre elas, a de lubrificar a broca e não permitir o seu aquecimento excessivo. Outra função é a de combater o fechamento da parede da rocha (arrombamento), através da substituição do campo de tensões dentro do poço. Isso é necessário, uma vez que o estado de tensão inicial da formação tende a fechar o poço perfurado. Além disso, o dimensionamento deste fluido de perfuração deve levar em consideração a pressão de início de fratura, como mostrado em Shahri et al. (2015). Por outro lado, o peso de lama não pode ser baixo demais, para que não haja fuga do fluido da formação para dentro do poço. Dessa forma, chega-se em uma janela de peso de lama, em que o limite superior é a pressão de fratura e o estado inicial de tensão da rocha, enquanto o limite inferior é a poropressão da formação.

De acordo com Fitzgerald et al. (2000), o mau dimensionamento da lama utilizada na perfuração é muitas vezes o motivo para o aumento no custo da construção, podendo inclusive levar à perda do poço. Em Chen et al. (2015), o foco principal do estudo é a perda de circulação do fluido de perfuração. Os autores avaliam a influência desse fenômeno na temperatura e nas tensões no poço ao longo do tempo.

A perfuração é feita em diferentes estágios, onde em cada um deles, uma camada é escavada e em seguida, revestida e cimentada. $\mathrm{O}$ tubo de aço, conhecido 
como revestimento, é instalado no poço após a perfuração de cada seguimento. Ao longo da profundidade, diferentes diâmetros do poço e diferentes revestimentos são utilizados. O revestimento de um poço possui diversas funções, como a de isolar os fluidos da formação do fluido interno do revestimento. Além disso, o revestimento possibilita o fluxo de fluido do reservatório até a superfície, servindo ainda como uma prevenção ao colapso do poço, conforme descrito em Rodriguez et al. (2003). A Figura 2.1, adaptada de Carrizo et al. (2011), apresenta diferentes projetos de poços para a Bacia de Santos.

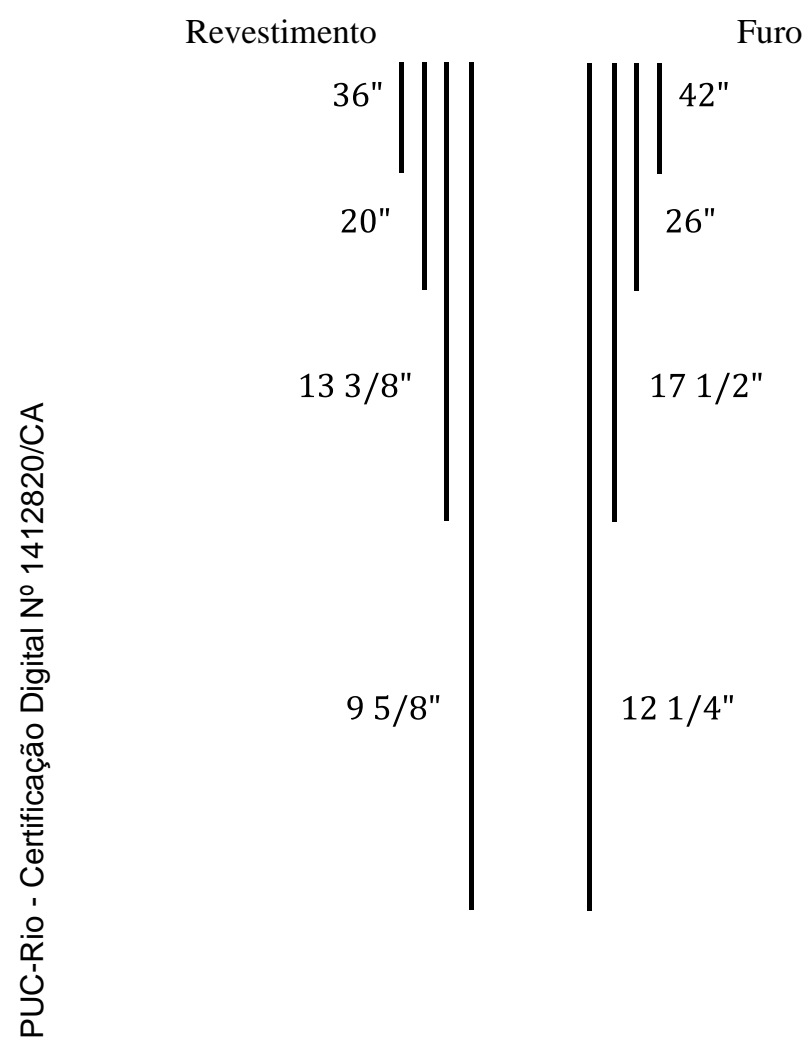

a)

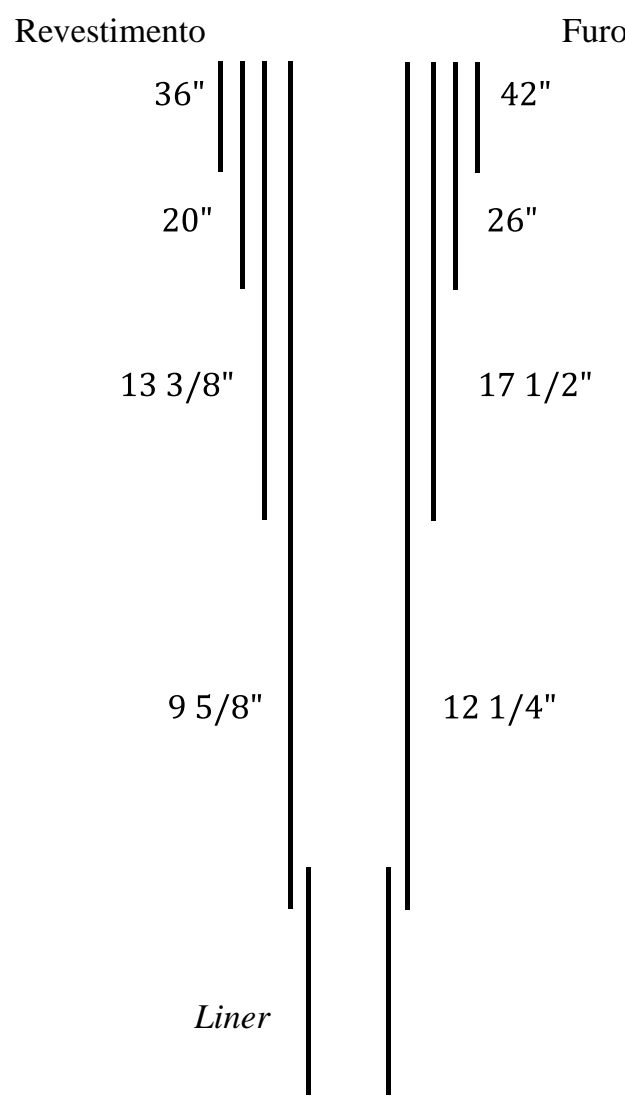

b)

Figura 2.1 - Projeto de poços de petróleo na Bacia de Santos, Brasil. (Fonte: Adaptada de Carrizo et al., 2011).

Na Figura 2.1a, o revestimento condutor é de 36", instalado em um furo de 42 ", enquanto o revestimento de superfície é de 20 " instalado em poço de 26 ". Na fase seguinte, o revestimento intermediário de 13 3/8" é colocado no poço com 17 $1 / 2$ " de diâmetro, e por último é instalado o revestimento de produção de 9 5/8" em um poço de 12 1/4". Caso seja necessário, é instalado um revestimento chamado de liner no final do revestimento de produção (Figura 2.1b). A principal diferença entre um liner e um segundo revestimento de produção é a forma de posicionamento. $\mathrm{O}$ 
topo do liner termina um pouco acima da sapata do revestimento da fase anterior, enquanto o revestimento tem seu topo prolongado até a superfície, como mostrado na Figura 2.1.

Após a descida do revestimento, este fica imerso em fluido de perfuração até o início da injeção do cimento por dentro do tubo. O cimento fluido desce pelo poço até o fim da fase perfurada, e então começa a subir pelo espaço entre a parede externa do revestimento e a parede interna da formação, denominada anular, conforme a Figura 2.2.

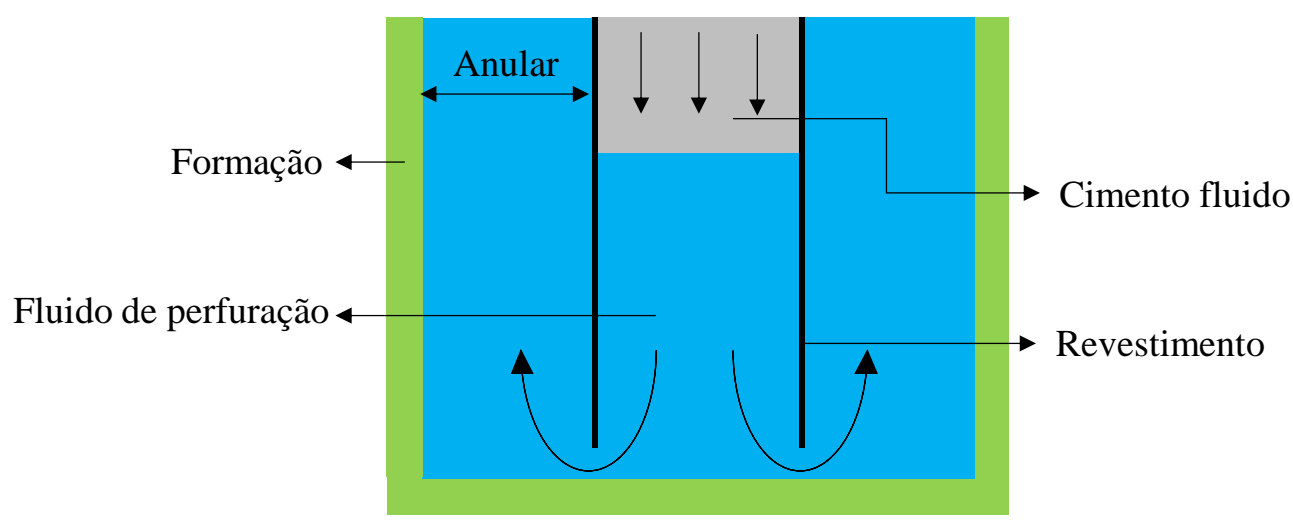

Figura 2.2 - Vista da seção longitudinal durante o deslocamento do cimento.

Com o fluxo do cimento fluido, a lama de perfuração é expulsa do poço, e então o cimento começa seu processo de endurecimento no anular entre o revestimento e a formação, Figura 2.3.

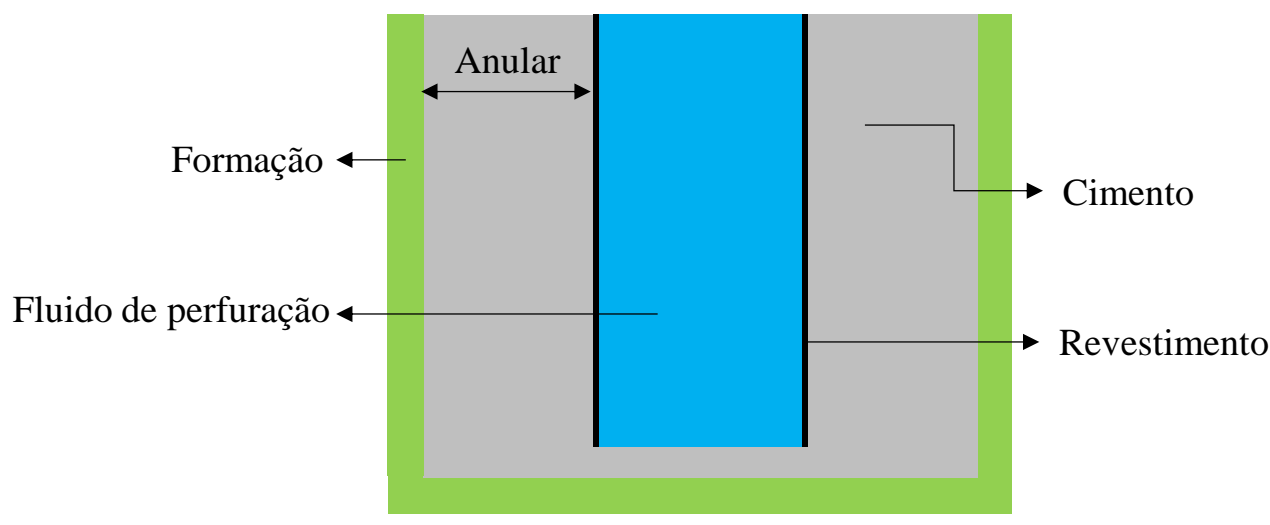

Figura 2.3 - Vista da seção longitudinal após o endurecimento do cimento no anular.

Após o fim da construção do poço, a completação se inicia, com a injeção do fluido de completação no poço enquanto os equipamentos necessários para a produção de hidrocarboneto são instalados. Em alguns casos, para aumentar a produtividade do poço é necessário aumentar a permeabilidade do reservatório. Uma técnica muito utilizada para esse fim é o fraturamento hidráulico, que pode ser 
induzido através da injeção de um fluido com alta pressão. Essas fases, que ocorrem após a construção, são mostradas em Gray et al. (2007).

A última fase da vida do poço é a produção, momento em que o fluido interno do revestimento é alterado novamente. Além da variação da pressão interna no revestimento, a poropressão no reservatório também é alterada, podendo aumentar ou diminuir, de acordo com a função do poço. Caso seja um poço injetor, a poropressão da formação aumenta, e em um poço produtor, o reservatório será depletado, diminuindo a poropressão da formação. Outro fenômeno observado durante a produção é a variação de temperatura na superfície interna do revestimento a uma cota acima do reservatório, devido ao aumento da temperatura na coluna de produção. Com o aumento da profundidade, a temperatura na rocha tende a aumentar, portanto, durante a produção, o fluido do reservatório que entra na coluna de produção possui uma temperatura superior à temperatura do revestimento na fase anterior, conforme apresentado por Poiate Jr. (2012). Assim, essa variação térmica na coluna de produção leva a um aumento da temperatura do revestimento, afetando o cimento e a rocha. Ao longo do tempo, essa alteração da temperatura chega nas camadas de rocha mais rasas, tornando importante a avaliação da distância que essa variação influencia as tensões na formação. Jandhyala et al. (2013) estuda o comportamento de um poço em zona de sal levando em conta o efeito da temperatura na análise do estado de tensão final do poço.

Outros problemas em campos de petróleo são estudados na literatura, como em Righetto et al. (2014), em que os autores estudam o comportamento do reservatório considerando o acoplamento dos efeitos fluido e mecânico. A análise em microescala, utilizando o método das diferenças finitas é realizada e, com os resultados obtidos, um modelo de poço em elementos finitos é utilizado para avaliar a influência do reservatório no estado de tensão ao redor do poço e, consequentemente, a integridade do revestimento. 


\section{3 Solução analítica para o cálculo de tensões em poços}

\section{1. Introdução}

Diversos trabalhos têm sido desenvolvidos na área de soluções analíticas para o cálculo das tensões nos poços de petróleo. Diferentes hipóteses são adotadas em cada um dos estudos realizados, além de serem abordados cenários distintos em cada um deles.

Em Mackay et al. (2008a), um modelo numérico é validado através de uma solução analítica utilizando as equações de Bradley. A partir dessas equações, é possível calcular as componentes de tensão radial e tangencial no poço após a perfuração. Outra forma de validação é a comparação de um modelo com revestimento sujeito a pressões interna e externa com as equações de Lamé, assim como apresentado por Berger et al. (2004) e Rodriguez et al. (2003).

No trabalho de $\mathrm{Xu}$ et al. (2015), uma solução analítica é apresentada considerando o revestimento, o cimento e a formação em uma única fase da vida útil do poço (produção). Os autores adotam uma condição de contato perfeito entre o revestimento e o cimento, e entre o cimento e a formação, onde não há separação entre essas superfícies. Em seguida, as componentes de tensão em cada material são calculadas considerando a solução de Lamé para paredes espessas. Os carregamentos aplicados no sistema são uma pressão interna na parede do revestimento e, simultaneamente, uma variação instantânea e uniforme de temperatura, com o mesmo valor para o revestimento, para o cimento e para a rocha. A perfuração, a descida do revestimento e a cimentação não são levadas em conta, tampouco o estado de tensão inicial e a variação da poropressão da formação. Posteriormente, os autores apresentam os resultados das componentes de tensão radial e tangencial no cimento, considerando diferentes pressões internas no revestimento.

Teodoriu et al. (2010) também apresentam uma solução analítica para as tensões em poços de petróleo. Em uma abordagem um pouco diferente, as 
componentes de tensão no revestimento são calculadas através da teoria de cilindros de paredes finas, enquanto no cimento e na formação, as componentes são calculadas através da teoria de cilindros de paredes espessas. Além do efeito mecânico, a variação de temperatura também é adicionada na solução. São consideradas duas variações de temperatura, uma no revestimento, e outra no cimento e na formação. Essas são variações instantâneas na temperatura, e a análise é feita sem levar em conta o tempo de simulação.

Nos dois últimos trabalhos citados, Xu et al. (2015) e Teodoriu et al. (2010), o cálculo das componentes de tensão a partir do efeito térmico é feito de forma bem simplificada, uma vez que supõe a mesma variação de temperatura nos materiais ao longo da distância radial. Além disso, a solução apresentada pelos autores não varia com o tempo, sendo uma solução em regime permanente.

No presente trabalho, o cálculo do perfil de temperatura da rocha é realizado com base nas equações apresentadas em Ostrowski \& Michalak (2011) para um cilindro vazado. Os autores comparam a solução analítica de temperatura com as soluções obtidas através dos métodos da diferença finita e dos elementos finitos.

O trabalho de Mendes et al. (2005) apresenta o desenvolvimento de uma solução para o cálculo do perfil de temperatura em um poço de petróleo com dois revestimentos, considerando a condução e a convecção. A equação transiente de temperatura apresentada pelos autores é avaliada através do método da separação de variáveis e assume-se que as propriedades térmicas são constantes e o contato térmico é perfeito.

Além de considerar o efeito da temperatura no estado de tensão ao redor do poço, o trabalho de Chen \& Ewy (2005) contempla o efeito da variação da temperatura na mudança da poropreesão da rocha. Dessa forma é feita uma análise acoplada, em que os efeitos da temperatura, do fluido e das pressões são considerados para calcular o estado de tensão final da rocha.

Diferentes soluções analíticas também são apresentadas levando em consideração outros fenômenos. Em Jo \& Gray (2010), uma solução analítica é apresentada, acoplando os efeitos mecânico, térmico e de fluido. A variação de temperatura utilizada na solução é assumindo a condição de regime permanente. Posteriormente, os autores avaliam a integridade do cimento ao modificar alguns parâmetros, como a temperatura, a pressão e as propriedades elásticas do cimento. Em Shahri et al. (2015), um fluxo de trabalho é desenvolvido utilizando soluções 
analíticas acoplando os efeitos, térmico, poro e mecânico em um estado transiente. O fluxo de trabalho apresentado pelos autores consiste em quatro etapas: o cálculo da tensão ao redor do poço, a estabilidade do poço, o fortalecimento do poço e a perda de circulação. O cálculo das tensões ao redor de um poço inclinado é apresentado por Atkinson \& Eftaxiopoulos (1996). Os autores realizam uma compatibilidade entre as tensões e os deslocamentos nas interfaces entre o revestimento e o cimento e entre o cimento e a rocha em uma única fase do poço. A solução apresentada serve para o cálculo de poços inclinados, revestidos e cimentados, com a presença de pressão interna no revestimento. Ao final do trabalho, essa solução é comparada com um modelo em elementos finitos. Uma abordagem mais complexa é apresentada por Atkinson \& Eftaxiopoulos (2002), onde uma solução para o problema de fraturamento hidráulico em poços de petróleo com revestimento e cimento é apresentada. A solução abrange poços inclinados e somente fraturas retas. A solução é comparada com modelos feitos através do método dos elementos finitos. Oyarhossein \& Dusseault (2015) desenvolvem uma solução analítica para o cálculo da tensão efetiva ao redor do poço e, em seguida, assumem valores para a retração do cimento, encontrando novas curvas de tensão. Posteriormente, os resultados obtidos são comparados com a solução pelo programa de elementos finitos ABAQUS ${ }^{\circledR}$.

Uma nova e simples solução analítica para o cálculo das tensões em um poço é apresentada neste capítulo. Utiliza-se o programa Maple ${ }^{\mathrm{TM}}$ para o desenvolvimento dessa formulação analítica. Essa solução mostra-se poderosa, uma vez que serve de calibração para soluções numéricas, que apesar de muito utilizadas na engenharia, necessitam de um conhecimento prévio das técnicas e dos métodos utilizados durante a modelagem. Além disso, o grande esforço computacional para a solução das equações diferenciais prejudica a velocidade de processamento dessas soluções numéricas.

A solução analítica apresentada pode ser dividida em quatro fases: perfuração, descida do revestimento, cimentação do poço e a produção do hidrocarboneto, como mostrado em De Simone et al. (2015). Aplicando o princípio da superposição dos efeitos, cada uma das fases é avaliada, e os incrementos de tensões são calculados separadamente e então, somados no final da simulação. 


\section{2. \\ Hipóteses adotadas}

Para que a solução analítica desenvolvida possa ser utilizada, algumas hipóteses são consideradas. Todos os materiais são lineares elásticos, homogêneos e isotrópicos. Os modelos analisados são bidimensionais e assume-se a hipótese simplificadora de estado plano de deformação. Além disso, não é modelado nenhum tipo de geometria ou carregamento não uniforme, como falhas na cimentação ou vazios na rocha. O poço e o revestimento são perfeitamente circulares e o revestimento está centralizado. O contato entre os diferentes materiais é considerado perfeito, ou seja, não há separação entre eles.

Além da análise mecânica feita em todas as fases, é considerada também a variação térmica no poço durante a produção. A solução térmica é apresentada considerando regime transiente na rocha, e com isso, é possível determinar a temperatura em qualquer instante de tempo e em qualquer ponto da formação. Para o revestimento e o cimento, é admitido que a temperatura seja totalmente conduzida ao longo das espessuras, por serem muito pequenas quando comparadas à espessura da rocha. Diante disso, utiliza-se uma variação de temperatura constante ao longo da espessura dos revestimentos e dos cimentos, realizando uma análise em regime permanente. Posteriormente, uma solução térmica mais abrangente é considerada, na qual a variação de temperatura é calculada para cada interface entre os materiais. Os processos de perfuração, descida do revestimento e cimentação ocorrem em um intervalo de tempo muito pequeno, diferente da produção, onde a temperatura é alterada e avaliada ao longo da vida útil do poço, adotada neste trabalho como 20 anos (Wilson et al., 2002).

A influência do efeito mecânico gerado pela variação da poropressão da rocha nas tensões do poço é avaliada. Apesar dessa variação ocorrer ao longo do tempo, neste trabalho é adotada uma variação instantânea da poropressão na rocha. Essa alteração ocorre simultaneamente à variação da pressão interna no revestimento em virtude da produção. Como a poropressão da rocha está sendo levada em consideração, os valores de tensão inicial da formação que são utilizados como dados de entrada são referentes às tensões efetivas. A distribuição de poros considerando um fluido não penetrante é adotada para simular o comportamento mecânico do poço sem considerar o fluxo entre os fluidos do poço e da formação. 
A Figura 3.1 apresenta a distribuição da pressão de poros adotada neste trabalho, onde $P_{\text {int }}$ é a pressão do fluido atuando na parede interna do poço e $P P$ é a poropressão da formação.

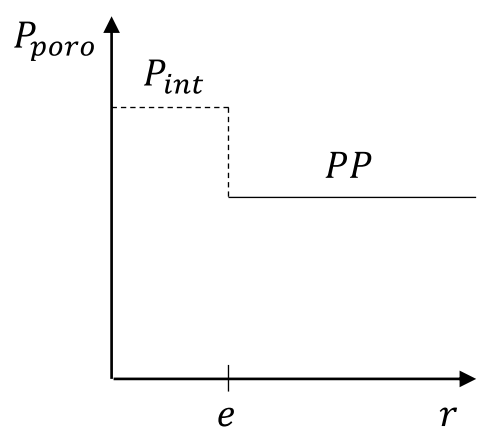

a)

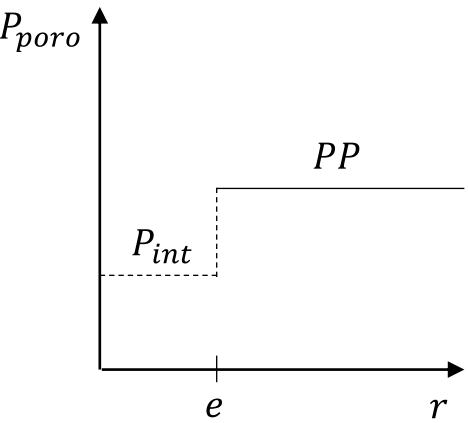

b)

Figura 3.1 - Distribuição da pressão de poros no poço quando adotado fluido não penetrante.

(Fonte: Adaptada de Rocha \& de Azevedo, 2009)

A poropressão da formação $(P P)$ pode ser inferior à pressão interna do poço $\left(P_{\text {int }}\right)$, Figura 3.1a, nesse caso, a tensão efetiva na parede do poço é definida como a diferença entre as duas pressões, $\sigma_{r}{ }_{r}=P_{\text {int }}-P P>0$. O contrário também pode ocorrer, Figura 3.1b, sendo a tensão efetiva calculada por $\sigma_{r}{ }_{r}=P_{\text {int }}-P P<0$. Para simular a variação de poropressão na solução analítica, forças de superfície são aplicadas na parede do poço. No caso de injeção de fluido, os poros da rocha são preenchidos, gerando assim um efeito expansivo na rocha com tendência ao fechamento do poço. Por outro lado, quando há depleção do reservatório, a rocha sofre um efeito compressivo, tendendo a aumentar o diâmetro do poço. Dessa forma, para simular a depleção, uma pressão é aplicada na parede do poço, enquanto na injeção, uma força de superfície de tração é aplicada, conforme Figura 3.9.

A Figura 3.2 apresenta a geometria do poço considerando dois revestimentos, além dos raios de cada superfície. 


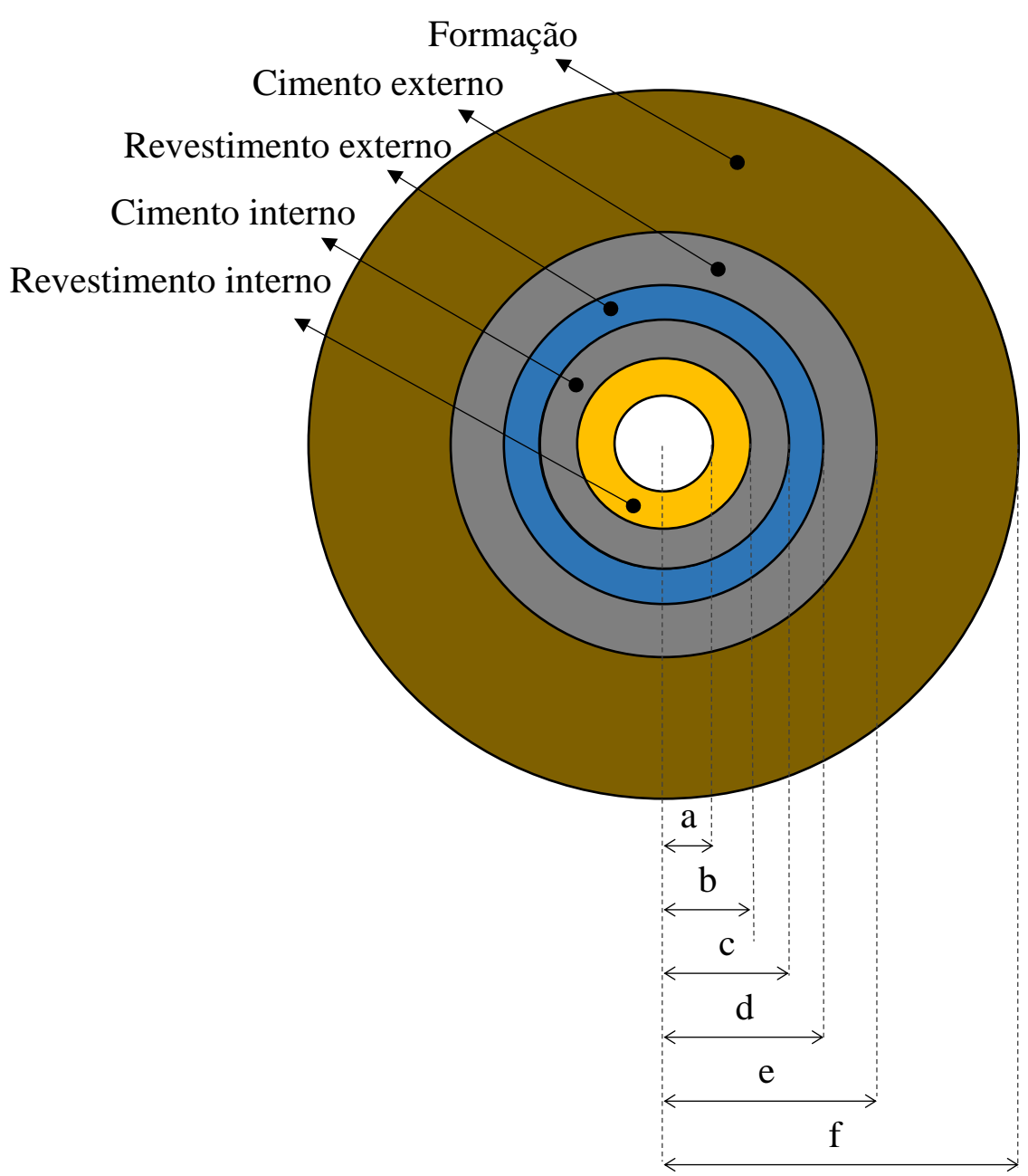

Figura 3.2 - Nomenclatura utilizada para os raios de cada material no caso de um poço com dois revestimentos.

\section{3.}

Solução para um revestimento

\subsection{1.}

\section{Perfuração}

Após a perfuração e aplicação do fluido de perfuração no furo, a rocha sofre uma deformação elástica em resposta ao desconfinamento da parede do poço. As equações de Bradley são uma boa aproximação das componentes de tensão radial e tangencial durante esta fase. Essas tensões são expressas em relação às coordenadas polares $r$ e $\theta$, onde $r$ representa a distância do eixo do poço até o ponto a ser avaliado e $\theta$ é o ângulo em relação ao eixo $x$ no plano $x-y$, medido no sentido anti-horário. A solução de Bradley (1979) apud Fjaer et al. (2008) calcula as componentes de tensão radial e tangencial ao longo do raio, considerando uma placa infinita com furo, sob um estado de tensão inicial e com uma pressão interna (Figura 
3.3). Neste trabalho, o cenário imediatamente após a perfuração é tratado com o sobrescrito (0).

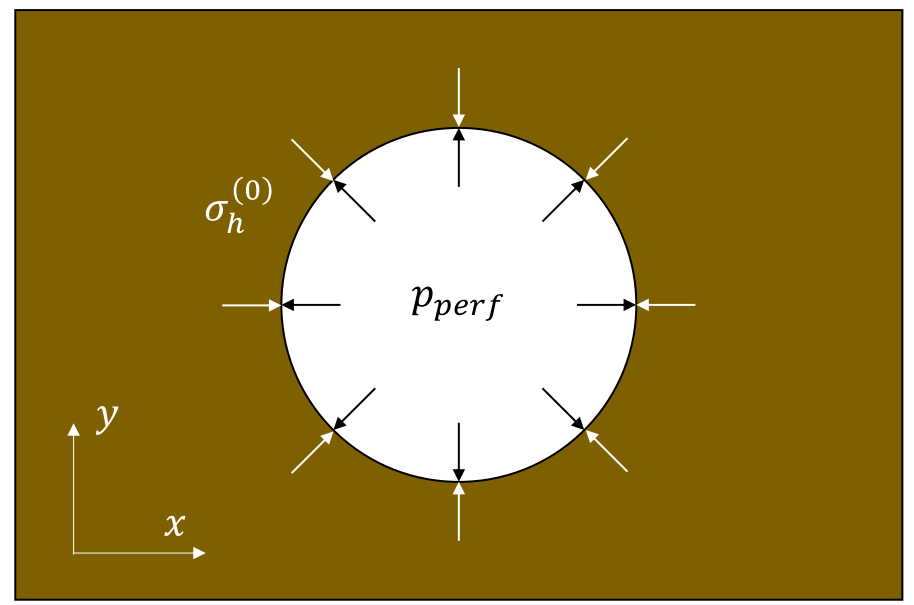

Figura 3.3 - Esquema com o estado inicial de tensão da rocha e a pressão do fluido de perfuração.

A formulação de Bradley para o cálculo da tensão radial na formação $\left(\sigma_{r F}^{(0)}\right)$ é apresentada na equação (3.1).

$$
\begin{gathered}
\sigma_{r F}^{(0)}=\left(\frac{\sigma_{x}^{(0)}+\sigma_{y}^{(0)}}{2}\right)\left(1-\frac{e^{2}}{r^{2}}\right)+\left(\frac{\sigma_{x}^{(0)}-\sigma_{y}^{(0)}}{2}\right)\left(1+\frac{3 \cdot e^{4}}{r^{4}}+\frac{4 \cdot e^{4}}{r^{2}}\right) \\
\cos (2 \theta)+\tau_{x y}^{(0)}\left(1+\frac{3 \cdot e^{4}}{r^{4}}+\frac{4 \cdot e^{4}}{r^{2}}\right) \operatorname{sen}(2 \theta)+\Delta p_{\text {fluido }} \cdot \frac{e^{2}}{r^{2}}
\end{gathered}
$$

A tensão tangencial na formação $\left(\sigma_{r F}^{(0)}\right)$ é apresentada na equação (3.2).

$$
\begin{gathered}
\sigma_{\theta F}^{(0)}=\left(\frac{\sigma_{x}^{(0)}+\sigma_{y}^{(0)}}{2}\right)\left(1+\frac{e^{2}}{r^{2}}\right)-\left(\frac{\sigma_{x}^{(0)}-\sigma_{y}^{(0)}}{2}\right)\left(1+\frac{3 \cdot e^{4}}{r^{4}}\right) \cos (2 \theta) \\
-\tau_{x y}^{(0)}\left(1+\frac{3 \cdot e^{4}}{r^{4}}\right) \operatorname{sen}(2 \theta)-\Delta p_{\text {fluido }} \cdot \frac{e^{2}}{r^{2}}
\end{gathered}
$$

Onde $\sigma_{x}^{(0)}$ e $\sigma_{y}^{(0)}$ são as componentes da tensão normal inicial nas direções $x$ e $y, \tau_{x y}^{(0)}$ é a tensão cisalhante inicial, $e$ é o raio do poço e $\Delta p_{\text {fluido }}$ é a diferença entre a pressão interna que atua na parede do poço, que nessa fase é a pressão do fluido de perfuração $\left(p_{p e r f}\right)$, e a poropressão da formação $(P P)$.

Essa análise é feita considerando uma profundidade específica, já que em diferentes cotas, o estado de tensão do poço tem valores distintos. No estado plano de deformação, o resultado obtido em um determinado plano de análise pode ser adotado para qualquer outro plano, porém, como nesse caso é levado em consideração o estado de tensão inicial do poço, e esse varia com a profundidade, a 
análise deve ser feita na cota mais crítica, e esse resultado não pode ser utilizado para outra profundidade.

No presente trabalho, as tensões normais no plano $\left({\sigma_{x}^{\prime}}_{x}^{(0)}\right.$ e $\left.\sigma_{y}^{(0)}\right)$ são as tensões efetivas in situ da rocha (geostático) e são assumidas com o mesmo valor $\left(\sigma_{h}^{\prime(0)}\right)$, enquanto a tensão cisalhante $\left(\tau_{x y}^{(0)}\right)$ é considerada igual a zero. Vale ressaltar que a solução também pode ser utilizada para um estado de tensões diferentes em $x \mathrm{e}$ em $y$.

O sinal negativo antes da tensão efetiva inicial $\left(\sigma_{h}^{(0)}-P P\right)$ é colocado nas equações (3.3) e (3.4), por se tratar de uma tensão de compressão. O sinal negativo antes do valor do fluido de perfuração, $p_{\text {perf }}$ também se dá por causa da convenção de sinais adotada nas equações de Bradley.

$$
\begin{aligned}
& \sigma_{r F}^{(0)}=-\left(\sigma_{h}^{(0)}-P P\right)\left(1-\frac{e^{2}}{r^{2}}\right)+\left(-p_{\text {perf }}+P P\right) \frac{e^{2}}{r^{2}} \\
& \sigma_{\theta F}^{(0)}=-\left(\sigma_{h}^{(0)}-P P\right)\left(1+\frac{e^{2}}{r^{2}}\right)-\left(-p_{\text {perf }}+P P\right) \frac{e^{2}}{r^{2}}
\end{aligned}
$$

Após a perfuração, as componentes de tensão radial $\left(\sigma_{r F}^{(0)}\right)$ e tangencial $\left(\sigma_{\theta F}^{(0)}\right)$ da formação são modificadas. Observa-se, que por $\tau_{x y}^{(0)}$ ser zero, e a tensão inicial em $x$ ser igual a tensão inicial em $y$, os termos que dependem de $\theta$ somem da equação, dependendo então somente do raio $r$.

\subsection{2.}

\section{Descida do revestimento}

Após a perfuração do poço, ocorre a descida do revestimento. Por ser considerada uma análise linear elástica, adota-se um cenário de pressões onde o cimento fluido no anular atua na superfície externa do revestimento e na parede do poço, enquanto o fluido de perfuração atua como uma pressão interna no revestimento, conforme ilustra a Figura 3.4. 


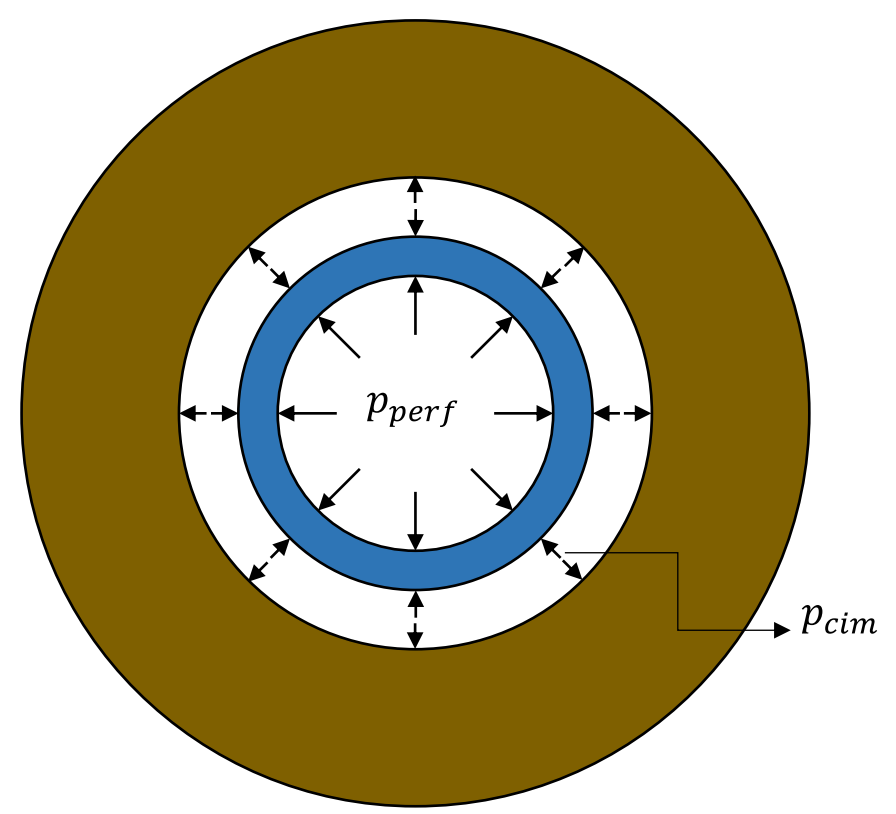

Figura 3.4 - Fase de descida do revestimento com pressão interna do fluido de perfuração e pressão devida ao cimento fluido no anular.

São considerados durante esta fase, um cilindro com apenas pressão interna (formação) e outro com pressões interna e externa (revestimento). Utilizando coordenadas cilíndricas, a lei de Hooke pode ser escrita conforme equações (3.5) e (3.6). A parcela da temperatura $(\alpha \cdot \Delta T)$ é levada em conta no revestimento e no cimento, pois é considerada uma variação de temperatura $(\Delta T)$ em regime permanente para esses dois materiais, sendo $\alpha$ o coeficiente de dilatação térmica do material. Para a rocha, a análise é transiente, e os cálculos são apresentados na seção 3.3.5. A variação da temperatura somente é contemplada durante a produção, simulando um fluido injetor, ou a produção do hidrocarboneto.

$$
\begin{aligned}
& \Delta \epsilon_{\theta}=\frac{1}{E}\left[\Delta \sigma_{\theta}-v\left(\Delta \sigma_{z}+\Delta \sigma_{r}\right)\right]+\alpha \cdot \Delta T \\
& \Delta \epsilon_{z}=\frac{1}{E}\left[\Delta \sigma_{z}-v\left(\Delta \sigma_{\theta}+\Delta \sigma_{r}\right)\right]+\alpha \cdot \Delta T
\end{aligned}
$$

Onde $E$ é o módulo de elasticidade; $v$ é o coeficiente de Poisson do material; $\Delta \epsilon_{\theta}$ e $\Delta \epsilon_{z}$ são os incrementos de deformação tangencial e axial, respectivamente; $\mathrm{e}$ $\Delta \sigma_{\theta}, \Delta \sigma_{r}$ e $\Delta \sigma_{z}$ são os incrementos de tensão tangencial, radial e axial, respectivamente. A condição de estado plano de deformação adotada admite $\epsilon_{z}=$ 0, portanto, a partir da equação (3.6), a tensão em $z$ pode ser escrita através da equação (3.7).

$$
\Delta \sigma_{z}=v\left(\Delta \sigma_{\theta}+\Delta \sigma_{r}\right)-\alpha \cdot E \cdot \Delta T
$$


Substituindo a equação (3.7) na equação (3.5), chega-se na equação (3.8).

$$
\Delta \epsilon_{\theta}=\frac{\left(1-v^{2}\right) \Delta \sigma_{\theta}}{E}-\frac{\left(v+v^{2}\right) \Delta \sigma_{r}}{E}+v \cdot \alpha \cdot \Delta T+\alpha \cdot \Delta T
$$

O deslocamento radial ao longo do raio $r$, dado por $\Delta u_{r}=r \cdot \Delta \epsilon_{\theta}$, pode ser reescrito conforme equação (3.9).

$$
\Delta u_{r}=r\left[\frac{\left(1-v^{2}\right) \Delta \sigma_{\theta}}{E}-\frac{\left(v+v^{2}\right) \Delta \sigma_{r}}{E}+v \cdot \alpha \cdot \Delta T+\alpha \cdot \Delta T\right]
$$

Para o cálculo das tensões no revestimento e na formação, são utilizadas as equações de Lamé para um cilindro de paredes espessas. Assim, utilizam-se as equações (3.10) e (3.11) para o cálculo da variação de tensão radial e tangencial, respectivamente. Os sinais de cada pressão aplicada devem ser positivos se forem no sentido da Figura 3.5 e negativos caso contrário.

$$
\begin{aligned}
\Delta \sigma_{r} & =\frac{\Delta p_{\text {int }} \cdot r_{i}^{2}}{r_{e}^{2}-r_{i}^{2}}\left(1-\frac{r_{e}^{2}}{r^{2}}\right)-\frac{\Delta p_{\text {ext }} \cdot r_{e}^{2}}{r_{e}^{2}-r_{i}^{2}}\left(1-\frac{r_{i}^{2}}{r^{2}}\right) \\
\Delta \sigma_{\theta} & =\frac{\Delta p_{i n t} \cdot r_{i}^{2}}{r_{e}^{2}-r_{i}^{2}}\left(1+\frac{r_{e}^{2}}{r^{2}}\right)-\frac{\Delta p_{e x t} \cdot r_{e}^{2}}{r_{e}^{2}-r_{i}^{2}}\left(1+\frac{r_{i}^{2}}{r^{2}}\right)
\end{aligned}
$$

Para cada um dos materiais, os raios interno $\left(r_{i}\right)$ e externo $\left(r_{e}\right)$, e os incrementos de pressão interna $\left(\Delta p_{\text {int }}\right)$ e externa $\left(\Delta p_{\text {ext }}\right)$ são substituídos pelos valores correspondentes. Assim, encontram-se os incrementos das componentes de tensão radial e tangencial ao longo do raio em todos os materiais. Esse procedimento será realizado para cada fase da vida útil do poço.

As equações (3.12) e (3.13) representam os incrementos das componentes de tensão radial e tangencial no revestimento, respectivamente. $O$ cenário na fase de descida do revestimento externo é indicado com o sobrescrito (1). A Figura 3.5 apresenta as pressões que atuam no revestimento durante a sua descida.

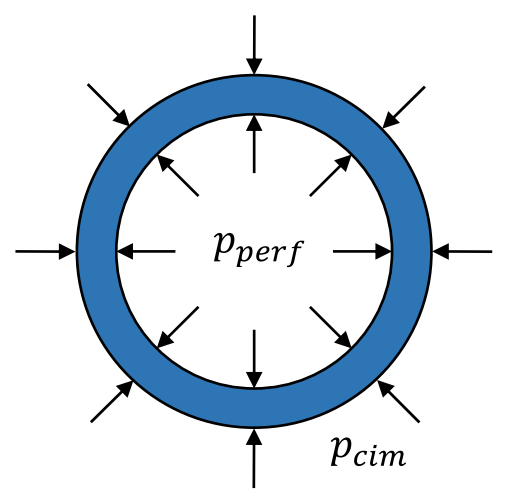

Figura 3.5 - Pressões atuando no revestimento na fase de descida do revestimento. 


$$
\begin{aligned}
& \Delta \sigma_{r S}^{(1)}=\frac{p_{p e r f} \cdot c^{2}}{d^{2}-c^{2}}\left(1-\frac{d^{2}}{r^{2}}\right)-\frac{p_{c i m} \cdot d^{2}}{d^{2}-c^{2}}\left(1-\frac{c^{2}}{r^{2}}\right) \\
& \Delta \sigma_{\theta S}^{(1)}=\frac{p_{p e r f} \cdot c^{2}}{d^{2}-c^{2}}\left(1+\frac{d^{2}}{r^{2}}\right)-\frac{p_{c i m} \cdot d^{2}}{d^{2}-c^{2}}\left(1+\frac{c^{2}}{r^{2}}\right)
\end{aligned}
$$

A pressão $p_{\text {cim }}$ representa a pressão hidrostática do cimento fluido que é aplicada na superfície externa do revestimento. Na superfície interna do revestimento, o fluido de perfuração $p_{\text {perf }}$ é aplicado. Os raios interno e externo do revestimento são definidos por $r_{i}=c$ e $r_{e}=d$, como pode ser visto na Figura 3.2. Para a formação, a Figura 3.6 apresenta a pressão devida ao cimento fluido na parede do poço, e não é considerada nenhuma pressão na superfície externa da rocha.

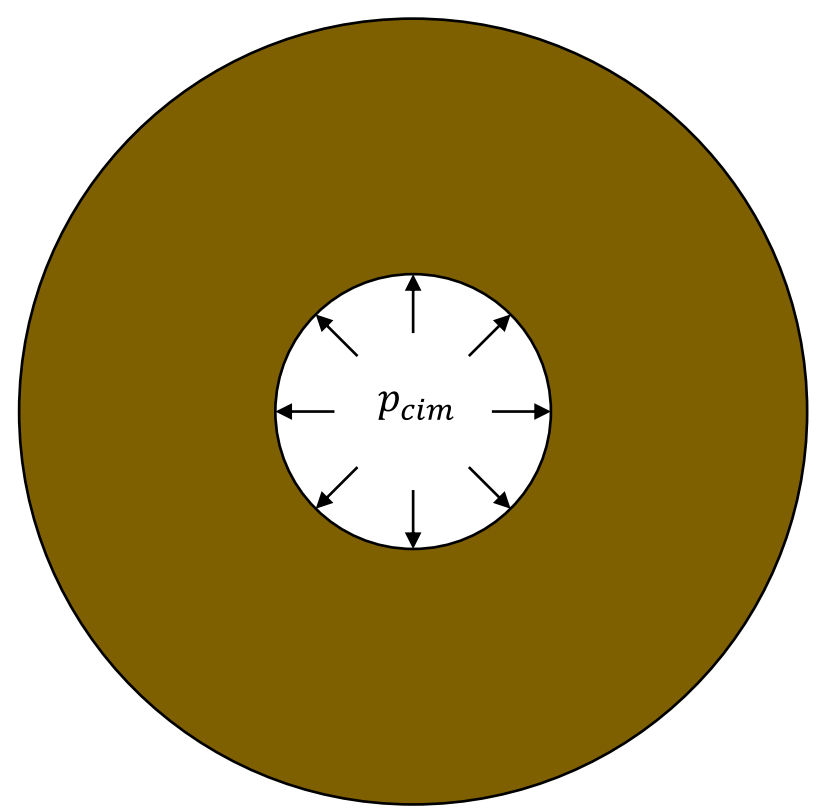

Figura 3.6 - Pressão atuando na formação durante a fase de descida do revestimento.

As equações (3.14) e (3.15) representam os incrementos das componentes de tensão radial e tangencial na formação, respectivamente. A variação de pressão que deve ser aplicada na parede do poço é o incremento entre a pressão devida ao cimento fluido, $p_{\text {cim }}$ que atua nesta fase e a pressão devida ao fluido de perfuração que atuou durante a perfuração, $p_{\text {perf }}$. A mesma hipótese de fluido não penetrante adotada na perfuração continua sendo utilizada.

$$
\begin{aligned}
& \Delta \sigma_{r F}^{(1)}=\frac{\left(p_{\text {cim }}-p_{\text {perf }}\right) e^{2}}{f^{2}-e^{2}}\left(1-\frac{f^{2}}{r^{2}}\right) \\
& \Delta \sigma_{\theta F}^{(1)}=\frac{\left(p_{\text {cim }}-p_{\text {perf }}\right) e^{2}}{f^{2}-e^{2}}\left(1+\frac{f^{2}}{r^{2}}\right)
\end{aligned}
$$


O cenário após a descida do revestimento externo é indicado com o sobrescrito (1).

\subsection{3.}

\section{Cimento endurecido}

Na seção anterior a pasta de cimento é injetada, porém, a análise é feita considerando apenas o cimento fluido, aplicando pressões sem levar em conta a sua rigidez. Nesta seção, calculam-se as tensões na fase em que o cimento já está endurecido. Para isso, utilizam-se as equações de Lamé (equações (3.10) e (3.11)) para o cálculo das variações das componentes de tensão em cada material, mantendo a compatibilidade de deslocamento radial entre as superfícies em contato.

Para o revestimento, o incremento de pressão aplicado na sua superfície interna é nulo, já que a pressão devida ao fluido de perfuração na fase anterior (descida do revestimento) continua atuando durante o endurecimento do cimento. Como o estado inicial de tensão do cimento possui o mesmo valor que a pressão hidrostática do fluido de perfuração, conforme Cooke et al. (1983), a diferença entre a pressão externa aplicada no revestimento nesta fase e na fase anterior é a força de contato $S C^{(2)}$ mais a diferença entre as pressões devidas ao estado de tensão inicial do cimento, $\sigma_{C}^{(0)}$ e do cimento fluido, $p_{\text {cim }}$. As equações (3.16) e (3.17) são apresentadas para o revestimento durante a fase em que o cimento está endurecido. Esse cenário é tratado com o sobrescrito (2).

$$
\begin{aligned}
& \Delta \sigma_{r S}^{(2)}=-\frac{\left(S C^{(2)}+\sigma_{C}^{(0)}-p_{c i m}\right) \cdot d^{2}}{d^{2}-c^{2}}\left(1-\frac{c^{2}}{r^{2}}\right) \\
& \Delta \sigma_{\theta S}^{(2)}=-\frac{\left(S C^{(2)}+\sigma_{C}^{(0)}-p_{c i m}\right) \cdot d^{2}}{d^{2}-c^{2}}\left(1+\frac{c^{2}}{r^{2}}\right)
\end{aligned}
$$

Para o cimento, a pressão interna é a força de contato entre o revestimento e o cimento, e a pressão externa é a força de contato $C F^{(2)}$ entre o cimento e a formação. As equações (3.18) e (3.19) apresentam os incrementos das componentes de tensão radial e tangencial no cimento ao longo da espessura da parede da bainha do cimento.

$$
\Delta \sigma_{r C}^{(2)}=\frac{S C^{(2)} \cdot d^{2}}{e^{2}-d^{2}}\left(1-\frac{e^{2}}{r^{2}}\right)-\frac{C F^{(2)} \cdot e^{2}}{e^{2}-d^{2}}\left(1-\frac{d^{2}}{r^{2}}\right)
$$




$$
\Delta \sigma_{\theta C}^{(2)}=\frac{S C^{(2)} \cdot d^{2}}{e^{2}-d^{2}}\left(1+\frac{e^{2}}{r^{2}}\right)-\frac{C F^{(2)} \cdot e^{2}}{e^{2}-d^{2}}\left(1+\frac{d^{2}}{r^{2}}\right)
$$

$\mathrm{Na}$ formação, o cálculo da variação de tensão é feito utilizando a pressão interna devida ao estado de tensão inicial do cimento, não havendo pressão atuando na superfície externa da rocha. Internamente, como a pressão devida ao cimento fluido, $p_{\text {cim }}$ foi aplicada na fase anterior, o incremento de pressão considerado é a pressão de contato $C F^{(2)}$ entre o cimento e a formação, somada à diferença entre a pressão devida ao estado de tensão inicial do cimento, $\sigma_{C}^{(0)}$ e a pressão devida ao cimento fluido, $p_{\text {cim }}$. Dessa forma, as variações das componentes de tensão radial e tangencial na formação são dadas pelas equações (3.20) e (3.21).

$$
\begin{aligned}
& \Delta \sigma_{r F}^{(2)}=\frac{\left(C F^{(2)}+\sigma_{C}^{(0)}-p_{c i m}\right) \cdot e^{2}}{f^{2}-e^{2}}\left(1-\frac{f^{2}}{r^{2}}\right) \\
& \Delta \sigma_{\theta F}^{(2)}=\frac{\left(C F^{(2)}+\sigma_{C}^{(0)}-p_{c i m}\right) \cdot e^{2}}{f^{2}-e^{2}}\left(1+\frac{f^{2}}{r^{2}}\right)
\end{aligned}
$$

As únicas variáveis desconhecidas do problema são as forças de contato $S C^{(2)}$ e $C F^{(2)}$. São calculados os deslocamentos radiais da superfície externa do revestimento e da superfície interna do cimento, substituindo as equações (3.10) e (3.11) na equação (3.9). A equação (3.22) representa a compatibilidade de deslocamento radial entre o revestimento e o cimento, substituindo $r_{i}=c, r_{e}=d$, $v=v_{S}, E=E_{S}, p_{\text {int }}=0$ e $p_{\text {ext }}=\left(S C^{(2)}+\sigma_{C}^{(0)}-p_{\text {cim }}\right)$ para o revestimento e $r_{i}=d, r_{e}=e, v=v_{C}, E=E_{C}, p_{\text {int }}=S C^{(2)}$ e $p_{\text {ext }}=C F^{(2)}$ para o cimento.

$$
\begin{aligned}
& \frac{d}{E_{s}}\left\{\left(1-v_{s}^{2}\right) \cdot[\right.\left.-\left(\frac{d^{2}+c^{2}}{d^{2}-c^{2}}\right)\left(S C^{(2)}+\sigma_{C}^{(0)}-p_{\text {cim }}\right)\right] \\
&+\left.\left(S C^{(2)}+\sigma_{C}^{(0)}-p_{c i m}\right)\left(v_{s}+v_{s}^{2}\right)\right\}= \\
& \frac{d}{E_{c}}\left\{\left(1-v_{c}^{2}\right)\left[\left(\frac{d^{2}+e^{2}}{e^{2}-d^{2}}\right) S C^{(2)}-\left(\frac{2 \cdot e^{2}}{e^{2}-d^{2}}\right) C F^{(2)}\right]\right. \\
&\left.+S C^{(2)}\left(v_{c}+v_{c}^{2}\right)\right\}
\end{aligned}
$$

O mesmo é feito para as superfícies externa do cimento e interna da formação. Dessa forma, a equação (3.23) representa a compatibilidade de deslocamento radial entre o cimento e a rocha. 


$$
\begin{aligned}
& \frac{e}{E_{c}}\left\{\left(1-v_{c}^{2}\right)[\right.\left.\left(\frac{2 \cdot d^{2}}{e^{2}-d^{2}}\right) S C^{(2)}-\left(\frac{e^{2}+d^{2}}{e^{2}-d^{2}}\right) C F^{(2)}\right] \\
&+\left.C F^{(2)}\left(v_{c}+v_{c}^{2}\right)\right\} \\
&=\frac{e}{E_{f}}\left\{\left(1-v_{f}^{2}\right)\left[\left(\frac{e^{2}+f^{2}}{f^{2}-e^{2}}\right)\left(C F^{(2)}+\sigma_{C}^{(0)}-p_{c i m}\right)\right]\right. \\
&\left.+\left(C F^{(2)}+\sigma_{C}^{(0)}-p_{c i m}\right)\left(v_{f}+v_{f}^{2}\right)\right\}
\end{aligned}
$$

A Figura 3.7 apresenta a configuração do sistema com as pressões atuantes.

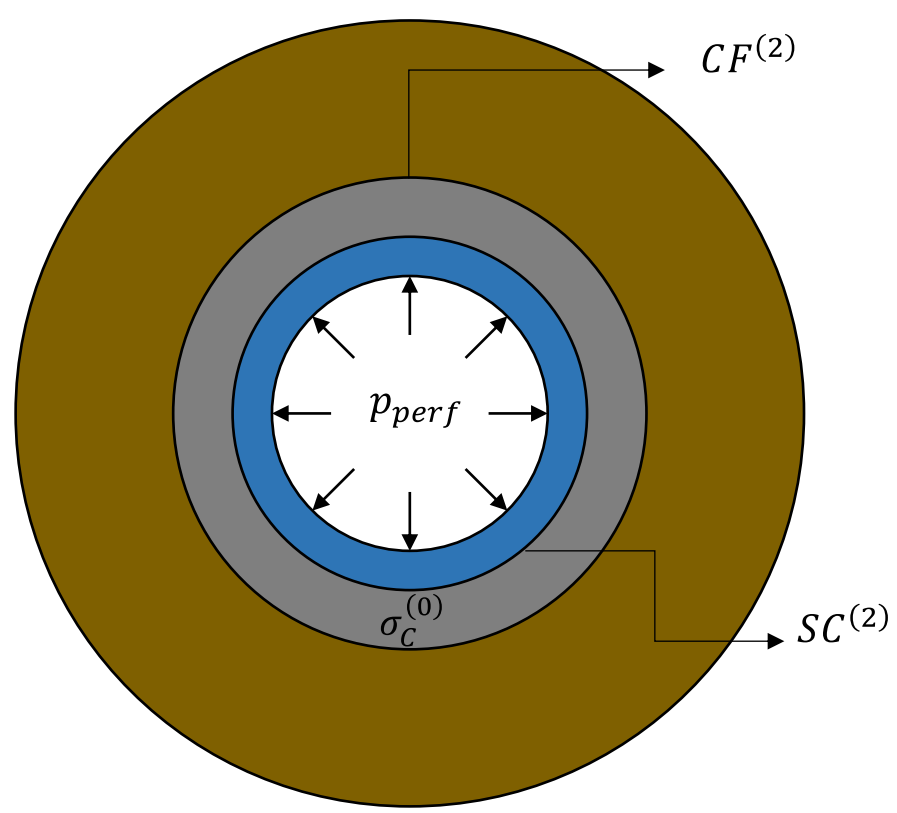

Figura 3.7 - Representação do poço com as pressões na fase em que o cimento está endurecido.

Com as equações (3.22) e (3.23) de compatibilidade é possível encontrar os valores de $S C^{(2)}$ e $C F^{(2)}$. Para encontrar as tensões em cada material, basta substituir os valores de $S C^{(2)}$ e $C F^{(2)}$ nas equações de (3.16) até (3.21).

\subsection{4.}

\section{Produção (efeito mecânico e temperatura em regime permanente no revestimento e cimento)}

Durante a produção, a temperatura e a pressão interna no revestimento sofrem variações. A pressão interna deixa de ser a pressão devida ao fluido de perfuração e começa a ser uma pressão proveniente da produção do hidrocarboneto ou do fluido injetor, dependendo da função do poço. Assim, o incremento de pressão aplicado nesta fase é $p_{\text {prod }}-p_{\text {perf }}$, já que a pressão devida à perfuração, $p_{\text {perf }}$ aplicada da fase anterior é substituída pela pressão de produção, $p_{\text {prod }}$. Com essa 
alteração, os valores das novas forças de contato, $S C^{(3)}$ e $C F^{(3)}$ são calculados a partir das equações de compatibilidade. O cenário de tensões após a produção é indicado com o sobrescrito (3). A Figura 3.8 apresenta os incrementos de pressão aplicados nos materiais durante a produção.

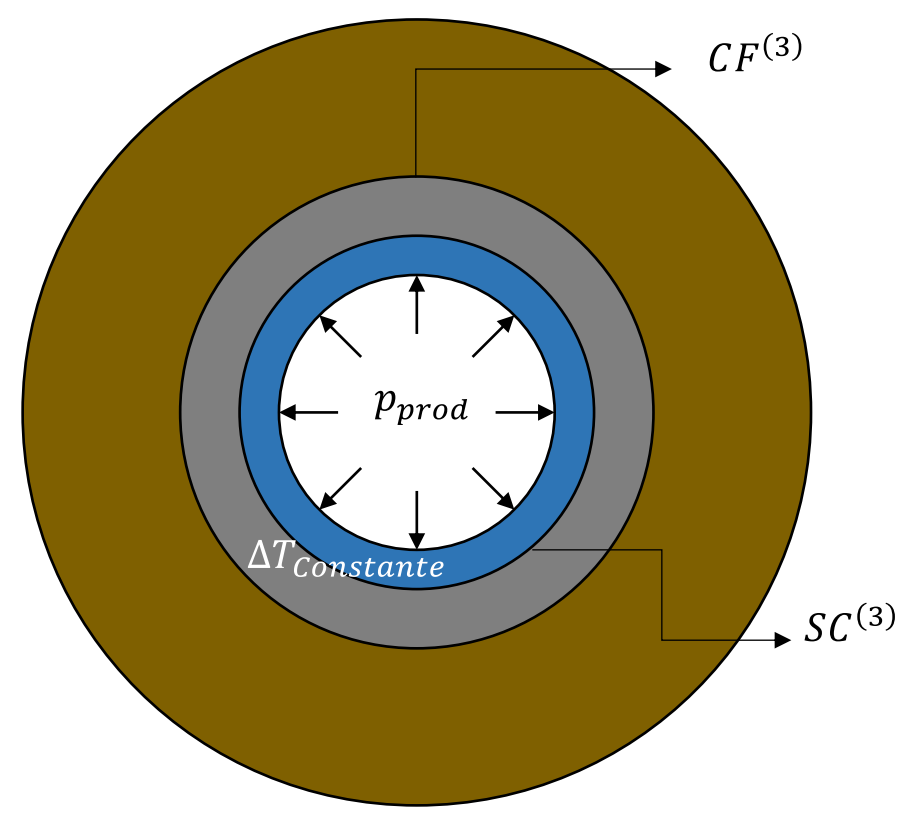

Figura 3.8 - Pressões atuando nos materiais durante a produção.

Para o revestimento, os incrementos das componentes de tensão são apresentados pelas equações (3.24) e (3.25).

$$
\begin{aligned}
& \Delta \sigma_{r S}^{(3)}=\frac{\left(p_{\text {prod }}-p_{\text {perf }}\right) c^{2}}{d^{2}-c^{2}}\left(1-\frac{d^{2}}{r^{2}}\right)-\frac{S C^{(3)} \cdot d^{2}}{d^{2}-c^{2}}\left(1-\frac{c^{2}}{r^{2}}\right) \\
& \Delta \sigma_{\theta S}^{(3)}=\frac{\left(p_{\text {prod }}-p_{\text {perf }}\right) c^{2}}{d^{2}-c^{2}}\left(1+\frac{d^{2}}{r^{2}}\right)-\frac{S C^{(3)} \cdot d^{2}}{d^{2}-c^{2}}\left(1+\frac{c^{2}}{r^{2}}\right)
\end{aligned}
$$

Para o cimento, as equações (3.26) e (3.27) apresentam os incrementos das componentes de tensão radial e tangencial durante a produção.

$$
\begin{aligned}
& \Delta \sigma_{r C}^{(3)}=\frac{S C^{(3)} \cdot d^{2}}{e^{2}-d^{2}}\left(1-\frac{e^{2}}{r^{2}}\right)-\frac{C F^{(3)} \cdot e^{2}}{e^{2}-d^{2}}\left(1-\frac{d^{2}}{r^{2}}\right) \\
& \Delta \sigma_{\theta C}^{(3)}=\frac{S C^{(3)} \cdot d^{2}}{e^{2}-d^{2}}\left(1+\frac{e^{2}}{r^{2}}\right)-\frac{C F^{(3)} \cdot e^{2}}{e^{2}-d^{2}}\left(1+\frac{d^{2}}{r^{2}}\right)
\end{aligned}
$$

As equações (3.28) e (3.29) apresentam os incrementos de tensão na formação com a influência do efeito mecânico da variação da poropressão na rocha, $\Delta P P$.

$$
\Delta \sigma_{r F}^{(3)}=\frac{\left(C F^{(3)}-\Delta P P\right) \cdot e^{2}}{f^{2}-e^{2}}\left(1-\frac{f^{2}}{r^{2}}\right)
$$




$$
\Delta \sigma_{\theta F}^{(3)}=\frac{\left(C F^{(3)}-\Delta P P\right) \cdot e^{2}}{f^{2}-e^{2}}\left(1+\frac{f^{2}}{r^{2}}\right)
$$

Para o caso de depleção, o valor a ser substituído é negativo e no caso de injeção, é positivo, conforme Figura 3.9.

ل)

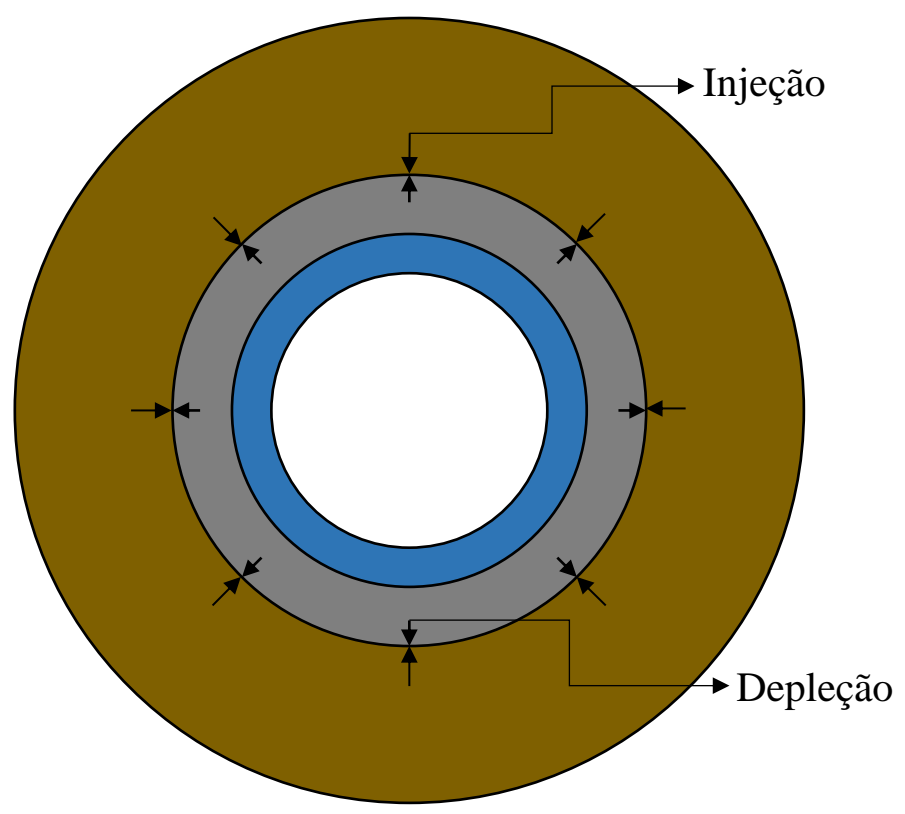

Figura 3.9 - Variação da poropressão na formação durante a produção.

Realizando a compatibilidade entre os deslocamentos radiais da superfície interna do cimento e da superfície externa do revestimento, chega-se à equação (3.30).

$$
\begin{aligned}
& \frac{d}{E_{S}}\left\{\left(1-v_{S}^{2}\right)[\right.\left.\left(\frac{2 \cdot c^{2}}{d^{2}-c^{2}}\right)\left(p_{\text {prod }}-p_{\text {perf }}\right)-\left(\frac{d^{2}+c^{2}}{d^{2}-c^{2}}\right) S C^{(3)}\right] \\
&\left.+S C^{(3)}\left(v_{S}+v_{S}^{2}\right)\right\}+\left(v_{S} \cdot \alpha_{S} \cdot \Delta T \cdot d+\alpha_{S} \cdot \Delta T \cdot d\right)= \\
& \frac{d}{E_{C}}\left\{\left(1-v_{C}^{2}\right)\left[\left(\frac{d^{2}+e^{2}}{e^{2}-d^{2}}\right) S C^{(3)}-\left(\frac{2 \cdot e^{2}}{e^{2}-d^{2}}\right) C F^{(3)}\right]\right. \\
&\left.+S C^{(3)}\left(v_{C}+v_{C}^{2}\right)\right\}+\left(v_{C} \cdot \alpha_{C} \cdot \Delta T \cdot d+\alpha_{C} \cdot \Delta T \cdot d\right)
\end{aligned}
$$

Igualando os deslocamentos radiais da superfície externa do cimento e da superfície interna da formação, chega-se à equação (3.31).

$$
\begin{aligned}
\frac{e}{E_{C}}\left\{\left(1-v_{C}^{2}\right)\right. & {\left[\left(\frac{2 \cdot d^{2}}{e^{2}-d^{2}}\right) S C^{(3)}-\left(\frac{e^{2}+d^{2}}{e^{2}-d^{2}}\right) C F^{(3)}\right] } \\
& \left.+C F^{(3)}\left(v_{C}+v_{C}^{2}\right)\right\}+\left(v_{C} \cdot \alpha_{C} \cdot \Delta T \cdot e+\alpha_{C} \cdot \Delta T \cdot e\right)=
\end{aligned}
$$




$$
\begin{aligned}
\frac{e}{E_{C}}\left\{\left(1-v_{F}^{2}\right)\right. & {\left[\left(\frac{e^{2}+f^{2}}{f^{2}-e^{2}}\right)\left(C F^{(3)}-\Delta P P\right)\right]+\left(C F^{(3)}\right.} \\
& \left.-\Delta P P)\left(v_{F}+v_{F}^{2}\right)\right\}
\end{aligned}
$$

Resolvendo as equações (3.30) e (3.31) encontram-se os valores de $S C^{(3)} \mathrm{e}$ $C F^{(3)}$. Ao substituir esses valores nas equações de (3.24) a (3.29), é possível obter os incrementos de tensões ao longo do raio do poço durante a produção.

\subsection{5.}

\section{Produção (efeito térmico - transiente)}

O efeito térmico é considerado através da imposição de uma variação de temperatura e das tensões associadas. Para o cimento e o revestimento, por serem cilindros de espessura bem inferiores quando comparados à formação, o cálculo das tensões é feito de modo simplificado. A variação de temperatura ocorre na superfície interna do revestimento devida ao fluido de produção. Essa variação de temperatura é prescrita no revestimento e no cimento, portanto, as deformações são calculadas como mostrado pelas equações (3.5) a (3.9). Essa mesma diferença é aplicada na parede da rocha, e então é feito o estudo transiente, analisando o perfil de temperatura ao longo do raio e do tempo na formação. A Figura 3.10 apresenta como a variação da temperatura é imposta em cada material do modelo.

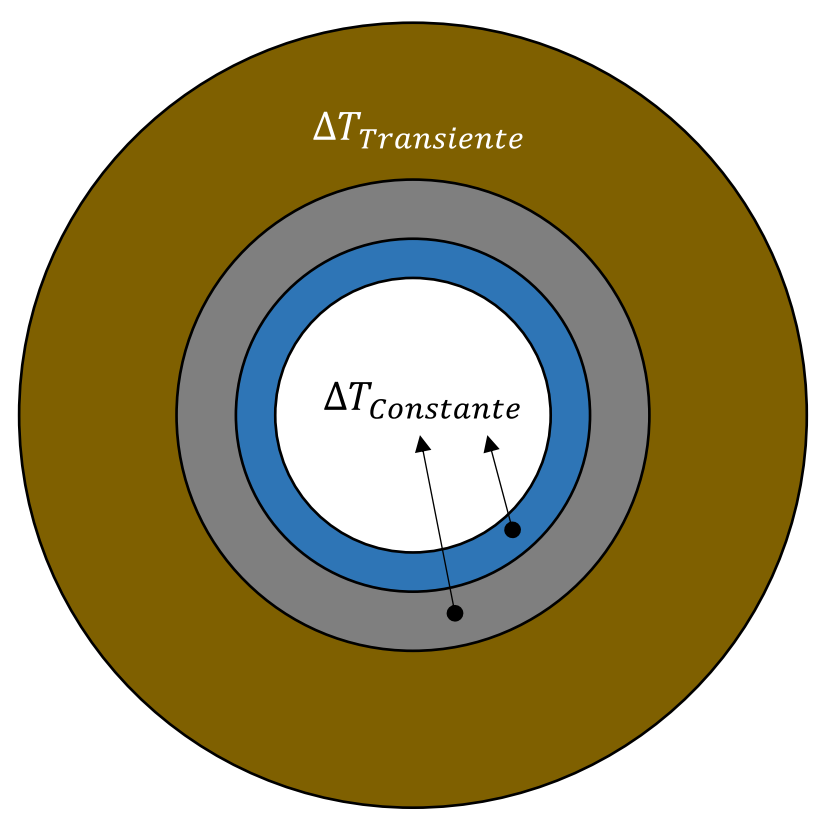

Figura 3.10 - Fase de produção considerando somente o efeito térmico.

A variação de pressão é um fenômeno de curta duração, enquanto a diferença de temperatura tem uma evolução mais lenta, variando com o tempo. Devido a isso, 
a análise é feita considerando uma variação de temperatura transiente na rocha. Para este cálculo, utiliza-se a solução de Ostrowski \& Michalak (2011) para um cilindro vazado com temperaturas prescritas nas superfícies interna, $T_{i}$ e externa, $T_{e}$.

$$
\begin{gathered}
T(r, t)=T_{i}+\left(T_{e}-T_{i}\right)\left(\frac{\ln r-\ln r_{i}}{\ln r_{e}-\ln r_{i}}\right)+ \\
\pi \sum_{n=1}^{\infty} \frac{C_{o}\left(r, \lambda_{n}\right)}{F\left(\lambda_{n}\right)} J_{0}\left(r_{e} \cdot \lambda_{n}\right)\left[T_{e} \cdot J_{0}\left(r_{i} \cdot \lambda_{n}\right)-T_{i} \cdot J_{0}\left(r_{e} \cdot \lambda_{n}\right)\right] e^{-\beta \cdot \lambda_{n}^{2} \cdot t}
\end{gathered}
$$

A equação (3.32) apresenta a temperatura final de um cilindro vazado e com um valor de difusividade térmica $(\beta)$ calculado através da equação (3.33).

$$
\beta=\frac{k}{\rho \cdot c_{T}}
$$

Onde $k$ é a condutividade térmica do material, $\rho$ é a densidade e $c_{T}$ é a capacidade térmica. A solução considera uma temperatura $\left(T_{i}\right)$ no raio interno $\left(r_{i}\right)$ do cilindro e outra temperatura $\left(T_{e}\right)$ no raio externo $\left(r_{e}\right)$. Admite-se que a temperatura inicial em todo o cilindro seja igual a zero $(T$ no domínio $=0$ em $t=$ 0) além de considerar as propriedades térmicas constantes. Dessa forma, as temperaturas que são substituídas na equação (3.32) são a variação em relação à temperatura inicial do sistema. As funções de $C_{0}$ e $F$ são apresentadas pelas equações (3.34) e (3.35).

$$
\begin{gathered}
C_{0}\left(r, \lambda_{n}\right)=J_{0}\left(r_{i} \cdot \lambda_{n}\right) \cdot Y_{0}\left(r \cdot \lambda_{n}\right)-J_{0}\left(r \cdot \lambda_{n}\right) \cdot Y_{0}\left(r_{i} \cdot \lambda_{n}\right) \\
F\left(\lambda_{n}\right)=J_{0}^{2}\left(r_{i} \cdot \lambda_{n}\right)-J_{0}^{2}\left(r_{e} \cdot \lambda_{n}\right)
\end{gathered}
$$

Para encontrar os valores de $\lambda_{n}$ (para $n=1,2, \ldots$ ) deve-se calcular as raízes da equação (3.36). Substituindo as equações (3.34) e (3.35) na equação (3.32) é possível encontrar o perfil de temperatura no cilindro ao longo da coordenada radial $(r)$ e ao longo do tempo $(t)$.

$$
J_{0}\left(r_{i} \cdot \lambda\right) \cdot Y_{0}\left(r_{e} \cdot \lambda\right)-J_{0}\left(r_{e} \cdot \lambda\right) \cdot Y_{0}\left(r_{i} \cdot \lambda\right)=0
$$

Onde $J_{0}$ é uma função do primeiro tipo e de ordem zero de Bessel e $Y_{0}$ é uma função de segundo tipo e de ordem zero de Bessel (Bowman, 1958).

Com a função de temperatura variando com o raio e com o tempo, pode-se então calcular a tensão que é gerada no material cilíndrico em um determinado instante de tempo. O cenário de tensões na rocha devido a efeitos térmicos após a produção é tratado com o sobrescrito (3T). Utilizando as equações (3.37) e (3.38) 
de Vullo (2014) são feitos os cálculos das tensões radial e tangencial, respectivamente, do cilindro de paredes espessas, sendo $\alpha$ o coeficiente de dilatação térmica do material.

$$
\begin{gathered}
\Delta \sigma_{r F}^{(3 T)}=\frac{\alpha \cdot E}{1-v}\left[\frac{1}{r_{e}^{2}-r_{i}^{2}}\left(1-\frac{r_{i}^{2}}{r^{2}}\right) \int_{r_{i}}^{r_{e}} T \cdot r \cdot d r-\frac{1}{r^{2}} \int_{r_{i}}^{r} T \cdot r \cdot d r\right] \\
\Delta \sigma_{\theta F}^{(3 T)}=\frac{\alpha \cdot E}{1-v}\left[\frac{1}{r_{e}^{2}-r_{i}^{2}}\left(1+\frac{r_{i}^{2}}{r^{2}}\right) \int_{r_{i}}^{r_{e}} T \cdot r \cdot d r+\frac{1}{r^{2}} \int_{r_{i}}^{r} T \cdot r \cdot d r-T\right]
\end{gathered}
$$

Por fim, deve-se substituir a equação (3.32) nas equações (3.37) e (3.38) para encontrar as tensões no cilindro devidas ao efeito térmico. As tensões $\Delta \sigma_{r F}^{(3 T)}$ e $\Delta \sigma_{\theta F}^{(3 T)}$ são as tensões radial e tangencial na rocha provenientes da variação da temperatura, respectivamente.

\subsection{6.}

\section{Superposição de efeitos}

Para a obtenção do estado de tensão final no sistema é necessário somar as parcelas de cada fase para o revestimento, para o cimento e para a rocha, já que as tensões iniciais e os incrementos de tensões são calculados em cada uma das fases. Essa superposição de efeitos é válida pois trata-se de uma análise linear elástica.

Para o revestimento, as componentes de tensão radial e tangencial finais são dadas pela equação (3.39);

$$
\begin{aligned}
& \sigma_{r S}=\Delta \sigma_{r S}^{(1)}+\Delta \sigma_{r S}^{(2)}+\Delta \sigma_{r S}^{(3)} \\
& \sigma_{\theta S}=\Delta \sigma_{\theta S}^{(1)}+\Delta \sigma_{\theta S}^{(2)}+\Delta \sigma_{\theta S}^{(3)}
\end{aligned}
$$

para o cimento, pela equação (3.40);

$$
\begin{gathered}
\sigma_{r C}=-\sigma_{C}^{(0)}+\Delta \sigma_{r C}^{(2)}+\Delta \sigma_{r C}^{(3)} \\
\sigma_{\theta C}=-\sigma_{C}^{(0)}+\Delta \sigma_{\theta C}^{(2)}+\Delta \sigma_{\theta C}^{(3)}
\end{gathered}
$$

e finalmente, para a formação, são dadas pela equação (3.41).

$$
\begin{aligned}
& \sigma_{r F}=\sigma_{r F}^{(0)}+\Delta \sigma_{r F}^{(1)}+\Delta \sigma_{r F}^{(2)}+\Delta \sigma_{r F}^{(3)}+\Delta \sigma_{r F}^{(3 T)} \\
& \sigma_{\theta F}=\sigma_{\theta F}^{(0)}+\Delta \sigma_{\theta F}^{(1)}+\Delta \sigma_{\theta F}^{(2)}+\Delta \sigma_{\theta F}^{(3)}+\Delta \sigma_{\theta F}^{(3 T)}
\end{aligned}
$$

\section{4.}

\section{Solução analítica com dois revestimentos}

Nesta seção é apresentada a solução analítica para o caso de um poço com dois revestimentos. Os mesmos procedimentos realizados anteriormente são 
reproduzidos. A fase em que é adicionado o cimento interno endurecido no modelo é exatamente igual à apresentada na seção 3.3 .3 (solução para um revestimento). Assim, no caso de dois revestimentos, é apresentada a formulação para a descida do revestimento interno, e em seguida para a produção. Dessa forma, a sequência das fases é a seguinte:

- Perfuração (sobrescrito (0));

- Descida do revestimento externo (sobrescrito (1));

- Cimento externo endurecido (sobrescrito (2));

- Descida do revestimento interno (sobrescrito (4));

- Cimento interno endurecido (sobrescrito (5));

- Produção (sobrescrito (6) e sobrescrito (6T) para o efeito térmico transiente na rocha).

As fases de perfuração, de descida do revestimento externo e de endurecimento do cimento externo apresentadas para o caso de um revestimento são idênticas para o caso de revestimento duplo. São então apresentadas as fases de descida do revestimento interno, de cimento interno endurecido e de produção.

\subsection{1.} Descida do revestimento interno

Utilizando as equações (3.10) e (3.11), o cálculo dos incrementos de tensão é feito para o revestimento interno. O cenário após a descida do revestimento interno é indicado com o sobrescrito (4). A Figura 3.11 apresenta as pressões envolvidas nessa fase. 


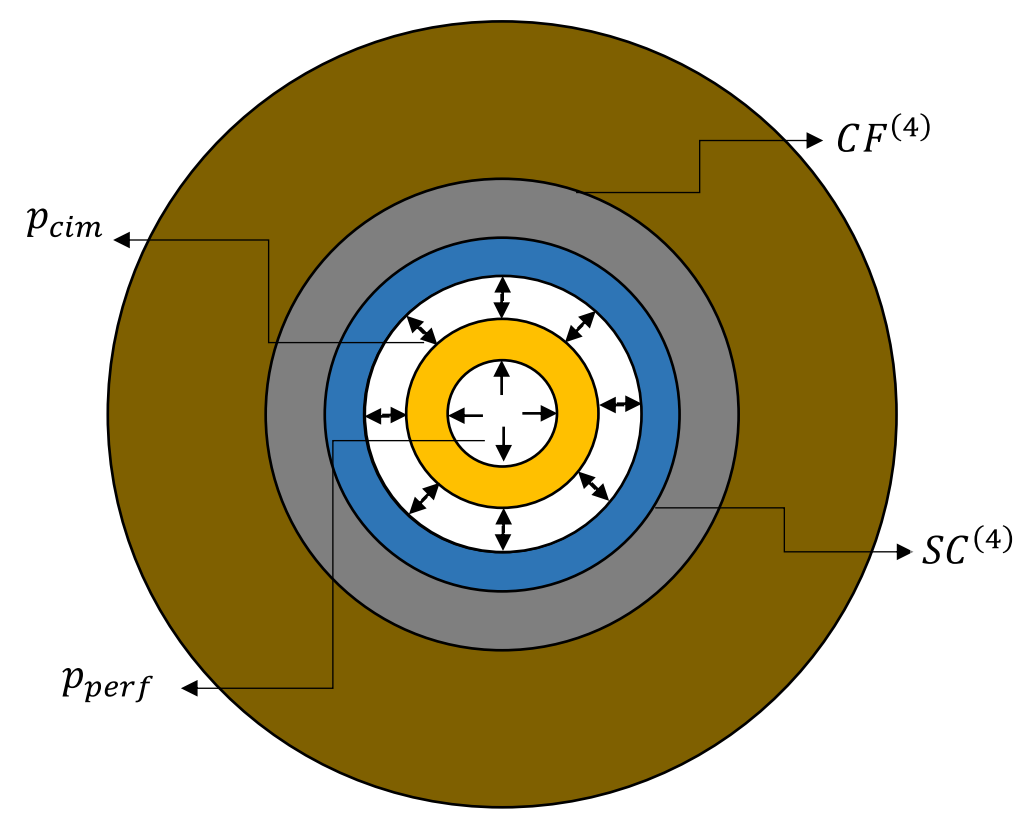

Figura 3.11 - Pressões atuando nos revestimentos, cimento externo e na formação após a descida do revestimento interno.

A pressão interna é devida ao fluido de perfuração, $p_{\text {perf }}$, enquanto na superfície externa, é aplicada a pressão ocasionada pelo cimento fluido, $p_{\text {cim }}$. Calculam-se os incrementos de tensão radial, $\Delta \bar{\sigma}_{r S}^{(4)}$ e tangencial, $\Delta \bar{\sigma}_{\theta S}^{(4)}$ do revestimento interno, conforme equações (3.42) e (3.43), onde $\left[^{-}\right]$refere-se aos materiais internos.

$$
\begin{aligned}
& \Delta \bar{\sigma}_{r S}^{(4)}=\frac{p_{p e r f} \cdot a^{2}}{b^{2}-a^{2}}\left(1-\frac{b^{2}}{r^{2}}\right)-\frac{p_{c i m} \cdot b^{2}}{b^{2}-a^{2}}\left(1-\frac{a^{2}}{r^{2}}\right) \\
& \Delta \bar{\sigma}_{\theta S}^{(4)}=\frac{p_{\text {perf }} \cdot a^{2}}{b^{2}-a^{2}}\left(1+\frac{b^{2}}{r^{2}}\right)-\frac{p_{c i m} \cdot b^{2}}{b^{2}-a^{2}}\left(1+\frac{a^{2}}{r^{2}}\right)
\end{aligned}
$$

Para o revestimento externo, a variação da pressão interna torna-se a diferença entre a pressão devida ao cimento fluido que está presente entre os dois revestimentos e a pressão devida ao fluido de perfuração que estava aplicada na fase anterior. A pressão externa, $S C^{(4)}$, é a força de contato entre o revestimento externo e o cimento externo. Os incrementos das componentes de tensão radial e tangencial para o revestimento externo após a descida do revestimento interno são apresentados nas equações (3.44) e (3.45).

$$
\begin{gathered}
\Delta \sigma_{r S}^{(4)}=\frac{\left(p_{\text {cim }}-p_{\text {perf }}\right) \cdot c^{2}}{d^{2}-c^{2}}\left(1-\frac{d^{2}}{r^{2}}\right)-\frac{S C^{(4)} \cdot d^{2}}{d^{2}-c^{2}}\left(1-\frac{c^{2}}{r^{2}}\right) \\
\Delta \sigma_{\theta S}^{(4)}=\frac{\left(p_{\text {cim }}-p_{\text {fluido }}\right) \cdot c^{2}}{d^{2}-c^{2}}\left(1+\frac{d^{2}}{r^{2}}\right)-\frac{S C^{(4)} \cdot d^{2}}{d^{2}-c^{2}}\left(1+\frac{c^{2}}{r^{2}}\right)
\end{gathered}
$$


As equações (3.46) e (3.47) representam os incrementos das componentes de tensão radial e tangencial no cimento externo, respectivamente. A pressão interna $S C^{(4)}$ é a força de contato entre o revestimento externo e o cimento externo, enquanto $C F^{(4)}$ é a força de contato entre o cimento externo e a formação.

$$
\begin{aligned}
& \Delta \sigma_{r C}^{(4)}=\frac{S C^{(4)} \cdot d^{2}}{e^{2}-d^{2}}\left(1-\frac{e^{2}}{r^{2}}\right)-\frac{C F^{(4)} \cdot e^{2}}{e^{2}-d^{2}}\left(1-\frac{d^{2}}{r^{2}}\right) \\
& \Delta \sigma_{\theta C}^{(4)}=\frac{S C^{(4)} \cdot d^{2}}{e^{2}-d^{2}}\left(1+\frac{e^{2}}{r^{2}}\right)-\frac{C F^{(4)} \cdot e^{2}}{e^{2}-d^{2}}\left(1+\frac{d^{2}}{r^{2}}\right)
\end{aligned}
$$

Os incrementos de tensões na formação, apresentados nas equações (3.48) e (3.49), são calculados considerando como pressão interna apenas a força de contato, $C F^{(4)}$, entre o cimento externo e a formação, enquanto a pressão externa é nula.

$$
\begin{aligned}
& \Delta \sigma_{r F}^{(4)}=\frac{C F^{(4)} \cdot e^{2}}{f^{2}-e^{2}}\left(1-\frac{f^{2}}{r^{2}}\right) \\
& \Delta \sigma_{\theta F}^{(4)}=\frac{C F^{(4)} \cdot e^{2}}{f^{2}-e^{2}}\left(1+\frac{f^{2}}{r^{2}}\right)
\end{aligned}
$$

Com o objetivo de obter os valores das forças de contato $S C^{(4)}$ e $C F^{(4)}$, devese impor a compatibilidade entre os deslocamentos radiais do revestimento externo e do cimento externo e entre o cimento externo e a formação.

A equação (3.50) apresenta a compatibilidade de deslocamentos do revestimento externo e do cimento externo, após substituição das equações (3.10) e (3.11) na equação (3.9).

$$
\begin{gathered}
\frac{d}{E_{s}}\left\{\left(1-v_{s}^{2}\right)\left[\left(\frac{2 \cdot c^{2}}{d^{2}-c^{2}}\right)\left(p_{c i m}-p_{\text {perf }}\right)-\left(\frac{d^{2}+c^{2}}{d^{2}-c^{2}}\right) S C^{(4)}\right]\right. \\
\left.+S C^{(4)}\left(v_{s}+v_{s}^{2}\right)\right\}= \\
\frac{d}{E_{c}}\left\{\left(1-v_{c}^{2}\right)\left[\left(\frac{d^{2}+e^{2}}{e^{2}-d^{2}}\right) S C^{(4)}-\left(\frac{2 \cdot e^{2}}{e^{2}-d^{2}}\right) C F^{(4)}\right]\right. \\
\left.+S C^{(4)}\left(v_{c}+v_{c}^{2}\right)\right\}
\end{gathered}
$$

A equação (3.51) representa a compatibilidade de deslocamento radial entre o cimento externo e a formação. 


$$
\begin{gathered}
\frac{e}{E_{c}}\left\{\left(1-v_{c}^{2}\right)\left[\left(\frac{2 \cdot d^{2}}{e^{2}-d^{2}}\right) S C^{(4)}-\left(\frac{e^{2}+d^{2}}{e^{2}-d^{2}}\right) C F^{(4)}\right]\right. \\
\left.+C F^{(4)}\left(v_{c}+v_{c}^{2}\right)\right\}= \\
\frac{e}{E_{f}}\left\{\left(1-v_{f}^{2}\right)\left[\left(\frac{e^{2}+f^{2}}{f^{2}-e^{2}}\right) C F^{(4)}\right]+C F^{(4)}\left(v_{f}+v_{f}^{2}\right)\right\}
\end{gathered}
$$

\subsection{2.}

\section{Cimento interno endurecido}

Para o poço com dois revestimentos, a formulação para a fase em que o cimento interno endurecido é adicionado ao modelo não é apresentada, uma vez que o cálculo é feito da mesma forma que na seção 3.3.3 (solução para um revestimento). A configuração de pressões atuando nos revestimentos, cimentos e formação na fase de cimento interno endurecido é apresentada na Figura 3.12. O cenário após o endurecimento do cimento interno é indicado com o sobrescrito (5). Assim, as forças de contato entre os materiais são $\overline{S C}^{(5)}, C S^{(5)}, S C^{(5)}$ e $C F^{(5)}$, enquanto a pressão interna atuando no revestimento interno é devida ao fluido de perfuração, $p_{\text {perf }}$. Vale ressaltar que da mesma forma que na seção 3.3.3, o estado de tensão inicial do cimento interno possui o mesmo valor da pressão devida ao fluido de perfuração (Cooke et al., 1983).

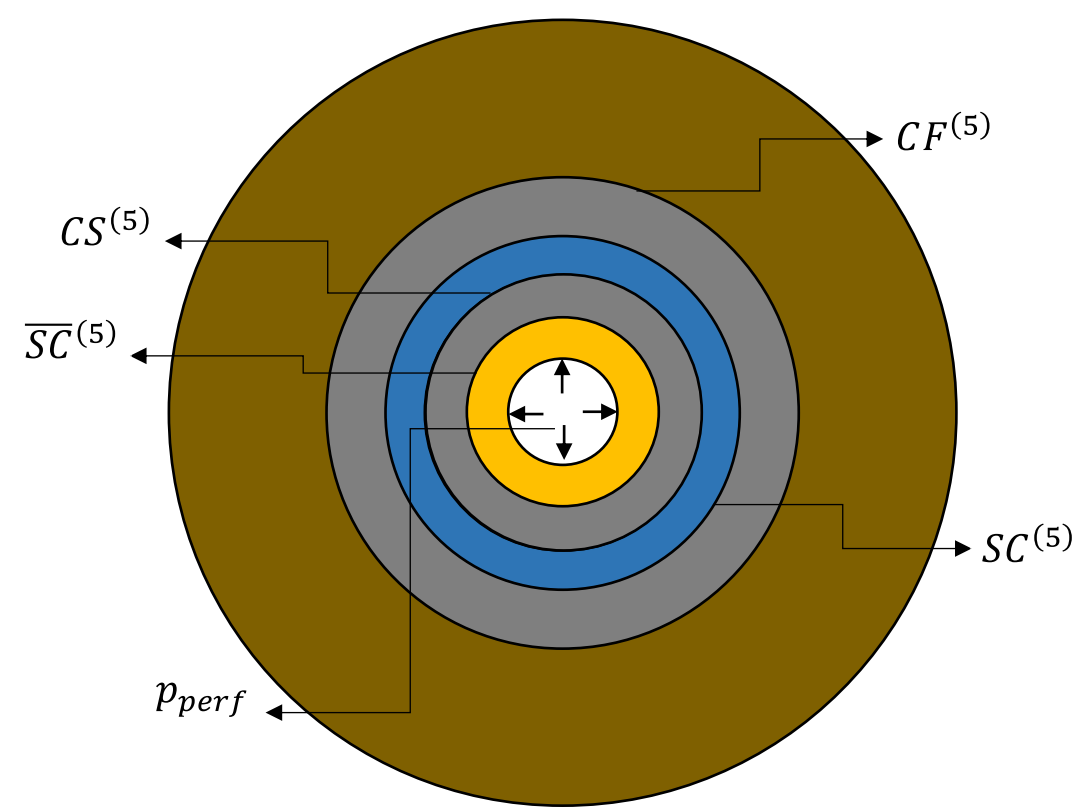

Figura 3.12 - Pressões atuando na fase de cimento interno endurecido. 


\subsection{3. Produção (efeitos mecânico e térmico)}

Para considerar a produção em um poço com dois revestimentos, a metodologia utilizada para um revestimento é novamente adotada. A pressão interna no revestimento interno é alterada, simulando a produção do hidrocarboneto. Há também uma variação na temperatura do fluido de produção dentro do poço. Esse efeito térmico é simulado nos revestimentos e nos cimentos como uma variação de temperatura prescrita e constante. Para a formação, a solução transiente apresentada na seção 3.3.5 é utilizada. A Figura 3.13 apresenta a configuração do sistema com as forças atuantes em cada superfície durante a produção.

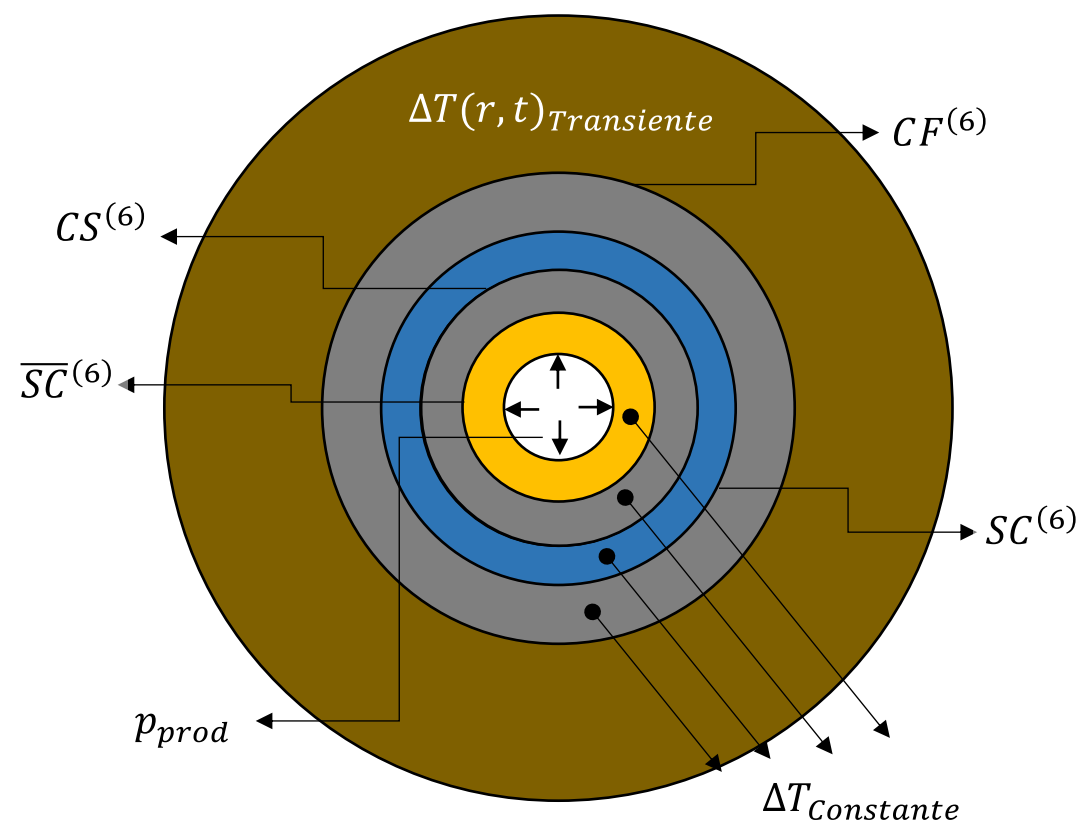

Figura 3.13 - Representação do poço com as pressões e com a variação de temperatura durante a produção.

As equações (3.52) e (3.53) apresentam os incrementos das componentes de tensão radial e tangencial no revestimento interno. A variação da pressão interna proveniente da produção é a diferença entre a pressão de produção e a pressão do fluido de perfuração (fase anterior). O cenário na produção é indicado com o sobrescrito (6). A pressão externa a ser aplicada é a força devida ao contato entre o revestimento interno e o cimento interno, $\overline{S C}^{(6)}$.

$$
\Delta \bar{\sigma}_{r S}^{(6)}=\frac{\left(p_{\text {prod }}-p_{\text {perf }}\right) \cdot a^{2}}{b^{2}-a^{2}}\left(1-\frac{b^{2}}{r^{2}}\right)-\frac{\overline{S C}^{(6)} \cdot b^{2}}{b^{2}-a^{2}}\left(1-\frac{a^{2}}{r^{2}}\right)
$$




$$
\Delta \bar{\sigma}_{\theta S}^{(6)}=\frac{\left(p_{\text {prod }}-p_{\text {perf }}\right) \cdot a^{2}}{b^{2}-a^{2}}\left(1+\frac{b^{2}}{r^{2}}\right)-\frac{\overline{S C}^{(6)} \cdot b^{2}}{b^{2}-a^{2}}\left(1+\frac{a^{2}}{r^{2}}\right)
$$

Avaliando os incrementos de tensão no cimento interno, deve-se aplicar como pressão interna a força de contato entre o revestimento interno e o cimento interno $\left(\overline{S C}^{(6)}\right)$. Como pressão externa, a força de contato entre o cimento interno e o revestimento externo é aplicada $\left(C S^{(6)}\right)$. As equações (3.54) e (3.55) apresentam os incrementos das tensões no cimento interno.

$$
\begin{aligned}
& \Delta \bar{\sigma}_{r C}^{(6)}=\frac{\overline{S C}^{(6)} \cdot b^{2}}{c^{2}-b^{2}}\left(1-\frac{c^{2}}{r^{2}}\right)-\frac{C S^{(6)} \cdot c^{2}}{c^{2}-b^{2}}\left(1-\frac{b^{2}}{r^{2}}\right) \\
& \Delta \bar{\sigma}_{\theta C}^{(6)}=\frac{\overline{S C}^{(6)} \cdot b^{2}}{c^{2}-b^{2}}\left(1+\frac{c^{2}}{r^{2}}\right)-\frac{C S^{(6)} \cdot c^{2}}{c^{2}-b^{2}}\left(1+\frac{b^{2}}{r^{2}}\right)
\end{aligned}
$$

Os incrementos das tensões no revestimento externo são apresentados pelas equações (3.56) e (3.57). A pressão interna aplicada no revestimento externo é a força de contato entre o cimento interno e o revestimento externo $C S^{(6)}$, enquanto a pressão externa é devida ao contato entre o revestimento externo e o cimento externo $S C^{(6)}$.

$$
\begin{aligned}
& \Delta \sigma_{r S}^{(6)}=\frac{C S^{(6)} \cdot c^{2}}{d^{2}-c^{2}}\left(1-\frac{d^{2}}{r^{2}}\right)-\frac{S C^{(6)} \cdot d^{2}}{d^{2}-c^{2}}\left(1-\frac{c^{2}}{r^{2}}\right) \\
& \Delta \sigma_{\theta S}^{(6)}=\frac{C S^{(6)} \cdot c^{2}}{d^{2}-c^{2}}\left(1+\frac{d^{2}}{r^{2}}\right)-\frac{S C^{(6)} \cdot d^{2}}{d^{2}-c^{2}}\left(1+\frac{c^{2}}{r^{2}}\right)
\end{aligned}
$$

Para o cimento externo a pressão interna é a força de contato entre o revestimento externo e o cimento externo $S C^{(6)}$ e a pressão externa é a força gerada no contato entre o cimento externo e a formação $C F^{(6)}$. As equações (3.58) e (3.59) apresentam os incrementos das componentes de tensão radial e tangencial no cimento externo ao longo do raio.

$$
\begin{aligned}
& \Delta \sigma_{r C}^{(6)}=\frac{S C^{(6)} \cdot d^{2}}{e^{2}-d^{2}}\left(1-\frac{e^{2}}{r^{2}}\right)-\frac{C F^{(6)} \cdot e^{2}}{e^{2}-d^{2}}\left(1-\frac{d^{2}}{r^{2}}\right) \\
& \Delta \sigma_{\theta C}^{(6)}=\frac{S C^{(6)} \cdot d^{2}}{e^{2}-d^{2}}\left(1+\frac{e^{2}}{r^{2}}\right)-\frac{C F^{(6)} \cdot e^{2}}{e^{2}-d^{2}}\left(1+\frac{d^{2}}{r^{2}}\right)
\end{aligned}
$$

$\mathrm{Na}$ formação, somente são consideradas a força de contato entre o cimento e a formação $C F^{(6)}$ e a variação da poropressão, $\Delta P P$. Dessa forma, os incrementos de tensão na formação são dados pelas equações (3.60) e (3.61). 


$$
\begin{aligned}
& \Delta \sigma_{r F}^{(6)}=\frac{\left(C F^{(6)}-\Delta P P\right) \cdot e^{2}}{f^{2}-e^{2}}\left(1-\frac{f^{2}}{r^{2}}\right) \\
& \Delta \sigma_{\theta F}^{(6)}=\frac{\left(C F^{(6)}-\Delta P P\right) \cdot e^{2}}{f^{2}-e^{2}}\left(1+\frac{f^{2}}{r^{2}}\right)
\end{aligned}
$$

As variáveis desconhecidas nesta fase são $\overline{S C}^{(6)}, C S^{(6)}, S C^{(6)}$ e $C F^{(6)}$.

Para considerar a variação da temperatura nos cálculos dos incrementos de tensão na formação, as equações (3.62) e (3.63) apresentam os incrementos das componentes de tensão radial $\Delta \sigma_{r F}^{(6 T)}$ e tangencial $\Delta \sigma_{\theta F}^{(6 T)}$, respectivamente. As tensões devidas ao efeito térmico são calculadas utilizando a formulação apresentada na seção 3.3.5 e possuem o sobrescrito (6T).

$$
\begin{gathered}
\Delta \sigma_{r F}^{(6 T)}=\frac{\alpha \cdot E}{1-v}\left[\frac{1}{r_{e}^{2}-r_{i}^{2}}\left(1-\frac{r_{i}^{2}}{r^{2}}\right) \int_{r_{i}}^{r_{e}} T \cdot r \cdot d r-\frac{1}{r^{2}} \int_{r_{i}}^{r} T \cdot r \cdot d r\right] \\
\Delta \sigma_{\theta F}^{(6 T)}=\frac{\alpha \cdot E}{1-v}\left[\frac{1}{r_{e}^{2}-r_{i}^{2}}\left(1+\frac{r_{i}^{2}}{r^{2}}\right) \int_{r_{i}}^{r_{e}} T \cdot r \cdot d r+\frac{1}{r^{2}} \int_{r_{i}}^{r} T \cdot r \cdot d r-T\right]
\end{gathered}
$$

São calculados os deslocamentos radiais de cada superfície como já apresentado anteriormente, e por fim, são igualados os deslocamentos radiais entre as superfícies que estão em contato. Com a compatibilidade de deslocamentos entre as superfícies em contato, quatro equações são encontradas. A equação (3.64) apresenta a compatibilidade de deslocamento radial entre o revestimento interno e o cimento interno.

$$
\begin{aligned}
& \frac{b}{E_{S}}\left\{\left(1-v_{s}^{2}\right)[\right.\left.\frac{2 \cdot a^{2}}{b^{2}-a^{2}}\left(p_{\text {prod }}-p_{\text {fluido }}\right)-\left(\frac{b^{2}+a^{2}}{b^{2}-a^{2}}\right) \overline{S C}^{(6)}\right] \\
&\left.+\overline{S C}^{(6)}\left(v_{s}+v_{S}^{2}\right)\right\}+b \cdot v_{S} \cdot \alpha_{S} \cdot \Delta T+b \cdot \alpha_{S} \cdot \Delta T= \\
& \frac{b}{E_{c}}\left\{\left(1-v_{c}^{2}\right)\left[\left(\frac{b^{2}+c^{2}}{b^{2}-a^{2}}\right) \overline{S C}(6)-\left(\frac{2 \cdot c^{2}}{c^{2}-b^{2}}\right) C S^{(6)}\right]\right. \\
&\left.+\overline{S C}^{(6)}\left(v_{c}+v_{c}^{2}\right)\right\}+b \cdot v_{C} \cdot \alpha_{C} \cdot \Delta T+b \cdot \alpha_{C} \cdot \Delta T
\end{aligned}
$$

A compatibilidade entre os deslocamentos radiais do cimento interno e do revestimento externo é apresentada na equação (3.65). 


$$
\begin{gathered}
\frac{c}{E_{c}}\left\{\left(1-v_{c}^{2}\right)\left[\left(\frac{2 \cdot b^{2}}{c^{2}-b^{2}}\right) \overline{S C}{ }^{(6)}+\left(\frac{c^{2}+b^{2}}{c^{2}-b^{2}}\right) C S^{(6)}\right]+C S^{(6)}\left(v_{c}+v_{c}^{2}\right)\right\} \\
+c \cdot v_{C} \cdot \alpha_{C} \cdot \Delta T+c \cdot \alpha_{C} \cdot \Delta T= \\
\frac{c}{E_{S}}\left\{\left(1-v_{S}^{2}\right)\left[\left(\frac{c^{2}+d^{2}}{d^{2}-c^{2}}\right) C S^{(6)}-\left(\frac{2 \cdot d^{2}}{d^{2}-c^{2}}\right) S C^{(6)}\right]+C S^{(6)}\left(v_{S}+v_{S}^{2}\right)\right\} \\
+c \cdot v_{S} \cdot \alpha_{S} \cdot \Delta T+c \cdot \alpha_{S} \cdot \Delta T
\end{gathered}
$$

A equação (3.66) é a igualdade entre os deslocamentos do revestimento externo e do cimento externo.

$$
\begin{gathered}
\frac{d}{E_{s}}\left\{\left(1-v_{s}^{2}\right)\left[\left(\frac{2 \cdot c^{2}}{d^{2}-c^{2}}\right) C S^{(6)}-\left(\frac{d^{2}+c^{2}}{d^{2}-c^{2}}\right) S C^{(6)}\right]+S C^{(6)}\left(v_{s}+v_{s}^{2}\right)\right\} \\
+d \cdot v_{S} \cdot \alpha_{S} \cdot \Delta T+d \cdot \alpha_{S} \cdot \Delta T= \\
\frac{d}{E_{c}}\left\{\left(1-v_{c}^{2}\right)\left[\left(\frac{d^{2}+e^{2}}{e^{2}-d^{2}}\right) S C^{(6)}-\left(\frac{2 \cdot e^{2}}{e^{2}-d^{2}}\right) C F^{(6)}\right]\right. \\
\left.+S C^{(6)}\left(v_{C}+v_{c}^{2}\right)\right\}+d \cdot v_{C} \cdot \alpha_{C} \cdot \Delta T+d \cdot \alpha_{C} \cdot \Delta T
\end{gathered}
$$

A última equação de compatibilidade para a produção é apresentada pela equação (3.67), que representa os deslocamentos radiais do cimento externo e da parede do poço.

$$
\begin{gathered}
\frac{e}{E_{c}}\left\{\left(1-v_{c}^{2}\right)\left[\left(\frac{2 \cdot d^{2}}{e^{2}-d^{2}}\right) S C^{(6)}-\left(\frac{e^{2}+d^{2}}{e^{2}-d^{2}}\right) C F^{(6)}\right]\right. \\
\left.+C F^{(6)}\left(v_{c}+v_{c}^{2}\right)\right\}+e \cdot v_{C} \cdot \alpha_{C} \cdot \Delta T+e \cdot \alpha_{C} \cdot \Delta T= \\
\frac{e}{E_{f}}\left\{\left(1-v_{f}^{2}\right)\left[\left(\frac{e^{2}+f^{2}}{f^{2}-e^{2}}\right)\left(C F^{(6)}-\Delta P P\right)\right]+\left(C F^{(6)}\right.\right. \\
\left.-\Delta P P)\left(v_{f}+v_{f}^{2}\right)\right\}
\end{gathered}
$$

Por fim, encontram-se os valores das variáveis $\overline{S C}^{(6)}, C S^{(6)}, S C^{(6)}$ e $C F^{(6)}$. Substituindo esses valores nas expressões para tensões da formação, do cimento externo, do revestimento externo, do cimento interno e do revestimento interno, o incremento das componentes de tensão radial e tangencial no poço durante a produção é obtido. 


\subsubsection{1.}

\section{Solução mais abrangente para gradientes térmicos}

Uma segunda abordagem para análise da temperatura nos revestimentos e cimentos é apresentada. Ao invés de adotar uma temperatura imposta e de mesmo valor para os revestimentos e cimentos, essa opção calcula uma temperatura constante, porém diferente, para cada um dos materiais a partir do valor da temperatura definida no interior do poço, $T_{0}$. A Figura 3.14 apresenta a temperatura na interface de cada material do modelo.

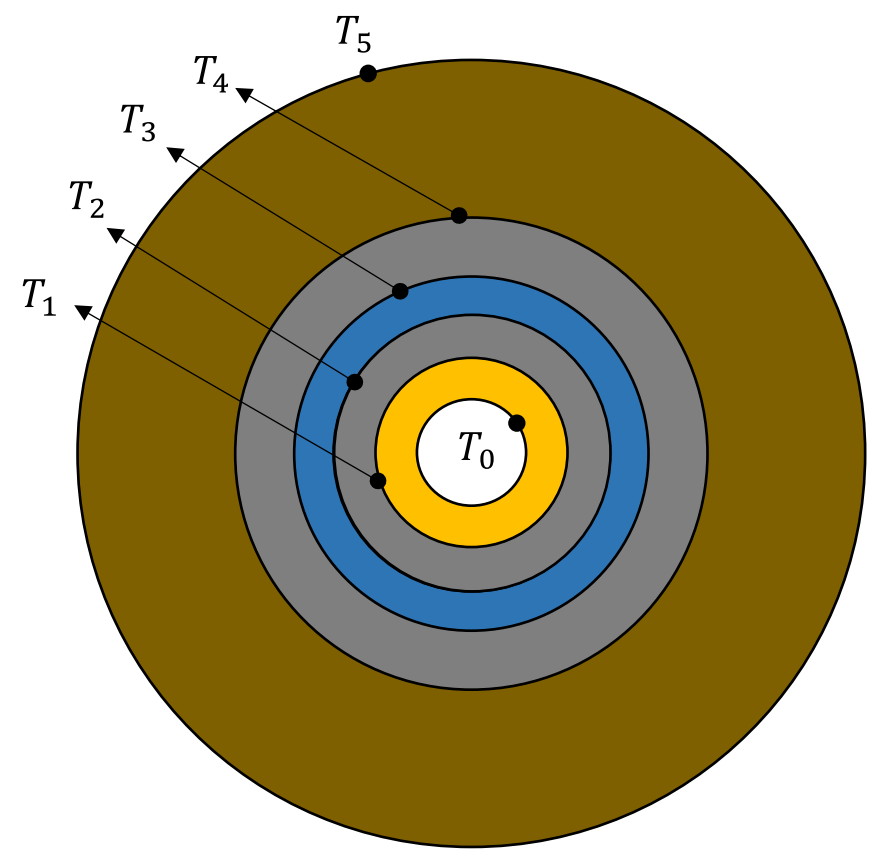

Figura 3.14 - Temperatura nas interfaces entre materiais.

Como não há geração de calor e a condutividade térmica não varia com a temperatura, a Lei de Fourier pode ser escrita conforme equação (3.68).

$$
Q=-k \cdot A \cdot \frac{d T}{d r} \stackrel{\text { sendo }}{\longrightarrow} A=2 \cdot \pi \cdot r
$$

Integrando a equação (3.68) ao longo da espessura do cilindro, a equação (3.69) é encontrada. Assim, é possível calcular a resistência térmica de cada material, $R_{i}$.

$$
Q=\frac{T_{i-1}-T_{i}}{R_{i}} \stackrel{\text { sendo }}{\longrightarrow} R_{i}=\frac{\ln \left(\frac{r_{i}}{r_{i-1}}\right)}{2 \cdot k \cdot \pi}
$$

A temperatura em cada superfície é calculada a partir da resistência térmica de cada material, considerando o regime permanente. A equação (3.70) apresenta as resistências de todos os materiais somadas. 


$$
R_{T}=\bar{R}_{S}+\bar{R}_{C}+R_{S}+R_{C}+R_{F}
$$

Onde $\bar{R}_{S}, \bar{R}_{C}, R_{S}, R_{C}$ e $R_{F}$ são chamadas de resistências térmicas do revestimento interno, cimento interno, revestimento externo, cimento externo e formação, respectivamente. A variável $k$ é a condutividade térmica do material, e $r_{i}$ e $r_{i-1}$ representam os raios externo e interno do cilindro, respectivamente.

A quantidade de transferência de calor $(Q)$ no sistema é calculada de acordo com a equação (3.71).

$$
Q=\frac{\mathrm{T}_{0}-\mathrm{T}_{5}}{R_{T}}
$$

Esse valor é utilizado para calcular a variação da temperatura em cada material, encontrando assim a temperatura em cada interface do sistema, conforme equação (3.72).

$$
T_{i}=T_{i-1}-Q \cdot R_{i}
$$

Na equação (3.72), $i$ varia de 1 a 5 , e indica o material considerado. $T_{i}$ é a temperatura na superfície externa e $R_{i}$ é a resistência térmica do material $i$. Com os valores da temperatura em cada superfície, calcula-se um valor médio para cada material.

A equação (3.73) apresenta a variação da temperatura para cada material $i$.

$$
\Delta T_{i}=\frac{T_{i}+T_{i-1}}{2}
$$

Dessa forma, as variações de temperatura para cada material são utilizadas durante a compatibilidade de deslocamentos na produção.

\subsection{4.}

\section{Superposição dos efeitos}

Para obter as tensões finais em cada um dos materiais, deve-se somar as parcelas encontradas em cada uma das diferentes fases de perfuração, descida do revestimento, cimentação e produção do poço, incluindo as fases apresentadas na seção 3.3 .

A equação (3.74) representa as componentes de tensão radial e tangencial finais para o revestimento interno.

$$
\begin{aligned}
& \bar{\sigma}_{r S}=\Delta \bar{\sigma}_{r S}^{(4)}+\Delta \bar{\sigma}_{r S}^{(5)}+\Delta \bar{\sigma}_{r S}^{(6)} \\
& \bar{\sigma}_{\theta S}=\Delta \bar{\sigma}_{\theta S}^{(4)}+\Delta \bar{\sigma}_{\theta S}^{(5)}+\Delta \bar{\sigma}_{\theta S}^{(6)}
\end{aligned}
$$


Para o cimento interno, a equação (3.75) apresenta as componentes de tensão radial e tangencial finais.

$$
\begin{aligned}
& \bar{\sigma}_{r C}=-\sigma_{C}^{(0)}+\Delta \bar{\sigma}_{r C}^{(5)}+\Delta \bar{\sigma}_{r C}^{(6)} \\
& \bar{\sigma}_{\theta C}=-\sigma_{C}^{(0)}+\Delta \bar{\sigma}_{\theta C}^{(5)}+\Delta \bar{\sigma}_{\theta C}^{(6)}
\end{aligned}
$$

A equação (3.76) representa as componentes de tensão radial e tangencial finais para o revestimento externo. Também são somadas as parcelas de variação de tensão calculadas após a descida do revestimento externo e após o endurecimento do cimento externo, apresentadas nas seções 3.3.2 e 3.3.3.

$$
\begin{aligned}
& \sigma_{r S}=\Delta \sigma_{r S}^{(1)}+\Delta \sigma_{r S}^{(2)}+\Delta \sigma_{r S}^{(4)}+\Delta \sigma_{r S}^{(5)}+\Delta \sigma_{r S}^{(6)} \\
& \sigma_{\theta S}=\Delta \sigma_{\theta S}^{(1)}+\Delta \sigma_{\theta S}^{(2)}+\Delta \sigma_{\theta S}^{(4)}+\Delta \sigma_{\theta S}^{(5)}+\Delta \sigma_{\theta S}^{(6)}
\end{aligned}
$$

Para o cimento externo, a equação (3.77) apresenta as componentes de tensão radial e tangencial finais. Deve-se levar em conta a parcela de incremento de tensões da fase de cimento externo endurecido, apresentada na seção 3.3.3.

$$
\begin{aligned}
& \sigma_{r C}=\Delta \sigma_{r C}^{(2)}+\Delta \sigma_{r C}^{(4)}+\Delta \sigma_{r C}^{(5)}+\Delta \sigma_{r C}^{(6)} \\
& \sigma_{\theta C}=\Delta \sigma_{\theta C}^{(2)}+\Delta \sigma_{\theta C}^{(4)}+\Delta \sigma_{\theta C}^{(5)}+\Delta \sigma_{\theta C}^{(6)}
\end{aligned}
$$

Para a formação, a equação (3.78) apresenta as componentes de tensão, levando em consideração a tensão gerada pelo equilíbrio entre a perfuração e o estado de tensão inicial da rocha descrita na seção 3.3.1. Além disso, os incrementos de tensão devidos à descida do revestimento externo e ao cimento externo endurecido, apresentadas nas seções 3.3.2 e 3.3.3 também são somadas. Além dos efeitos mecânicos, a parcela térmica também deve ser considerada no cálculo final.

$$
\begin{gathered}
\sigma_{r F}=\sigma_{r F}^{(0)}+\Delta \sigma_{r F}^{(1)}+\Delta \sigma_{r F}^{(2)}+\Delta \sigma_{r F}^{(4)}+\Delta \sigma_{r F}^{(5)}+\Delta \sigma_{r F}^{(6)}+\Delta \sigma_{r F}^{(6 T)} \\
\sigma_{\theta F}=\sigma_{\theta F}^{(0)}+\Delta \sigma_{\theta F}^{(1)}+\sigma_{\theta F}^{(2)}+\Delta \sigma_{\theta F}^{(4)}+\Delta \sigma_{\theta F}^{(5)}+\Delta \sigma_{\theta F}^{(6)}+\Delta \sigma_{\theta F}^{(6 T)}
\end{gathered}
$$

\section{5.}

\section{Critério de plastificação}

Para a avaliação dos materiais, são analisadas as componentes de tensão radial e tangencial. Além desses valores, o índice de plastificação $(I P)$ é avaliado para o aço (revestimento) e para o cimento ao longo deste trabalho. Esse índice é a relação entre a tensão que atua no material e uma tensão crítica do mesmo, e é definido no intervalo $0 \leq I P \leq 1$. Sendo o limite superior $(I P=1)$ a condição de plastificação do material. Para o aço, o cálculo é feito considerando o critério de von Mises, enquanto para o cimento é utilizado o critério de Mohr-Coulomb. 


\subsection{1.}

Aço

Para o aço, o cálculo da tensão equivalente de von Mises $\left(\sigma_{M}\right)$ é dada pela equação (3.79).

$$
\sigma_{M}=\frac{1}{\sqrt{2}}\left(\sqrt{\left(\sigma_{1}-\sigma_{2}\right)^{2}+\left(\sigma_{2}-\sigma_{3}\right)^{2}+\left(\sigma_{3}-\sigma_{1}\right)^{2}}\right)
$$

Onde o $\sigma_{1}$ é a tensão máxima atuando no revestimento, $\sigma_{2}$ é a tensão intermediária no aço e $\sigma_{3}$ é a tensão mínima atuante.

O índice de plastificação então é calculado através da equação (3.80).

$$
I P=\frac{\sigma_{M}}{\sigma_{y}}
$$

Onde o IP é o índice de plastificação e $\sigma_{y}$ é a tensão de escoamento do aço.

\subsection{2.}

\section{Cimento}

Para um estado geral de tensões, a equação (3.81) define a superfície de escoamento de Mohr-Coulomb ( $F)$,

$$
F=R_{M} \cdot \sigma_{c r}-p_{\text {hid }} \cdot \tan (\phi)-c_{0}=0
$$

onde $\sigma_{c r}$ é a tensão crítica do material; $p_{\text {hid }}$ é a pressão hidrostática, apresentada na equação (3.82); $c_{0}$ é a coesão; $\phi$ é o ângulo de atrito do material; e $R_{M}$ é uma constante definida pela equação (3.83).

$$
\begin{gathered}
p_{\text {hid }}=-\frac{1}{3} \cdot I_{1} \\
R_{M}=\frac{1}{\sqrt{3}} \cdot \frac{\operatorname{sen}\left(\theta+\frac{\pi}{3}\right)}{\cos (\phi)}+\frac{1}{3} \cdot \cos \left(\theta+\frac{\pi}{3}\right) \cdot \tan (\phi)
\end{gathered}
$$

$J_{2}$ é o segundo invariante do tensor das tensões desviadoras, $I_{1}$ é o primeiro invariante do tensor das tensões principais e $\theta$ é o ângulo de Lode, definido na equação (3.84),

$$
\theta=\frac{\arccos \left(\frac{r_{i n v}}{q}\right)^{2}}{3} \stackrel{\text { sendo }}{\longrightarrow} \quad r_{i n v}=3\left(\frac{1}{2} \cdot J_{3}\right)^{\frac{1}{3}}
$$

onde $J_{3}$ é o terceiro invariante do tensor das tensões desviadoras e $q$ é a tensão equivalente, equação (3.85); 


$$
q=\sqrt{3 \cdot J_{2}}
$$

O primeiro $\left(I_{1}\right)$, o segundo $\left(I_{2}\right)$ e o terceiro $\left(I_{3}\right)$ invariantes do tensor das tensões são dados em termos das tensões principais pelas equações (3.86), (3.87) e (3.88), respectivamente.

$$
\begin{gathered}
I_{1}=\sigma_{1}+\sigma_{2}+\sigma_{3} \\
I_{2}=\sigma_{1} \cdot \sigma_{2}+\sigma_{2} \cdot \sigma_{3}+\sigma_{3} \cdot \sigma_{1} \\
I_{3}=\sigma_{1} \cdot \sigma_{2} \cdot \sigma_{3}
\end{gathered}
$$

O segundo $\left(J_{2}\right)$ e o terceiro $\left(J_{3},\right)$ invariantes do tensor das tensões desviadoras são apresentados nas equações (3.89) e (3.90), respectivamente.

$$
\begin{gathered}
J_{2}=\frac{1}{3} \cdot I_{1}^{2}-I_{2}=\frac{1}{6} \cdot\left[\left(\sigma_{1}-\sigma_{2}\right)^{2}+\left(\sigma_{2}-\sigma_{3}\right)^{2}+\left(\sigma_{3}-\sigma_{1}\right)^{2}\right] \\
J_{3}=\frac{2}{27} \cdot I_{1}^{3}-\frac{1}{3} \cdot I_{1} \cdot I_{2}+I_{3}
\end{gathered}
$$

Isolando a tensão crítica do cimento $\left(\sigma_{c r}\right)$, a equação (3.83) pode ser reescrita conforme a equação (3.91).

$$
\sigma_{c r}=\frac{c_{0}+p_{\text {hid }} \cdot \tan (\phi)}{\mathrm{R}_{\mathrm{M}}}
$$

Para avaliar o índice de plastificação, a tensão equivalente atuante é dividida pela tensão crítica, conforme equação (3.92).

$$
I P=\frac{\sigma_{M}}{\sigma_{c r}}
$$




\section{4 \\ Modelagem numérica dos processos ao longo da vida útil dos poços}

\section{1. Introdução}

Neste capítulo, é apresentada uma metodologia para análise de tensões ao longo da vida útil de poços de petróleo por meio de simulação numérica com o método dos elementos finitos. São consideradas a construção do poço e a produção de hidrocarboneto. As variações da temperatura e das tensões no poço devidas ao efeito térmico são analisadas. Os efeitos da variação da poropressão da rocha nas tensões no revestimento, no cimento e na formação também são considerados na modelagem do poço. A metodologia é aplicada a modelos construídos e simulados no programa comercial ABAQUS ${ }^{\circledR}$.

A modelagem numérica de poços de petróleo é tratada em diversos trabalhos que abordam diferentes fenômenos e cenários. Em Fleckenstein et al. (2000), o foco da análise numérica é a avaliação do revestimento, considerando diferentes propriedades do cimento e da rocha. Os autores ainda adicionam um segundo revestimento e avaliam a integridade de ambos sob uma pressão interna. Lao et al. (2012) apresentam uma modelagem bidimensional e tridimensional de um poço, simulando três revestimentos sem a cimentação dos anulares. A avaliação da integridade dos revestimentos em Lao et al. (2012) é feita levando em conta o fechamento do sal ao longo do tempo e o contato entre a formação (sal) e o revestimento externo. Em Huang et al. (2000), o revestimento é avaliado sem o contato com nenhum outro material. Os autores avaliam a carga de colapso do revestimento, simulando imperfeições nos materiais e na geometria, como a ovalização do revestimento. Ainda com relação à avaliação da integridade do revestimento, porém com uma abordagem probabilística, Fossum \& Fredrich (2007) apresentam um cenário em que o revestimento é instalado no poço, em zona de sal, sem a presença do cimento no anular. O objetivo dos autores é definir o tempo em que o sal entra em contato com o revestimento e o tempo em que o aço 
começa a sofrer deformações plásticas. As variáveis aleatórias utilizadas são a temperatura, a pressão in situ do evaporito, o fluido de perfuração e o grau de ovalização da parede do poço.

Com um foco voltado para o cimento, Bosma et al. (1999) realizam um trabalho importante na área, uma vez que a modelagem adotada pelos autores aborda diferentes tipos de cimento, levando em conta as variações de pressão interna e de temperatura. Além disso, técnicas de modelagem como elementos de interface entre cada material são utilizadas com o objetivo de simular a separação do cimento e da rocha, e do cimento e do revestimento. Outro trabalho na área é o Mueller et al. (2004), em que os autores avaliam cinco cenários diferentes, onde propriedades do cimento e pressões internas são alteradas. Em Heathman \& Beck (2006) e em Ravi et al. (2006), as análises abordam diferentes tipos de cimento na construção do poço. Outros trabalhos, além de alterar as propriedades do cimento, também avaliam a influência da retração do cimento, como em Ravi et al. (2002) e Oyarhossein \& Dusseault (2015). O primeiro trabalho (Ravi et al., 2002) apresenta diversas fases durante a construção e operação de um poço, como perfuração, descida do revestimento, cimentação, aplicação do fluido de completação e, por último, operação de fraturamento hidráulico. O segundo trabalho (Oyarhossein \& Dusseault, 2015) já tem um foco maior na retração do cimento e as suas consequências na formação e nas tensões no poço. Rodriguez et al. (2003) utilizam as equações de Lamé para calcular as tensões no revestimento, em seguida são feitas análises adicionando à simulação as malhas do cimento e da formação. Posteriormente, os autores avaliam as tensões radiais e de von Mises para o revestimento, o cimento e a formação. No trabalho de Ravi et al. (2003) uma discussão para aprimorar o projeto de cimento nos poços do campo de Shearwater é apresentada, juntamente com a avaliação da integridade do cimento ao longo da vida útil do poço. Em uma análise numérica com o foco na fase de endurecimento do cimento, Brandão (2016) avalia o incremento do módulo de elasticidade do cimento ao longo do tempo.

Diversos estudos sobre poços já foram realizados considerando algumas das fases presentes ao longo da vida útil do poço. Diferentes abordagens são feitas nesses trabalhos. Em Poiate Jr. et al. (2006), Costa et al. (2010) e Poiate Jr. (2012) a modelagem é realizada em duas etapas distintas: a perfuração do poço e a posterior colocação do revestimento e do cimento simultaneamente. Nos trabalhos de 
Mackay \& Fontoura (2014) e Mackay (2011), a descida do revestimento ocorre na etapa anterior à colocação da malha do cimento. Os autores avaliam o endurecimento do cimento, e consequentemente o aumento no seu módulo de elasticidade ao longo do tempo. Outros estudos consideram efeitos da produção de hidrocarboneto nas tensões nos poços, como em Gray et al. (2007), que analisam as tensões geradas a partir da aplicação das pressões devidas à completação, ao fraturamento hidráulico e à produção de hidrocarbonetos. Além da construção e produção, há trabalhos que avaliam ainda a fase de abandono do poço, como o caso do Schreppers (2015), que simula um poço, com foco na integridade do cimento. O autor analisa diversas fases, como a perfuração, a descida do revestimento e cimentação, a completação, a operação e por último o abandono do poço.

Além das análises mecânicas, simulações considerando a variação da temperatura são encontradas na literatura. Em Lavrov et al. (2015) uma análise tridimensional é realizada considerando um perfil de temperatura no modelo, levando em conta uma variação das propriedades dos materiais em relação ao dano. Em Jandhyala et al. (2013) além da variação da pressão interna ao longo do tempo, a variação da temperatura no revestimento, no cimento e no sal é considerada. Em seguida, dois tipos de cimento, com diferentes propriedades elásticas são comparados. Também avaliando o comportamento do cimento sob a influência da pressão interna e da temperatura, Shahri et al. (2005) apresentam dois modelos numéricos, utilizando o método dos elementos finitos, em que são simulados diferentes parâmetros mecânicos e térmicos. Nabipour et al. (2010) avaliam as tensões em poços profundos de gás, sujeitos a pressões internas e a efeitos de temperatura no reservatório. As componentes de tensão radial e tangencial são apresentadas, assim com a tensão de von Mises para a bainha de cimento. Para avaliar a influência de pressões e altas temperaturas em poços geotérmicos, Kaldal et al. (2015) apresentam um trabalho onde o poço é simulado através de modelos 2D e 3D. Com o objetivo de avaliar a integridade do revestimento, uma análise transiente de temperatura é realizada, e variações nas pressões no revestimento são consideradas.

Alguns autores realizaram ainda estudos referentes às falhas na cimentação, ovalização do revestimento, e fluência na formação utilizando programas de elementos finitos. 
Trabalhos como os de Uribe et al. (2015), de Melo et al. (2015), Firme (2013), Costa et al. (2005), Poiate Jr. et al. (2006), Costa et al. (2010) e Poiate Jr. (2012) utilizam como modelo constitutivo para simular o comportamento de fluência dos evaporitos o modelo de Duplo Mecanismo. Assim, o sal sofre deformação ao longo do tempo, gerando tensões desviadoras no cimento e no revestimento, podendo levar o poço ao colapso. O comportamento simulado por esses autores é representado na Figura 4.1.

Para simular esse mesmo efeito de fluência do sal, Mackay et al. (2008b) e Firme (2013) utilizam como modelo constitutivo para o evaporito, a Lei da Potência. Firme et al. (2014) apresentam e comparam três diferentes modelos constitutivos para um mesmo cenário, sendo estes, a Lei da Potência, o Duplo Mecanismo e o Multi Mecanismo. Os problemas causados pela deformação ao longo do tempo das rochas de sal e os parâmetros importantes a serem considerados na simulação destas rochas são apresentados por Alves et al. (2009) e Wilson et al. (2002).

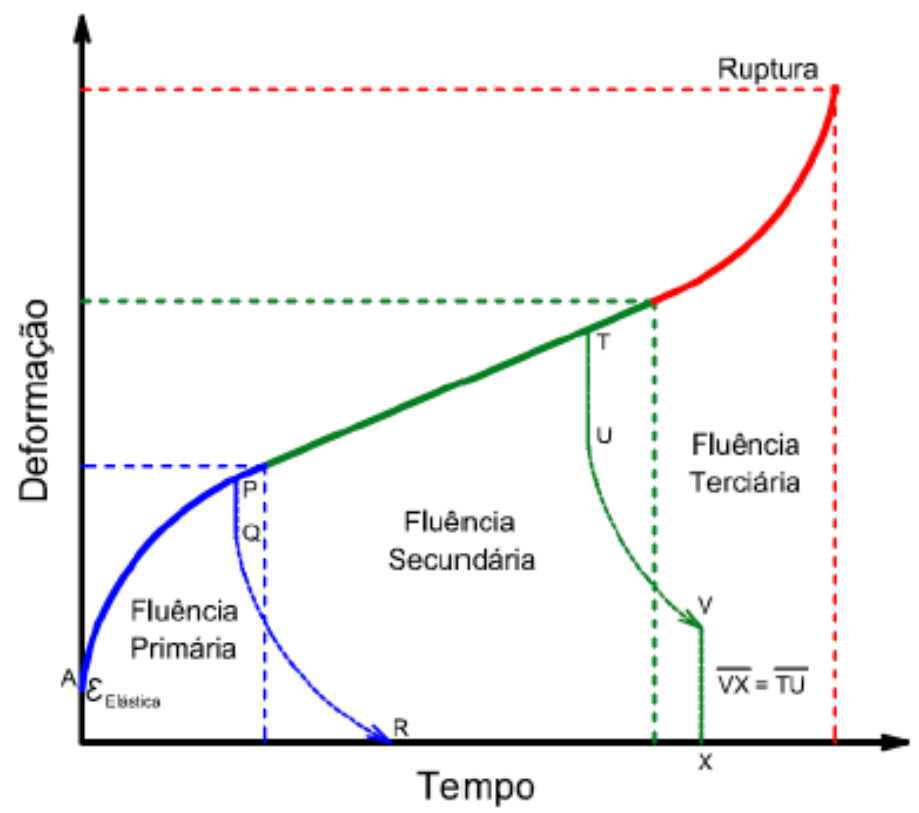

Figura 4.1 - Curva de fluência considerada para o cálculo da deformação do sal ao longo do tempo. (Fonte: Firme, 2013).

Através do trabalho de Poiate Jr. (2012) é possível compreender melhor o comportamento dos evaporitos. O autor compara diferentes tipos de rochas salinas com ensaios de laboratórios. A estabilidade e a integridade do poço são avaliadas, considerando a ovalização e a descentralização do revestimento e a falha na cimentação. No trabalho de Firme (2013), o comportamento do sal também é 
estudado, porém com um foco na análise probabilística. $O$ autor avalia a estabilidade do poço, considerando como variáveis aleatórias as propriedades elásticas e térmicas, e o estado de tensão da halita brasileira.

Além do comportamento da rocha, outros fenômenos podem ser estudados durante a simulação de poços utilizando programas de elementos finitos. Dentre eles estão a descentralização do revestimento, a falha na cimentação, os vazios na formação e a variação da poropressão, como mostrado por Berger et al. (2004) e Fleckenstein et al. (2005). Em ambos os trabalhos, os modelos compostos unicamente pelo revestimento são validados pelos autores através da equação de Lamé. A partir daí são feitos modelos mais complexos, onde a rocha e o cimento são adicionados e então simulados, considerando diferentes propriedades de cimento. Zervos et al. (1998) apresentam uma modelagem tridimensional de um poço inclinado. Um dos objetivos dos autores é obter uma estimativa do fluido de perfuração utilizando um modelo elastoplástico e assumindo diferentes critérios de ruptura da rocha.

Outro problema a ser analisado, que pode ocorrer durante a perfuração do poço, é a dissolução da rocha evaporítica (washout) formando cavidades na formação. Esse fenômeno é estudado por Plucenio et al (2013) e Lomba et al. (2013a,b). No trabalho de Firme et al. (2015), são avaliados os diferentes modos de falha do revestimento em regiões de washout.

Com um foco na modelagem numérica, Costa et al. (2015) realizam um estudo de sensibilidade de malha bidimensional e tridimensional de elementos finitos para a análise de estabilidade de um poço no pré-sal. Os autores variam o raio externo do modelo, assim como parâmetros da malha, como a quantidade de elementos na direção radial e o tamanho dos elementos nas direções axial e tangencial.

No presente trabalho, com o objetivo de comparar a solução numérica com a analítica e para tentar aproximar a modelagem de poços da realidade, é adotada uma metodologia na qual as fases consideradas mais importantes para a modelagem são simuladas. Essas fases são: o estado de tensão inicial dos materiais; a perfuração do poço com a presença do fluido de perfuração na parede da formação; a descida do revestimento; a cimentação do poço e, por último, a produção de hidrocarbonetos considerando as variações da pressão interna do revestimento, da poropressão na formação e da temperatura na superfície interna do revestimento. 


\section{2.}

\section{Hipóteses adotadas}

Para o trabalho, utiliza-se um poço convencional, vertical, sem falha na cimentação ou vazios na formação e perfeitamente circular. Os modelos são considerados com comportamento linear elástico. Essas mesmas hipóteses são adotadas nos modelos analíticos com os quais os resultados numéricos são comparados.

Para que um modelo numérico se aproxime ao máximo dos problemas em campo, o modelo mais apropriado é um tridimensional, levando em conta as direções radial, circunferencial e axial. Um modelo desse tipo, apesar de mais realista, é também mais complexo. Muitos problemas em elementos finitos podem, no entanto, ser aproximados por modelos bidimensionais, como em Rodriguez et al. (2003) e Jandhyala et al. (2013).

Para o caso da modelagem de poços de petróleo, simplificações podem ser feitas, utilizando condições de estado plano de deformação (EPD) e de axissimetria. O EPD é utilizado quando a dimensão perpendicular à seção de análise do corpo é muito grande em relação às demais dimensões e as cargas são aplicadas perpendicularmente ao eixo longitudinal e uniformemente distribuídas ao longo do eixo. Para o caso específico do poço, as pressões atuantes variam de acordo com a profundidade e, portanto, quando se utiliza o EPD, é necessário observar que o resultado obtido é válido somente para a cota analisada, e não pode ser adotado para outras profundidades. Para o caso axissimétrico, assume-se que a carga é aplicada em um sólido de revolução e depende das coordenadas radial e axial. No caso estudado, o poço é circular e centralizado, e a cimentação é considerada perfeita. Esse é um caso ideal, que pode não representar o que ocorre em campo. Pressões não uniformes no revestimento e no cimento, como mostrado em Berger et al. (2004), podem ocasionar o colapso do poço.

\section{3.}

\section{Fases modeladas}

\subsection{1.}

\section{Perfuração}

O processo de perfuração de um poço de petróleo pode ser simulado de diversas maneiras em um programa de elementos finitos. $\mathrm{O}$ método mais intuitivo 
para reproduzir uma escavação é remover os elementos da rocha que estão localizados no poço após inserir o estado de tensão inicial da formação, aplicando a pressão devida ao fluido de perfuração. Dessa forma, geram-se deformações na parede interna da rocha. Outra forma de simular esse processo é modelar a geometria já com o furo do poço, porém com todos os nós da parede do poço com os deslocamentos restringidos, simulando a presença de rocha no furo. Após atribuir o estado de tensão inicial na rocha, retiram-se os apoios dos nós da parede do poço e aplica-se a pressão devida ao fluido de perfuração na superfície interna da formação, conforme Figura 4.2. Este segundo método é o escolhido para este trabalho, considerando as funcionalidades disponíveis na ferramenta computacional adotada.

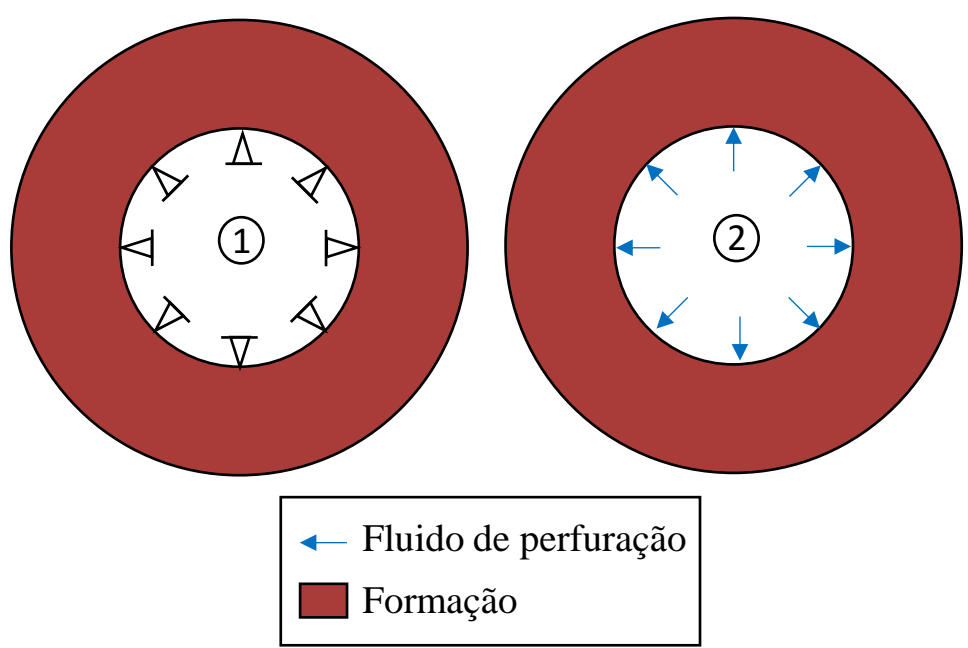

Figura 4.2 - Representação do estado inicial do modelo e da perfuração do poço (seção transversal).

\subsection{2. \\ Descida do revestimento e cimentação}

Entre a descida do revestimento e o cimento endurecido no anular, alguns cenários são considerados. Esses cenários se diferem no valor das pressões que atuam no revestimento e na formação, e nas condições de contorno, conforme os passos 3 a 7 da Figura 4.3. Durante a descida do revestimento, a pressão do fluido de perfuração é aplicada na parede da rocha e nas superfícies interna e externa do revestimento (passo 3). Logo em seguida, a cimentação se inicia considerando a pressão devida ao cimento fluido dentro do revestimento e mantendo a pressão devida ao fluido de perfuração na parede externa do revestimento e na parede do poço (passo 4). Após a injeção do cimento dentro do revestimento, esse cimento 
fluido começa a subir pelo anular (espaço entre o revestimento e a rocha), sendo então aplicada essa pressão nas superfícies interna e externa do aço e na parede da rocha (passo 5). Para continuar o processo de perfuração das próximas fases, um fluido de perfuração é injetado, sendo então aplicada uma pressão devida ao fluido de perfuração no interior do revestimento e mantendo a pressão do cimento fluido nas demais superfícies (passo 6). Por último, simula-se o cimento endurecido no anular (passo 7), colocando assim a malha do cimento com um estado de tensão inicial de valor igual à pressão do fluido de perfuração, conforme Cooke et al. (1983). Como a análise neste trabalho é feita adotando a hipótese de materiais linear elásticos, somente os dois últimos passos serão considerados: cimento fluido no anular (passo 6) e fluido de perfuração no poço e cimento endurecido no anular (passo 7).

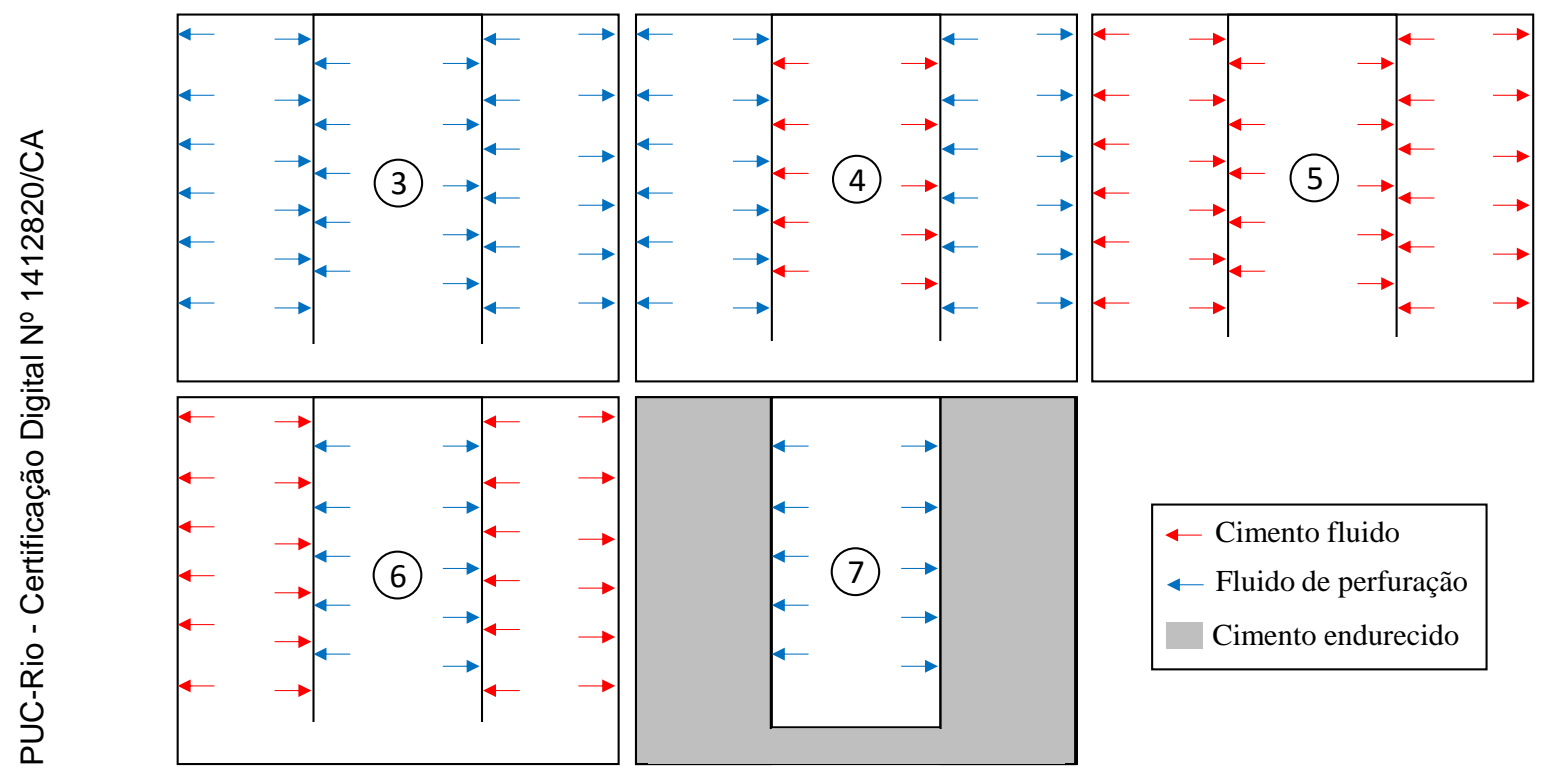

Figura 4.3 - Esquema com os passos de modelagem durante a descida do revestimento e a cimentação do poço (seção longitudinal). 


\subsection{3. Produção}

Para a produção, alteram-se a pressão dentro do revestimento, a poropressão na formação e a temperatura na superfície interna do revestimento. A pressão devida ao fluido de perfuração é retirada do modelo, e em seguida, a pressão devida ao fluido de produção é aplicada na parede interna do revestimento, simulando a mudança na pressão interna do poço. Para representar a depleção ou a injeção, é aplicada uma variação da poropressão em toda a formação, modificando assim o estado de tensão ao redor do poço.

A temperatura é mais um fenômeno que influencia o estado de tensão no revestimento, no cimento e na formação. Durante as primeiras fases de simulação, a variação de temperatura considerada para todo o modelo é igual a zero.

Durante a produção, o fluido interno (fluido de perfuração) no revestimento é substituído por um fluido de produção ou de injeção. Esse novo fluido que corre internamente pelo revestimento possui uma temperatura diferente quando comparada à do fluido da fase anterior. Dessa forma, essa variação térmica deve ser considerada no cálculo do estado de tensão final no poço. Para modelar esse fenômeno, considera-se uma temperatura prescrita na parede interna do revestimento e através de uma análise transiente observa-se a propagação dessa variação ao longo do raio do poço. Pode-se avaliar a distância radial em relação ao eixo central do poço afetada pela variação térmica e a consequente influência dessa temperatura no estado de tensão dos materiais. Vale ressaltar que as propriedades térmicas utilizadas não variam com o tempo nem com a temperatura. A Figura 4.4 representa os passos de produção adotados nessa análise.

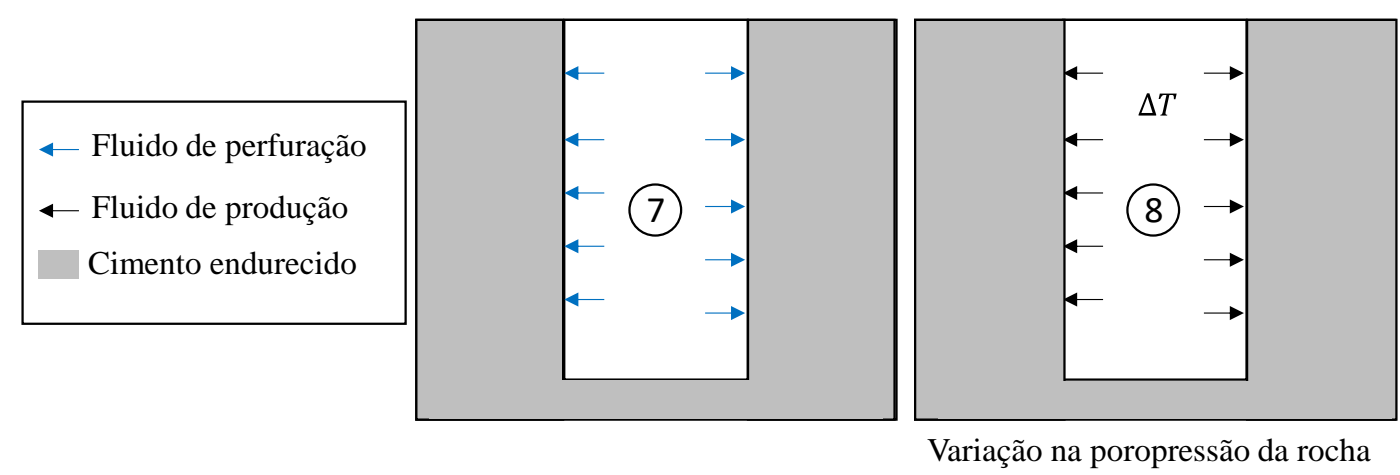

Figura 4.4 - Configuração da fase de produção de hidrocarboneto (seção longitudinal do poço). 
Ao avaliar a influência do efeito mecânico da variação da poropressão da rocha nas tensões do poço, não é levado em conta o efeito do fluido. Apesar da depleção ou injeção ocorrer aos poucos, essa variação da poropressão é aplicada de forma instantânea na rocha e, simultaneamente, a pressão interna no revestimento é alterada para a pressão de produção.

Uma vez que os elementos finitos adotados devem ser capazes de modelar os efeitos de poro, térmico e mecânico, esses elementos devem ter graus de liberdade de poropressão, temperatura e deslocamentos. Por outro lado, o programa de elementos finitos utilizado neste trabalho, não possui tal elemento bidimensional. Dessa forma, faz-se necessário desenvolver dois modelos para simular os diferentes efeitos. O primeiro modelo possui todos os nós bloqueados e é composto por elementos com grau de liberdade de poro. É aplicada uma variação da poropressão em toda a rocha, e então são obtidas as reações de apoio em todos os nós do poço. O segundo modelo consiste na análise termomecânica. Nele, durante a produção, são aplicadas essas forças de reação de apoio com sentido contrário, com os nós do modelo liberados. Dessa forma é possível simular o efeito da variação da poropressão em todos os materiais sem a necessidade do acoplamento hidro termomecânico. Ressalta-se que essa metodologia somente pode ser utilizada em análises lineares.

A metodologia adotada neste trabalho, utilizando o programa ABAQUS ${ }^{\circledR}$ para simular o efeito mecânico da variação da poropressão, utilizando dois modelos, foi validada com a modelagem com elementos poroelásticos. Nestas análises, não foi inserida a variação da temperatura, com o objetivo de comparar as duas soluções. Os resultados obtidos foram exatamente iguais, mostrando que a metodologia utilizada neste trabalho é uma boa forma de modelar o acoplamento termomecânico considerando ainda o efeito mecânico da variação da poropressão.

\section{4. \\ Modelos para simulação de poços}

Modelos bidimensionais podem muitas vezes ser utilizados na modelagem de poços de petróleo para substituir um tridimensional, que apesar de mais completo, é também mais complexo e tem um maior custo computacional. A escolha da condição a ser adotada se dá de acordo com as características do cenário analisado. 
Dessa forma, no estudo de poços, tanto modelos axissimétricos quanto modelos em estado plano de deformação (EPD) podem ser utilizados.

Para se analisar uma situação em que a litologia na proximidade do poço possui camadas finas de rochas com diferentes rigidezes, um modelo axissimétrico tende a representar de maneira mais confiável o comportamento do poço. Isso se justifica pelo fato de que as camadas de rocha mais rígidas tendem a diminuir as deformações e deslocamentos de camadas de rochas mais flexíveis. Caso seja feita uma análise em EPD na cota da camada com rocha mais flexível, a suposição de que as características desta seção transversal são as mesmas para todo o comprimento longitudinal do poço faz com que essa rocha mais flexível se deforme mais do que se for calculado utilizando a condição de axissimetria.

Em uma condição de EPD, modelos com falhas no revestimento, na cimentação e/ou na formação, e descentralização do revestimento são muito bem representados. Esses problemas não conseguem ser representados por modelos axissimétricos.

No presente trabalho, os poços são avaliados em uma cota cuja espessura da camada é grande o suficiente para não interferir nos resultados. Além disso, os poços são considerados perfeitamente circulares, centralizados e sem qualquer tipo de falhas. Dessa forma, a condição de EPD é utilizada nos modelos em elementos finitos que são comparados com a solução analítica. Essa escolha é feita principalmente por causa do tamanho do modelo, que por possuir dois eixos de simetria, pode ser representado por apenas um quarto da seção transversal do poço. Deve-se ressaltar que apesar de ser uma condição de estado plano de deformação, o resultado obtido na análise é válido somente para a profundidade estudada, i.e., não pode ser adotado para outras profundidades.

\section{5.}

\section{Critério de plastificação}

Os mesmos critérios de plastificação utilizados na seção 3.5 são utilizados na modelagem em elementos finitos no programa ABAQUS ${ }^{\circledR}$. Para o revestimento (aço), o cálculo é feito considerando o critério de von Mises (seção 3.5.1), enquanto para o cimento é utilizado o critério de Mohr-Coulomb (seção 3.5.2). 


\section{5 \\ Estudos de caso}

Neste capítulo, a solução analítica desenvolvida é comparada com a modelagem numérica por elementos finitos utilizando dois estudos de caso, um no Mar do Norte (campo de Shearwater) e outro na Bacia de Santos, Brasil.

Nessa modelagem, como a geometria e os carregamentos são uniformes, pode-se modelar apenas 1/4 da seção transversal do poço, como mostra Figura 5.1. Esse modelo apresentado é utilizado para uma melhor visualização do poço, uma vez que as componentes de tensão radial e tangencial variam apenas com o raio. Dessa forma, o poço poderia ser simulado por uma linha de elementos ao longo do raio.

Em todos os modelos, a malha adotada é a mesma, dividindo em 40 elementos os materiais na direção angular, e dividindo o revestimento, o cimento e a formação em 4, 6 e 250 elementos na direção radial, respectivamente. Na rocha, os elementos perto do poço começam pequenos, com tamanhos similares aos do cimento. De acordo com a distância em relação ao poço, os elementos se tornam gradualmente maiores. Utiliza-se então uma razão de aspecto de 300, que é a relação entre os tamanhos do menor elemento e do maior elemento da rocha. 


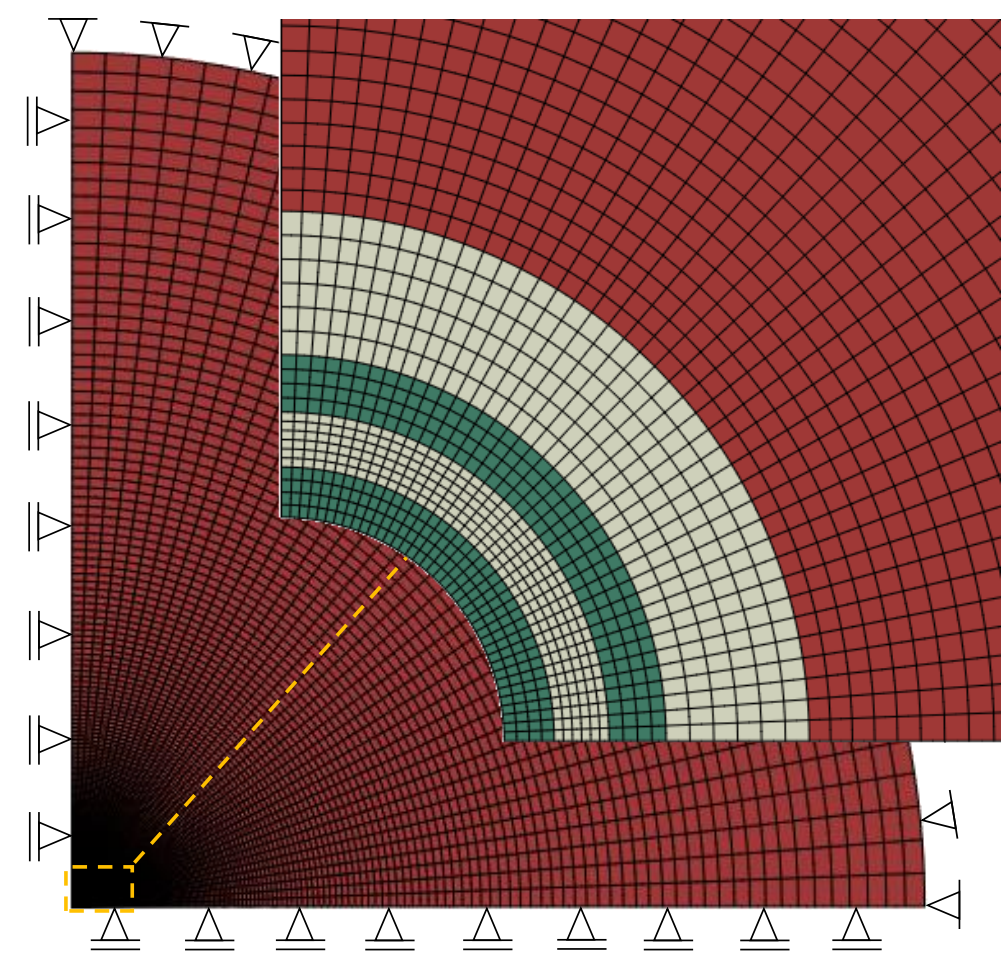

Figura 5.1 - Malha de elementos finitos para o caso de um poço com dois revestimentos.

Com o objetivo de reproduzir de maneira mais precisa geometrias curvas, os modelos utilizam elementos quadráticos quadrangulares e com integração reduzida.

\section{1.}

Estudo de caso A - Campo do Mar do Norte

\subsection{1.}

Parâmetros utilizados (Shearwater em -4765 m)

Para o primeiro estudo de caso, é utilizado um cenário de um poço com propriedades do campo de Shearwater, no Mar do Norte. As propriedades e os carregamentos estão descritos na Tabela 5.1. Os dados obtidos são do trabalho de Ravi et al. (2003). 
Tabela 5.1 - Parâmetros do poço.

\begin{tabular}{|l|c|c|}
\hline Parâmetro & Valor & Unidade \\
\hline Diâmetro da parede do poço (12 1/4") & 311,15 & $\mathrm{~mm}$ \\
\hline Diâmetro externo do revestimento (9 7/8") & 250,83 & $\mathrm{~mm}$ \\
\hline Diâmetro interno do revestimento (8,539") & 216,89 & $\mathrm{~mm}$ \\
\hline Borda externa do modelo & 200,00 & $\mathrm{~m}$ \\
\hline Profundidade (15630 pés) & 4765,00 & $\mathrm{~m}$ \\
\hline Lâmina d'água (300 pés) & 90 & $\mathrm{~m}$ \\
\hline Pressão do fluido de perfuração (14,3lb/gal) & 80063,91 & $\mathrm{kPa}$ \\
\hline Pressão do cimento (15,5 lb/gal) & 86782,56 & $\mathrm{kPa}$ \\
\hline Tensão in situ da formação $(1,0$ psi/pés) & 106596.60 & $\mathrm{kPa}$ \\
\hline Pressão do fluido de produção $(7000$ psi) & 48263,30 & $\mathrm{kPa}$ \\
\hline Temperatura de produção $\left(350^{\circ} \mathrm{F}\right)$ & 177,00 & ${ }^{\circ} \mathrm{C}$ \\
\hline Temperatura de construção $\left(250^{\circ} \mathrm{F}\right)$ & 121,00 & ${ }^{\circ} \mathrm{C}$ \\
\hline Poropressão na formação $(0,46$ psi/pés $)$ & 49571,93 & $\mathrm{kPa}$ \\
\hline
\end{tabular}

Fonte: Ravi et al. (2003).

Para a realização da modelagem numérica considerando o efeito térmico, é necessário entrar com algumas propriedades no programa de elementos finitos. Além do módulo de elasticidade e do coeficiente de Poisson, a condutividade térmica, a capacidade térmica, a densidade e o coeficiente de dilatação térmica (para avaliar a tensão devida à variação da temperatura) são dados de entrada. Para a solução analítica, além das propriedades elásticas, é necessário entrar com o valor da difusividade térmica e do coeficiente de dilatação térmica. A difusividade térmica é calculada através da equação (3.33).

As propriedades da rocha são apresentadas na Tabela 5.2, onde os dados elásticos são retirados de Palchik \& Hatzor (2002) e Al-Shayea (2004). 
Tabela 5.2 - Propriedades da rocha.

\begin{tabular}{|l|c|c|}
\hline Propriedade da rocha & Valor & Unidade \\
\hline Módulo de elasticidade $(\mathrm{E})$ & 40,00 & $\mathrm{GPa}$ \\
\hline Coeficiente de Poisson $(v)$ & 0,25 & - \\
\hline Condutividade térmica* $^{*}(\mathrm{k})$ & $1,46^{*}$ & $\mathrm{~W} / \mathrm{m}^{\circ} \mathrm{C}$ \\
\hline Capacidade térmica* $\left.^{*} \mathrm{c}_{\mathrm{T}}\right)$ & $740,00^{*}$ & $\mathrm{~J} / \mathrm{kg}^{\circ} \mathrm{C}$ \\
\hline Difusividade térmica $^{*}(\beta)$ & $7,30 \mathrm{E}-07^{*}$ & $\mathrm{~m}^{2} / \mathrm{s}$ \\
\hline Densidade* $\left.^{*} \rho\right)$ & $2702,70^{*}$ & $\mathrm{~kg} / \mathrm{m}^{3}$ \\
\hline Coeficiente de dilatação térmica $^{* *}(\alpha)$ & $3,40 \mathrm{E}-6^{* *}$ & $1 /{ }^{\circ} \mathrm{C}$ \\
\hline
\end{tabular}

Fonte: Palchik \& Hatzor (2002) e Al-Shayea (2004); ${ }^{*}$ Mongelli et al. (1982); ${ }^{* *}$ Wong \&

Brace (1979).

As propriedades do aço utilizadas nas análises numérica e analítica estão apresentadas na Tabela 5.3.

Tabela 5.3 - Propriedades do aço.

\begin{tabular}{|l|c|c|}
\hline Propriedade do aço (revestimento) & Valor & Unidade \\
\hline Módulo de elasticidade $(\mathrm{E})$ & 210,00 & $\mathrm{GPa}$ \\
\hline Coeficiente de Poisson $(v)$ & 0,30 & - \\
\hline Tensão de escoamento $\left(\sigma_{\mathrm{y}}\right)$ & 438,00 & $\mathrm{MPa}$ \\
\hline Condutividade térmica $^{*}(\mathrm{k})$ & $50,00^{*}$ & $\mathrm{~W} / \mathrm{m}^{\circ} \mathrm{C}$ \\
\hline Capacidade térmica* $\left.^{*} \mathrm{c}_{\mathrm{T}}\right)$ & $400,00^{*}$ & $\mathrm{~J} / \mathrm{kg}^{\circ} \mathrm{C}$ \\
\hline Densidade $^{*}(\rho)$ & $7850,00^{*}$ & $\mathrm{~kg} / \mathrm{m}^{3}$ \\
\hline Coeficiente de dilatação térmica $^{*}(\alpha)$ & $12,00 \mathrm{E}-6^{*}$ & $1 /{ }^{\circ} \mathrm{C}$ \\
\hline
\end{tabular}

Fonte: Fossum \& Fredrich (2007); "Kaldal et al. (2015).

As propriedades do cimento são apresentadas na Tabela 5.4, onde as propriedades elásticas são retiradas do Bosma et al.(1999).

Tabela 5.4 - Propriedades do cimento.

\begin{tabular}{|l|c|c|}
\hline Propriedade do cimento & Valor & Unidade \\
\hline Módulo de elasticidade $(\mathrm{E})$ & 8,30 & $\mathrm{GPa}$ \\
\hline Coeficiente de Poisson $(v)$ & 0,10 & - \\
\hline Coesão & 21,60 & $\mathrm{MPa}$ \\
\hline Ângulo de atrito & 17,10 & ${ }^{\circ}$ \\
\hline Condutividade térmica* $(\mathrm{k})$ & $0,81^{*}$ & $\mathrm{~W} / \mathrm{m}^{\circ} \mathrm{C}$ \\
\hline Capacidade térmica $^{*}\left(\mathrm{c}_{\mathrm{T}}\right)$ & $880,00^{*}$ & $\mathrm{~J} / \mathrm{kg}^{\circ} \mathrm{C}$ \\
\hline Densidade $^{*}(\rho)$ & $1600,00^{*}$ & $\mathrm{~kg} / \mathrm{m}^{3}$ \\
\hline Coeficiente de dilatação térmica $^{*}(\alpha)$ & $1,00 \mathrm{E}-6^{*}$ & $1 /{ }^{\circ} \mathrm{C}$ \\
\hline
\end{tabular}

Fonte: Bosma et al. (1999); ${ }^{*}$ Kaldal et al. (2015). 


\subsection{2. Metodologia alternativa}

Diferentes metodologias são estudadas na literatura, com o objetivo de simular a vida útil de um poço de petróleo. Costa et al. (2010) e Poiate Jr. (2012) fazem uma análise em estado plano de deformação considerando diferentes percentuais de falha na cimentação para um mesmo poço em zona de sal. Na metodologia de construção utilizada pelos autores, o revestimento e o cimento são adicionados simultaneamente no modelo.

A fim de comparar a metodologia proposta neste trabalho (instalação em etapas) e a apresentada por Costa et al. (2010) e Poiate Jr. (2012) (instalação simultânea), são realizados dois modelos considerando as mesmas geometrias e condições de contorno (variação de temperatura de $56^{\circ} \mathrm{C}$ ). Adicionalmente, as duas metodologias são comparadas utilizando as soluções analítica $(A)$ e numérica $(N)$, conforme Figura 5.2, Figura 5.3 e Figura 5.4, para as componentes de tensão radial e tangencial, e para o índice de plastificação. Para a aplicação da solução analítica utilizando a metodologia de instalação simultânea do revestimento e do cimento, algumas modificações (De Simone et al., 2016) foram necessárias em relação a solução apresentada no Capítulo 3. Nota-se que para as duas metodologias, o resultado através da solução numérica coincide com os resultados encontrados com a solução analítica.

Nos três materiais apresentados, utilizando a metodologia de instalação em etapas (proposta neste trabalho), a tensão radial é mais crítica do que a encontrada pela metodologia de instalação simultânea. 
Distância radial (m)

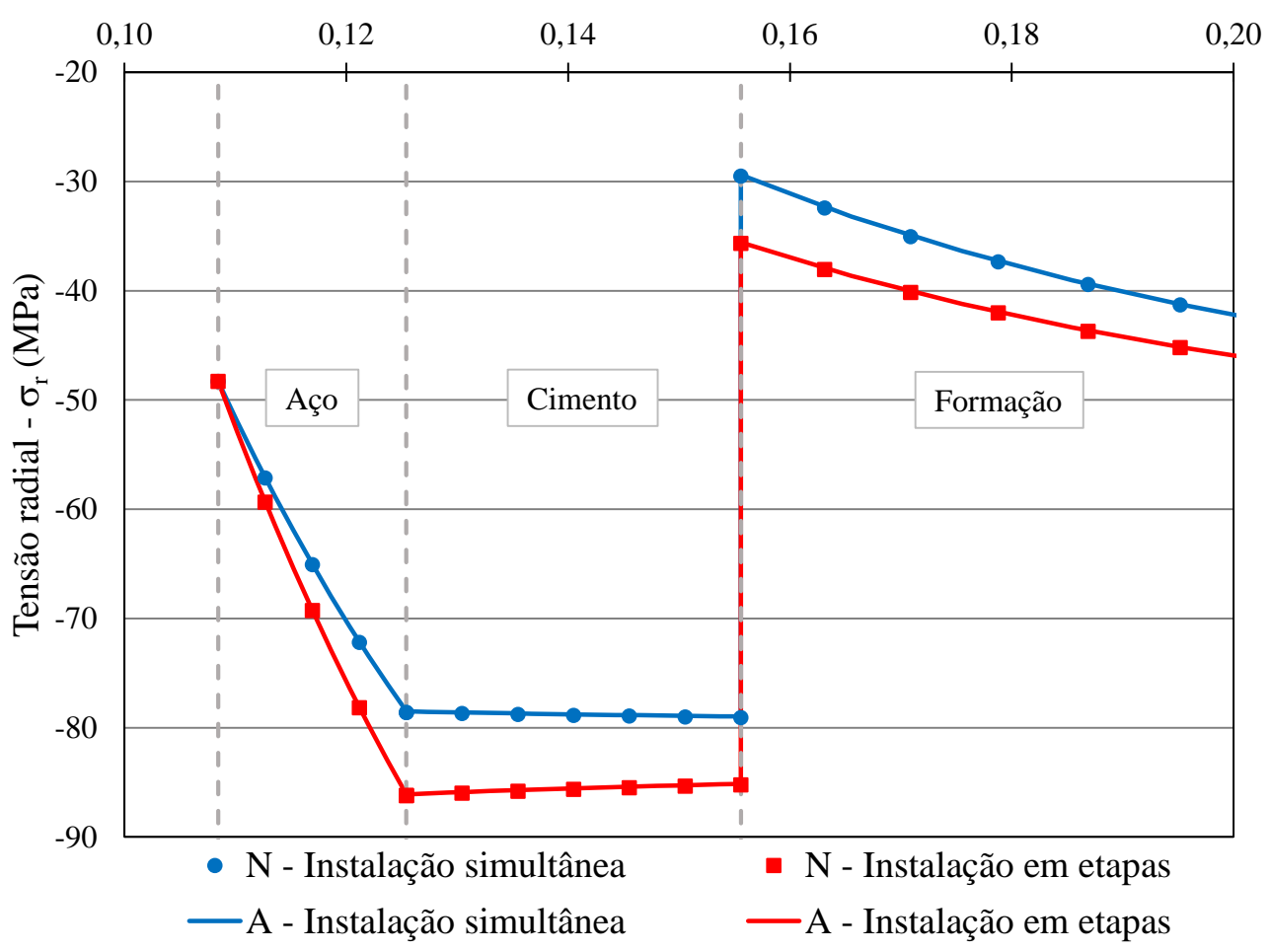

Figura 5.2 - Tensão radial para o revestimento e cimento para as duas metodologias apresentadas.

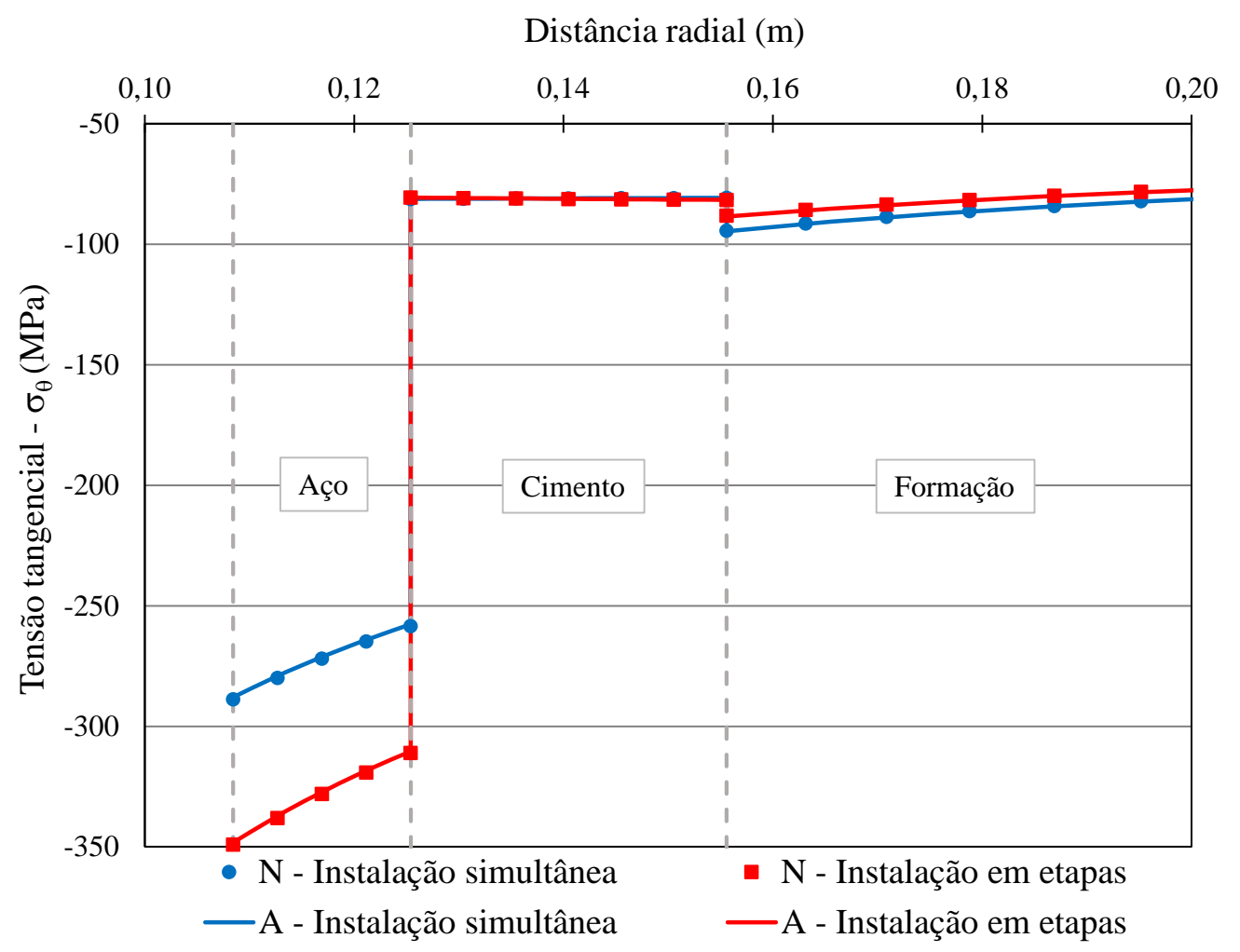

Figura 5.3 - Tensão tangencial para o revestimento e cimento para as duas metodologias apresentadas. 
O cenário mais crítico de tensão tangencial para o revestimento é considerando a instalação em etapas, com o valor de aproximadamente -350 MPa. Para os modelos em que o revestimento e o cimento são instalados simultaneamente, a tensão máxima no revestimento é de aproximadamente -290 MPa. Analisando o cimento, é possível perceber que a componente de tensão tangencial considerando as duas metodologias atinge praticamente o mesmo valor.

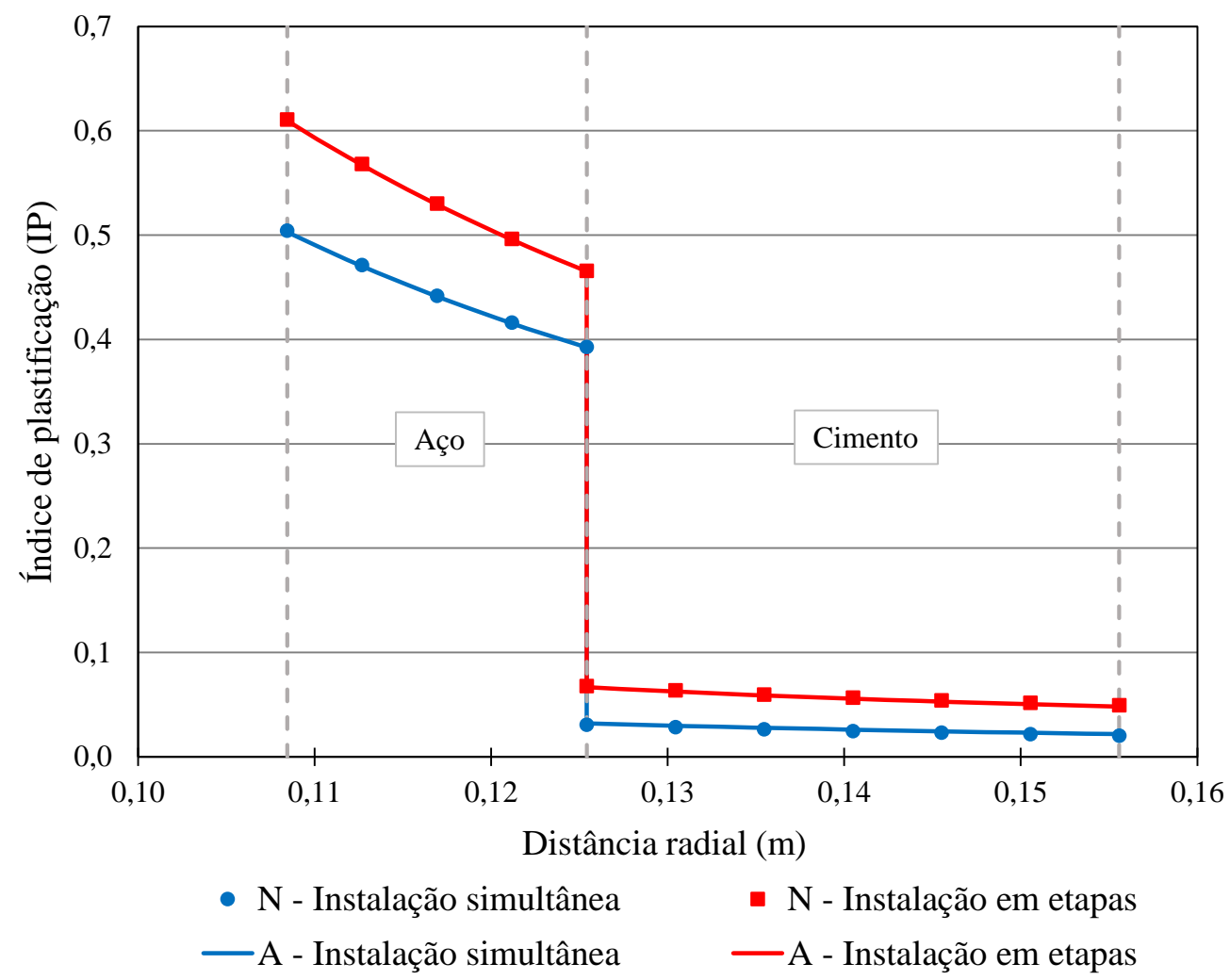

Figura 5.4 - Índice de plastificação no revestimento e no cimento utilizando diferentes metodologias.

Através do índice de plastificação, nota-se que para esse caso estudado, o modelo utilizando a metodologia em que o revestimento e o cimento são adicionados em etapas diferentes, possui um cenário mais crítico, tanto para o revestimento, como para o cimento. Isso ocorre, uma vez que o modelo em que o cimento e o revestimento entram simultaneamente, uma força de contato entre os materiais atua na interface revestimento-cimento, gerando tensões diferentes quando comparadas à metodologia em que o revestimento entra antes do cimento.

A metodologia em que o revestimento e o cimento são instalados em etapas diferentes é adotada para as soluções analítica e numérica durante este trabalho. Essa escolha se baseia principalmente por essa metodologia representar de forma 
mais realista o processo de construção de um poço de petróleo. Além disso, para esse caso estudado, a metodologia que simula as colocações do revestimento e do cimento em etapas distintas apresenta um cenário mais crítico quando comparado com a instalação simultânea.

\subsection{3.}

\section{Resultados (Shearwater em -4765 m)}

Os resultados das componentes de tensão radial e tangencial, e do índice de plastificação do modelo por elementos finitos são comparados com os resultados encontrados através da solução analítica. São apresentados resultados considerando o fim de algumas fases da vida útil do poço: perfuração, construção (após o cimento endurecido) e produção. Com o objetivo de avaliar a influência da temperatura na análise das tensões ao redor do poço, dois cenários são comparados: com variação de $56^{\circ} \mathrm{C}$ e sem variação de temperatura.

\subsubsection{1.}

\section{Perfuração}

As componentes de tensão radial (Figura 5.5) e tangencial (Figura 5.6) na formação ao longo do raio do poço durante a fase de perfuração (ainda sem a presença do revestimento e do cimento) são apresentadas. Onde $N$ representa o modelo numérico, e $A$ é o resultado obtido através da solução analítica. 


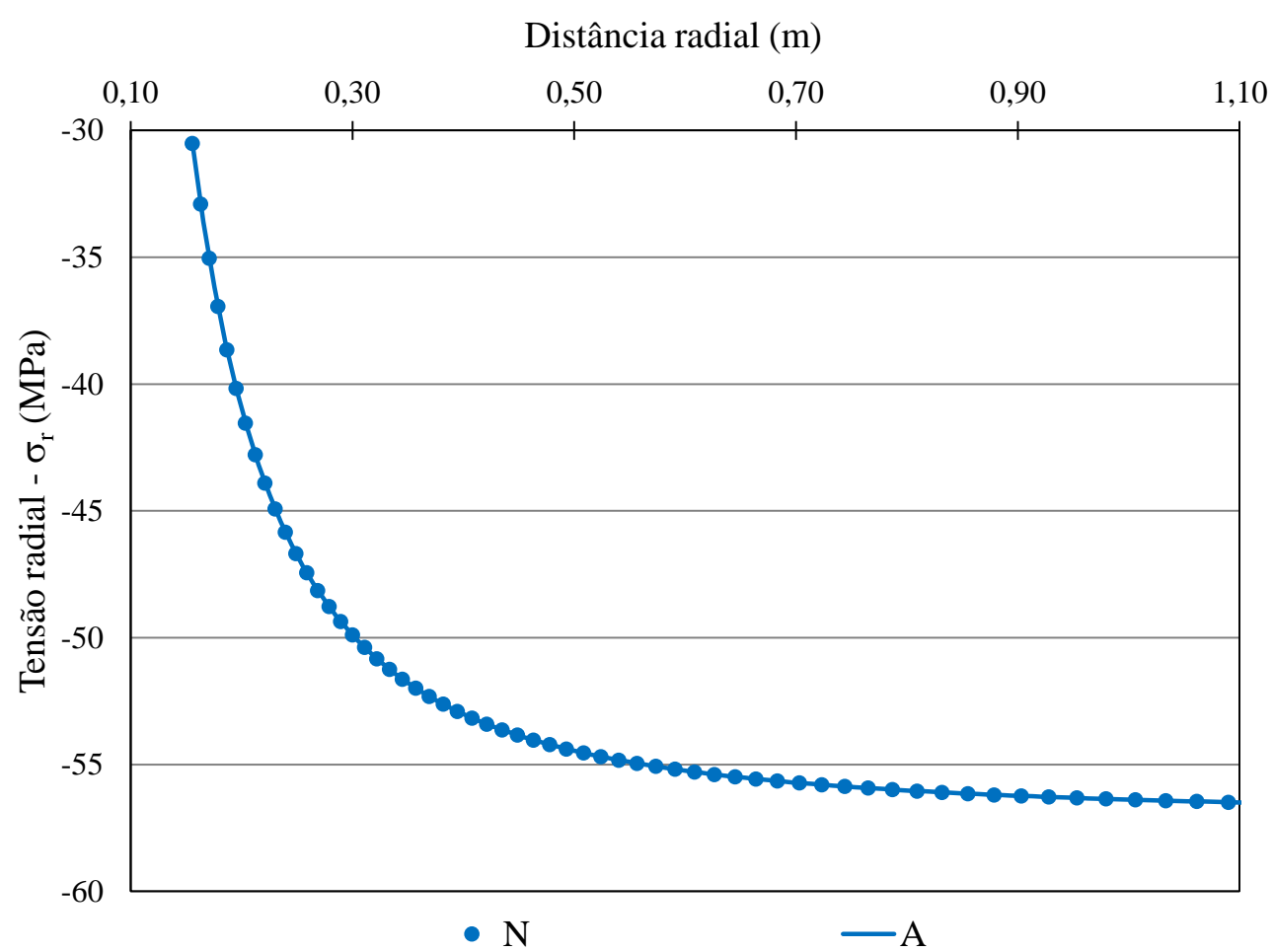

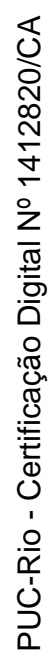

Figura 5.5 - Tensão radial ao longo do raio na rocha após a perfuração do poço.

Distância radial (m)

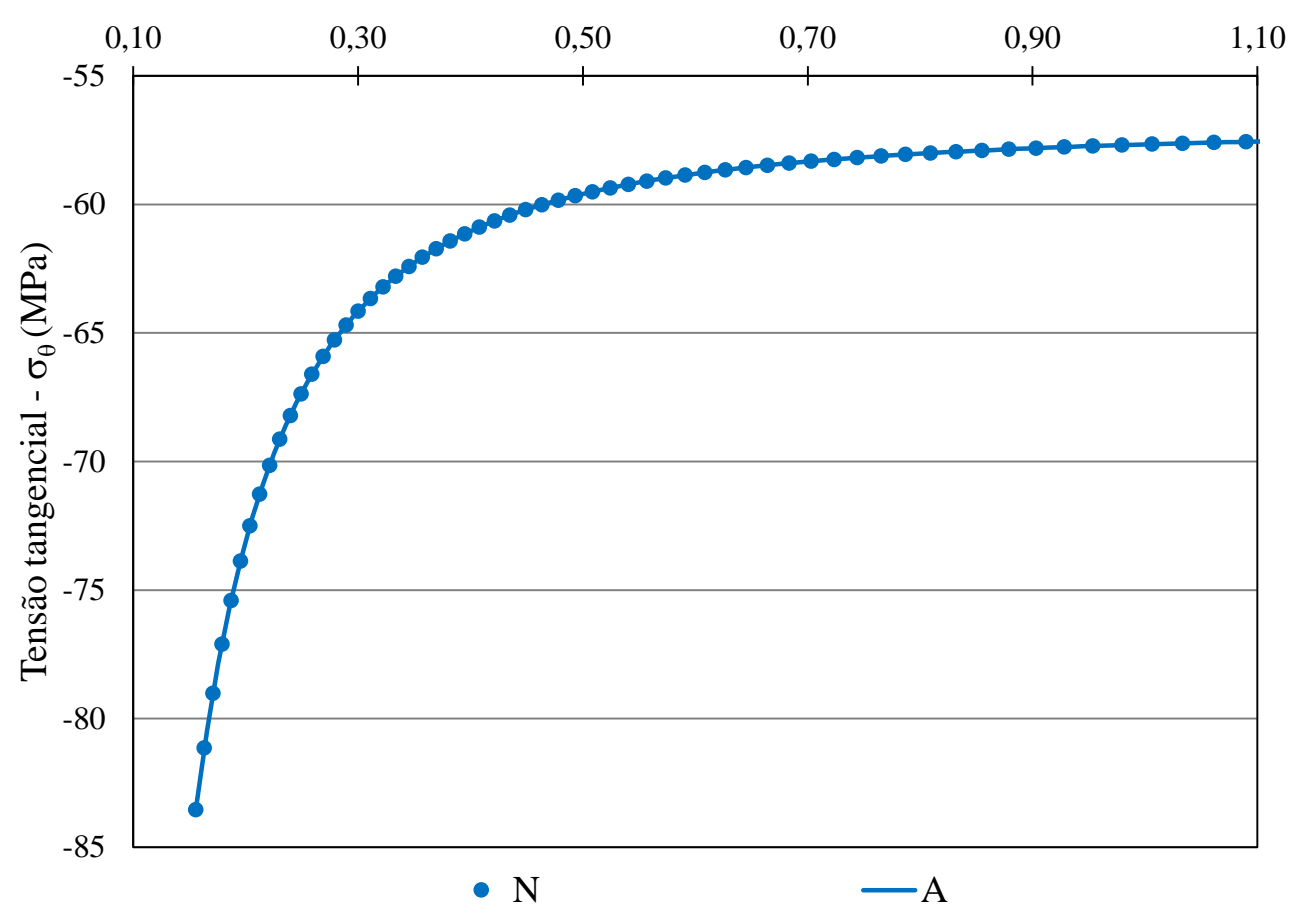

Figura 5.6 - Tensão tangencial ao longo do raio da formação após a perfuração do poço.

Durante a perfuração, a solução analítica é composta somente pelas equações de Bradley. Conforme os resultados apresentados pelas Figura 5.5 e Figura 5.6, é possível observar que as curvas de tensões obtidas pelas soluções analítica e 
numérica coincidem ao longo do raio da formação. A tensão radial na parede do poço em ambas as soluções é o valor do fluido de perfuração descontado da poropressão da rocha $(-30,49 \mathrm{MPa})$. Ao longo do raio, as componentes de tensão radial e tangencial convergem para o valor da tensão efetiva in situ da rocha, atingindo o valor de $-57,02 \mathrm{MPa}$ na borda do modelo.

\subsubsection{2.}

\section{Construção}

A Figura 5.7 apresenta a componente de tensão radial ao longo do raio do modelo enquanto a Figura 5.8 apresenta a componente de tensão radial no revestimento e no cimento ao longo do raio após a cimentação do poço. Nos gráficos apresentados a seguir, $N$ representa o modelo numérico, enquanto $A$ é calculado através da solução analítica.

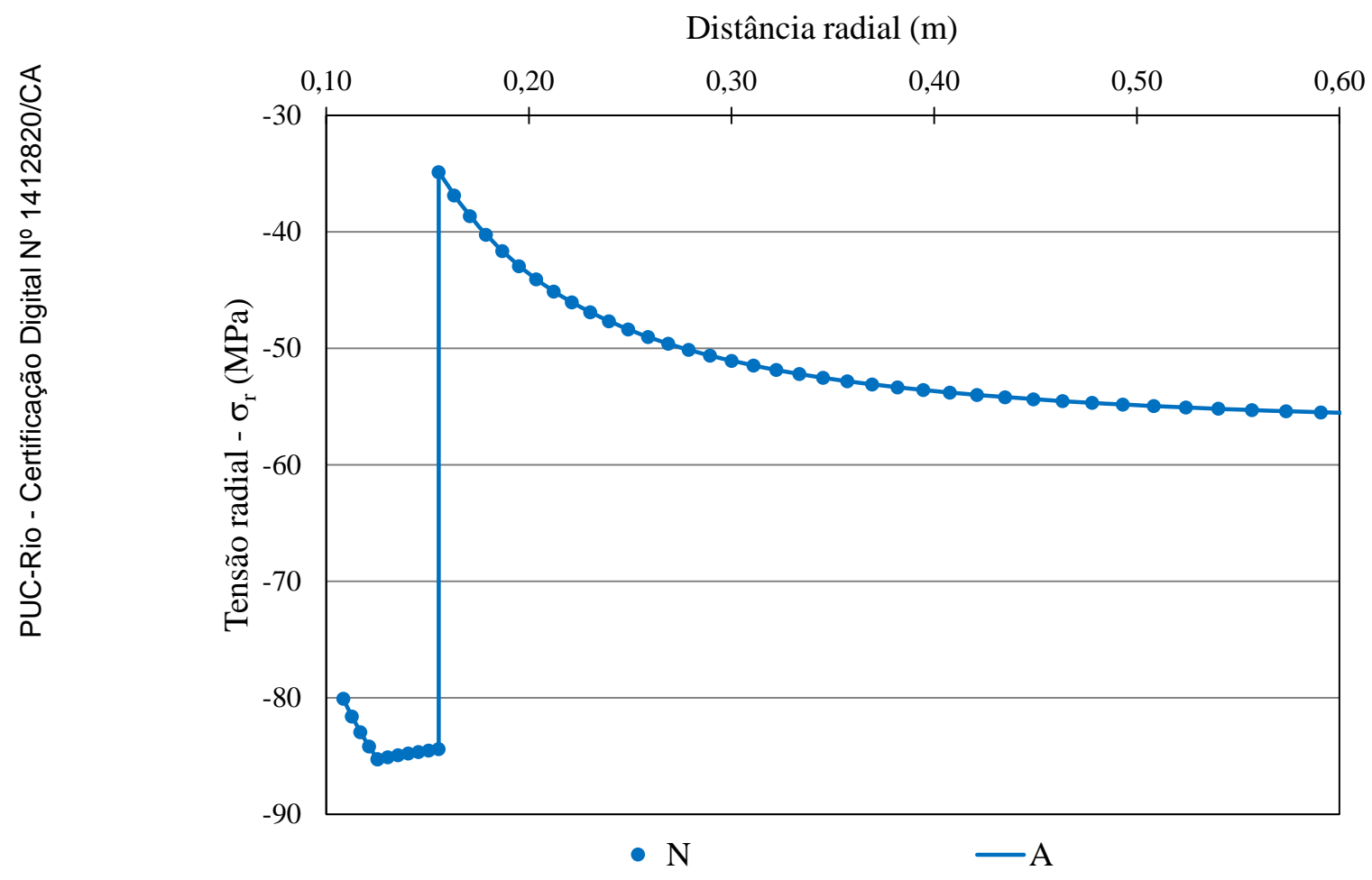

Figura 5.7 - Tensão radial ao longo do raio do modelo após a construção do poço. 


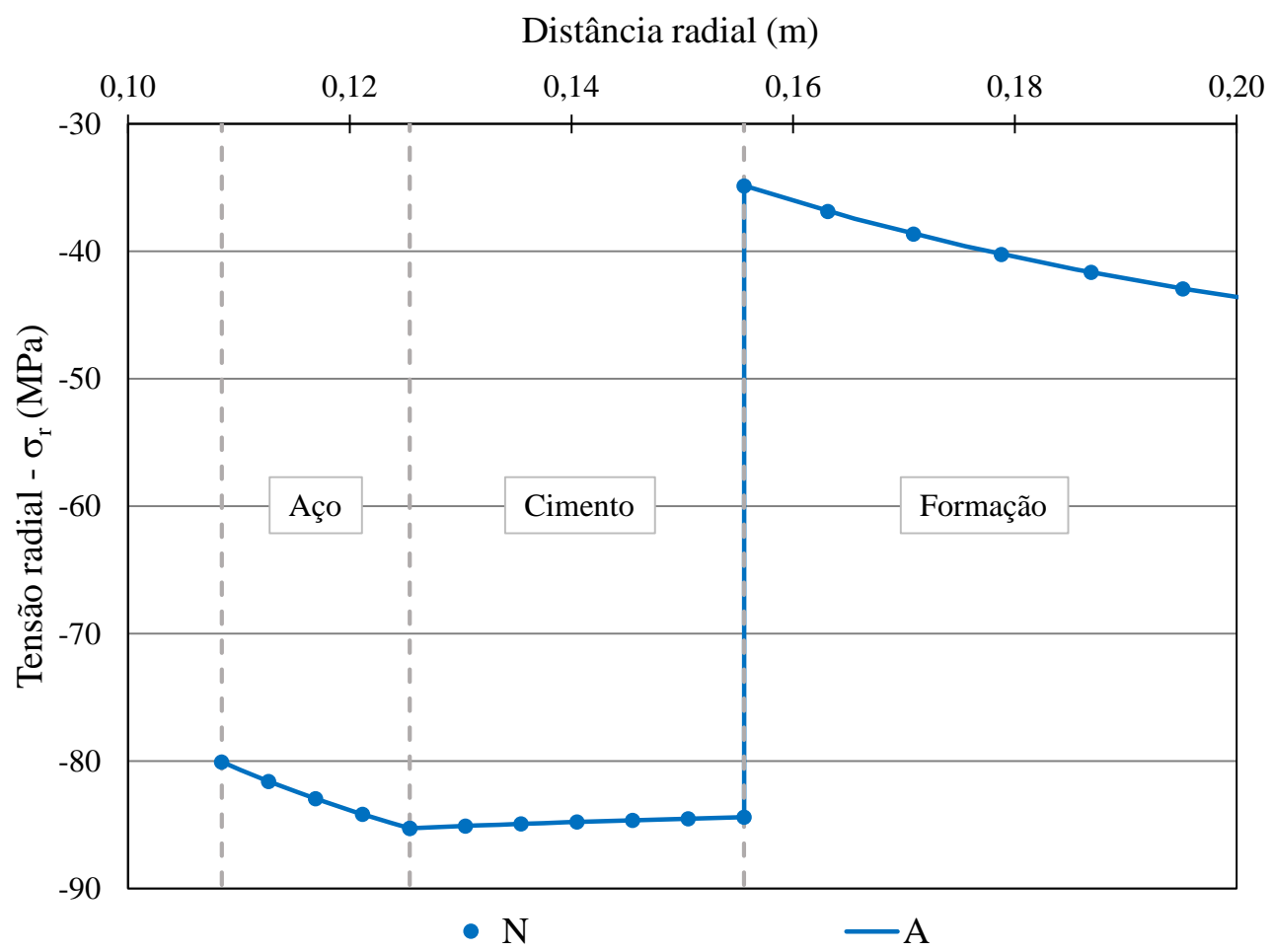

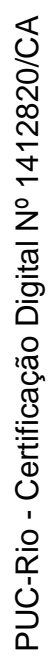

Figura 5.8 - Tensão radial ao longo da espessura do revestimento e do cimento após a construção do poço.

A tensão tangencial no modelo após a construção do poço é apresentada na Figura 5.9. Na Figura 5.10 é apresentada a componente de tensão tangencial no revestimento e no cimento.

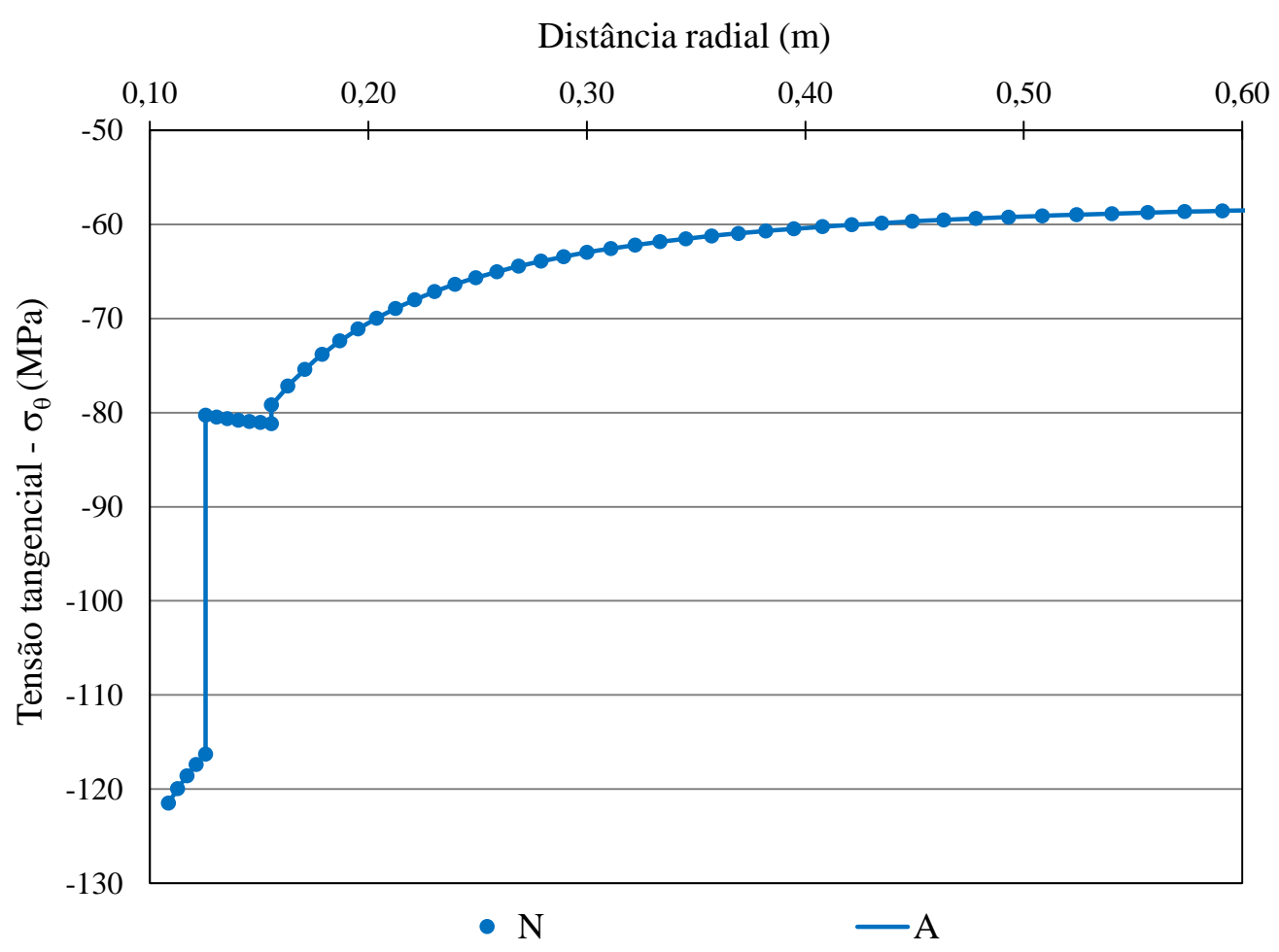

Figura 5.9 - Tensão tangencial ao longo do raio após a construção do poço. 


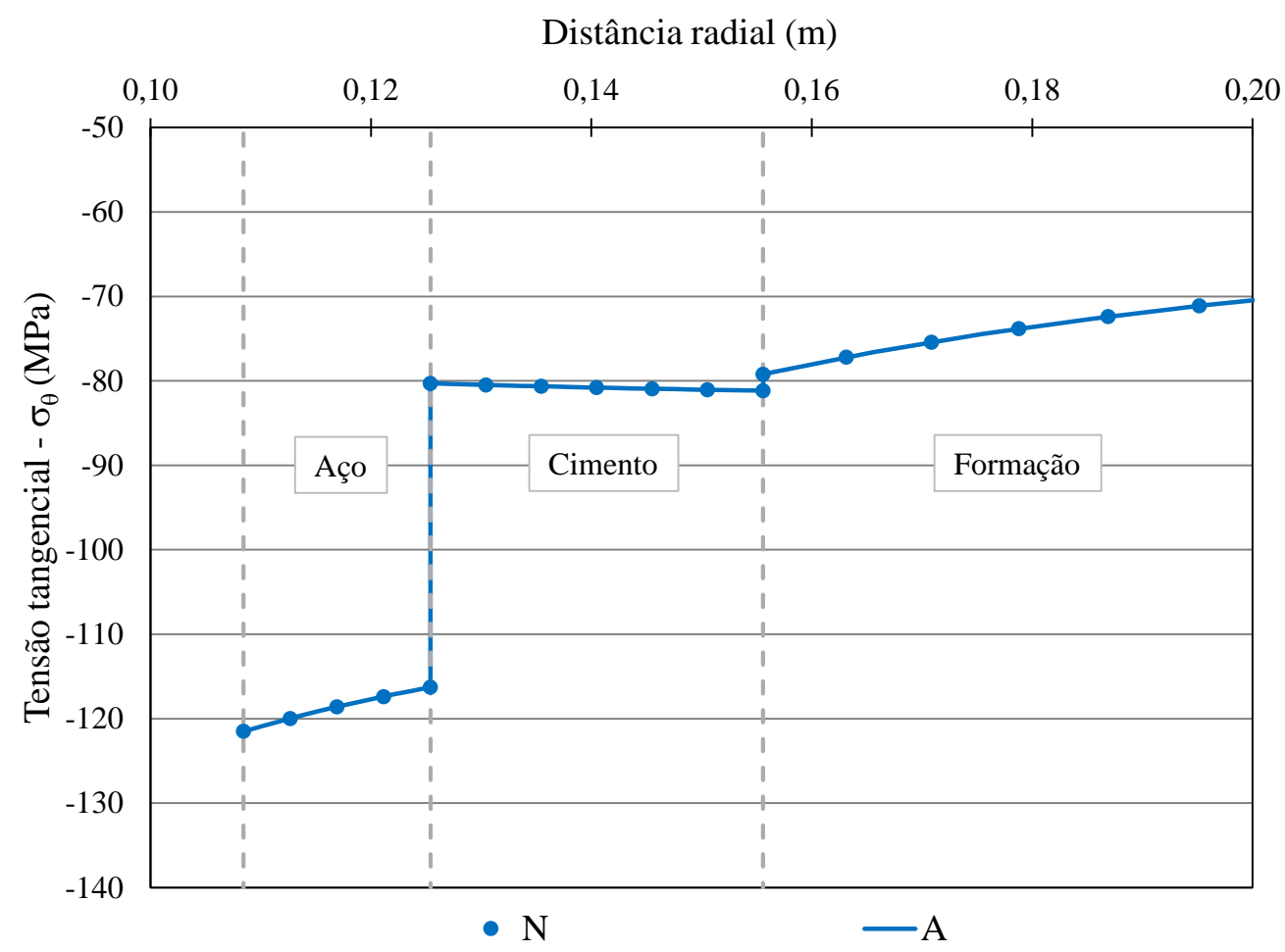

Figura 5.10 - Tensão tangencial ao longo da espessura do revestimento e do cimento após a construção do poço.

O valor do estado de tensão inicial no cimento é de -80,06 MPa, que é o mesmo valor da pressão do fluido de perfuração. Ao final da construção do poço, a tensão radial na superfície interna do revestimento possui o mesmo valor da pressão devido ao fluido de perfuração, de $-80,06 \mathrm{MPa}$. Além disso, nota-se uma descontinuidade na tensão radial na interface entre o cimento e a rocha. Esse salto da tensão radial possui o valor igual ao da poropressão inicial da rocha, de $-49,57$ MPa. As componentes de tensão na formação tendem ao valor do estado de tensão inicial da rocha (-57,02 MPa) conforme aumenta a distância radial em relação ao centro do poço.

O índice de plastificação é calculado através da solução analítica e do modelo numérico para o revestimento e para o cimento, e é apresentado na Figura 5.11 ao longo do raio. 


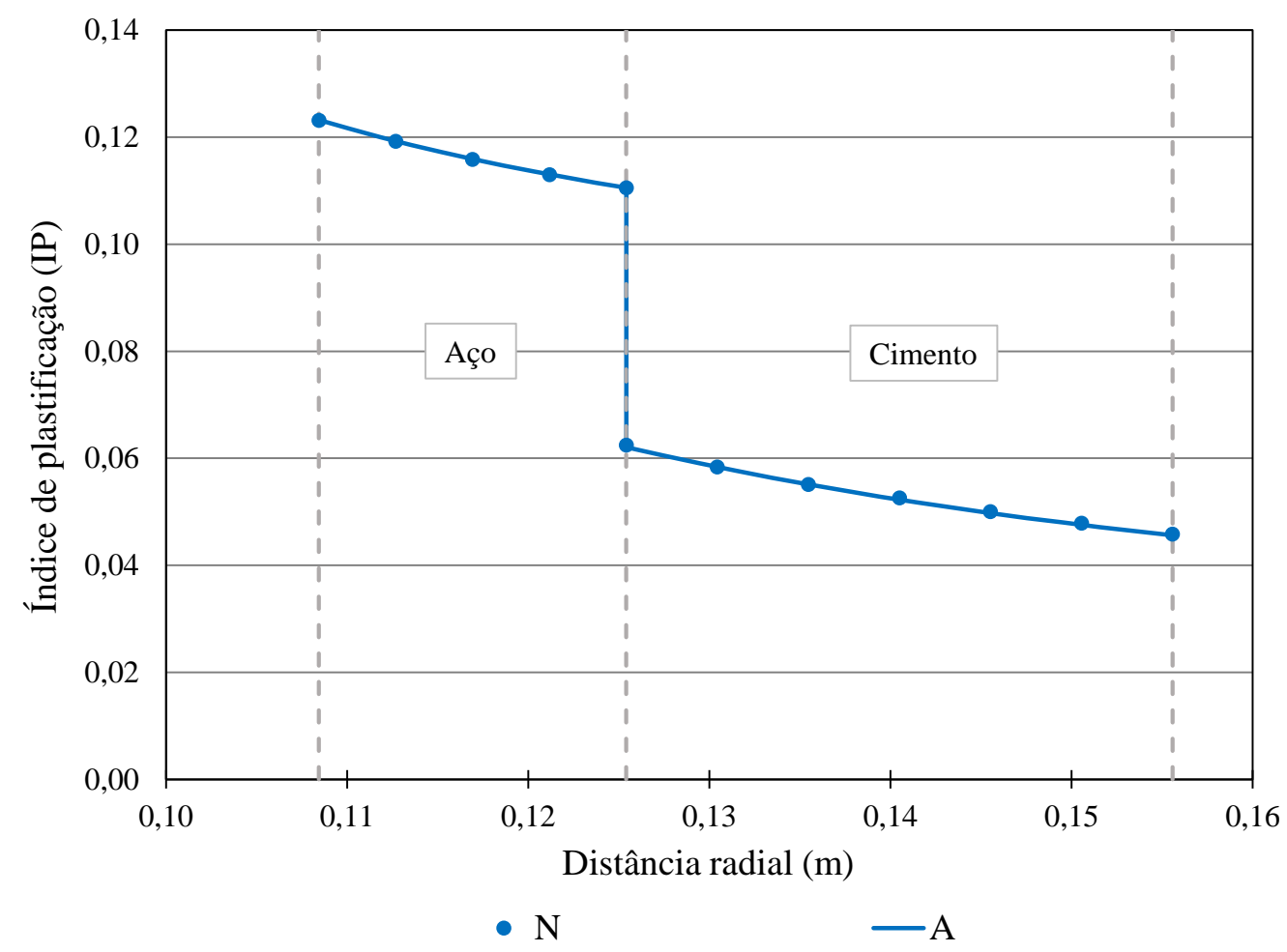

Figura 5.11 - Índice de plastificação no revestimento e no cimento após a construção do poço.

No revestimento de $97 / 8$ ", o IP na superfície interna atinge o valor aproximado de 0,12 , enquanto na superfície externa esse valor é de $\sim 0,11$. Os valores apresentados são muito inferiores ao limite de 1,0, não apresentando plastificação do revestimento. Em todos os resultados apresentados, a solução analítica e o modelo numérico possuem a mesma resposta.

\subsubsection{3.}

\section{Produção (variação de temperatura de $56^{\circ} \mathrm{C}$ )}

Uma variação de temperatura de $56^{\circ} \mathrm{C}$ é aplicada na superfície interna do revestimento na fase de produção, simulando uma variação na temperatura devido ao fluido de produção. A duração adotada para esta fase é de 20 anos de análise. Ao fim de 20 anos de simulação, o perfil de temperatura é apresentado na Figura 5.12 ao longo do raio do modelo e na Figura 5.13 ao longo da espessura do revestimento e do cimento. As componentes de tensão radial e tangencial e o índice de plastificação considerando a variação da temperatura são comparados com os resultados das simulações sem o efeito térmico. As letras $N$ e $A$ dos gráficos a seguir representam os modelos numérico e analítico, respectivamente. 


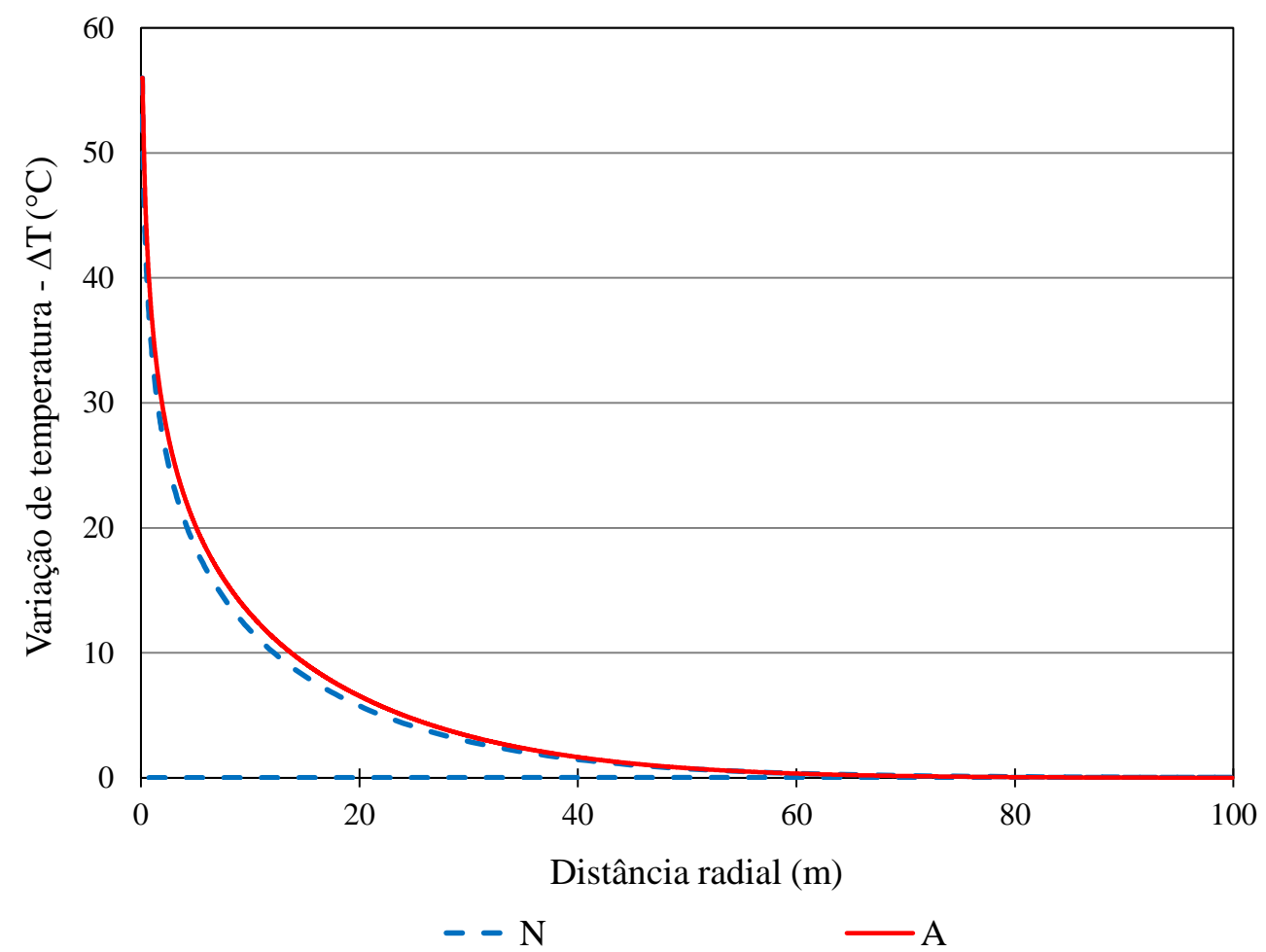

Figura 5.12 - Variação de temperatura ao longo do raio do poço para os modelos numérico e analítico, com variação de temperatura prescrita de $56^{\circ} \mathrm{C}$.

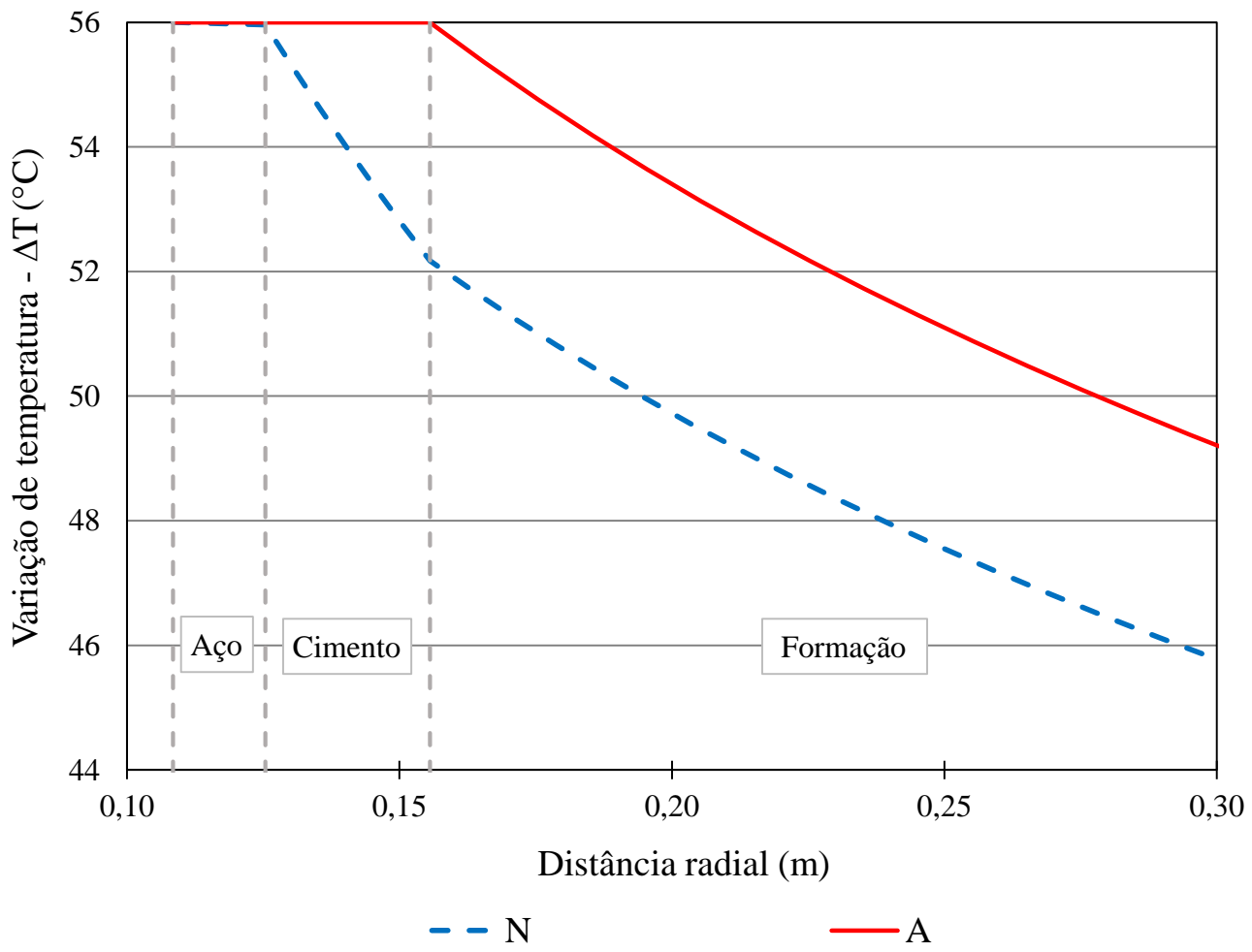

Figura 5.13 - Variação de temperatura no revestimento de $97 / 8^{\prime \prime}$ e no cimento utilizando os modelos numérico e analítico, com variação de temperatura prescrita de $56^{\circ} \mathrm{C}$. 
Na solução analítica, a variação de temperatura é avaliada sendo constante nos revestimentos e nos cimentos, no valor de $56^{\circ} \mathrm{C}$. Na parede da rocha é aplicada $56^{\circ} \mathrm{C}$ de variação de temperatura e a análise é feita de forma transiente. Por outro lado, na modelagem numérica, a variação de temperatura é aplicada na superfície interna do revestimento e então toda a análise térmica é feita em regime transiente. Por causa das diferentes hipóteses mencionadas anteriormente, a variação de temperatura na superfície interna da rocha é de $56^{\circ} \mathrm{C}$ na solução analítica e de aproximadamente $52^{\circ} \mathrm{C}$ no modelo por elementos finitos. Como visto nos resultados a seguir, essa diferença não é capaz de influenciar o estado de tensão final no poço. É possível constatar ainda, que por volta de 60 metros de distância do centro do poço, a variação de temperatura é aproximadamente nula.

A Figura 5.14 apresenta a componente de tensão radial no modelo ao final da simulação. A Figura 5.15 mostra a componente de tensão radial no revestimento e no cimento, comparando os dois cenários de variação de temperatura.

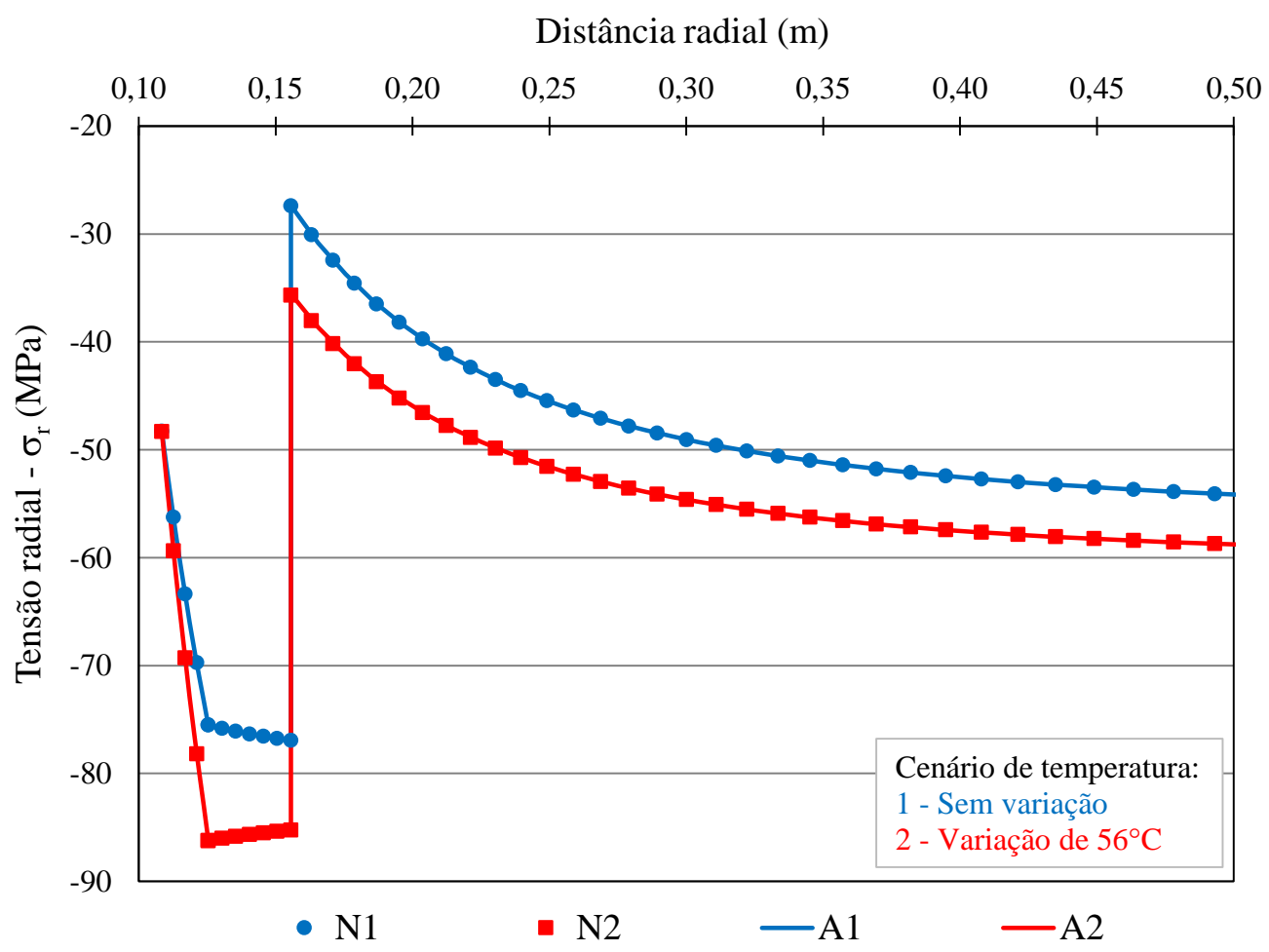

Figura 5.14 - Tensão radial ao longo do raio do poço ao final da análise. 


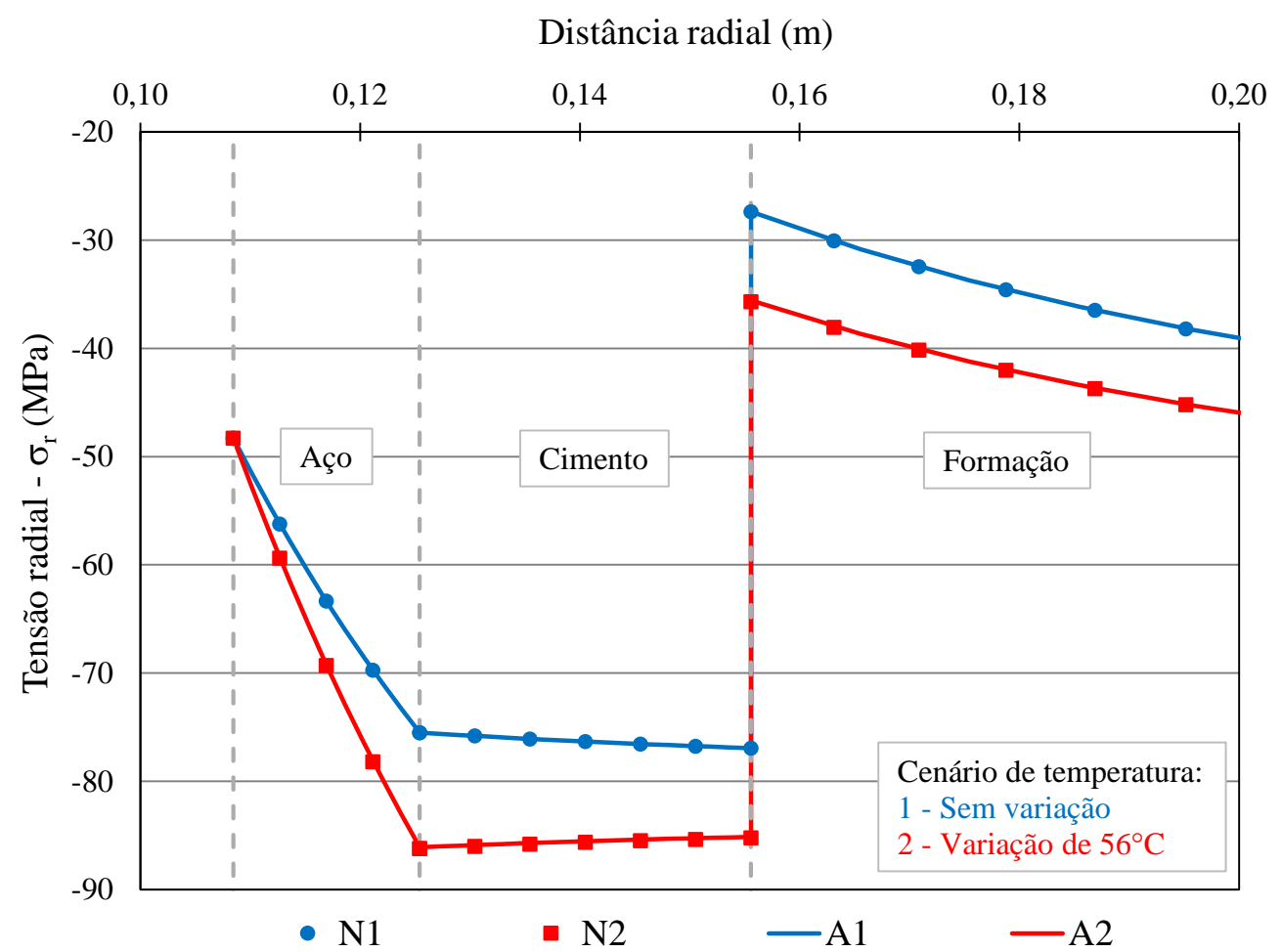

Figura 5.15 - Tensão radial ao longo da espessura do revestimento e do cimento após 20 anos de análise.

Observa-se que a descontinuidade na tensão radial na interface do cimento com a rocha tem o mesmo valor para ambos os casos. Essa descontinuidade possui o valor da poropressão inicial na formação, de -49,57 MPa. Ambos os modelos possuem a mesma tensão radial no ponto interno do revestimento $(-48,26 \mathrm{MPa})$, que é o valor da pressão devida ao fluido de produção.

A Figura 5.16 apresenta a componente de tensão tangencial em todos os materiais ao final da simulação. 


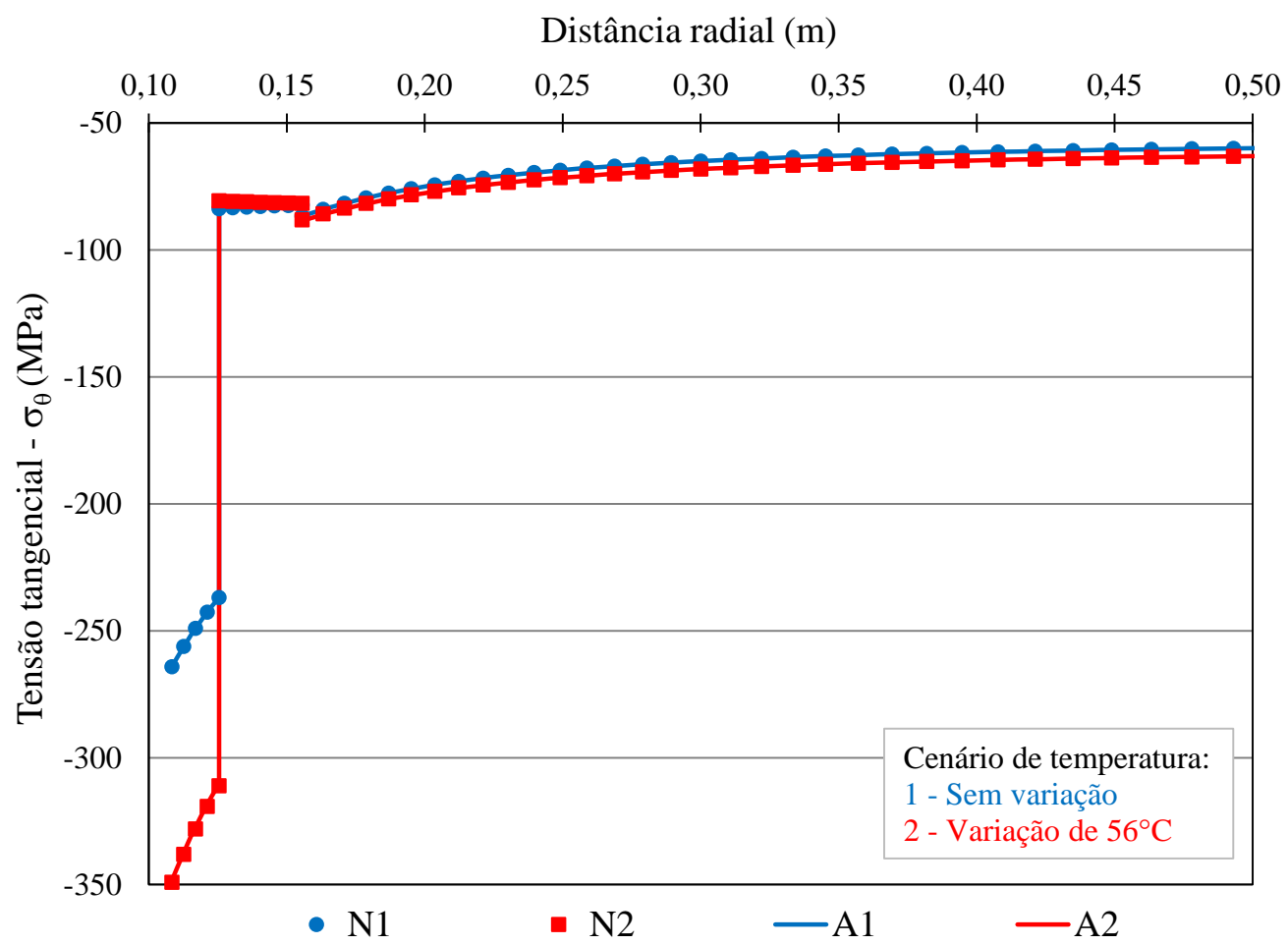

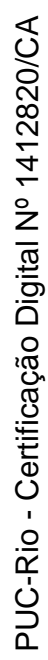

Figura 5.16 - Tensão tangencial ao longo do raio do poço após 20 anos de análise.

A Figura 5.17 mostra a componente de tensão tangencial no revestimento e no cimento para os dois cenários de variação de temperatura.

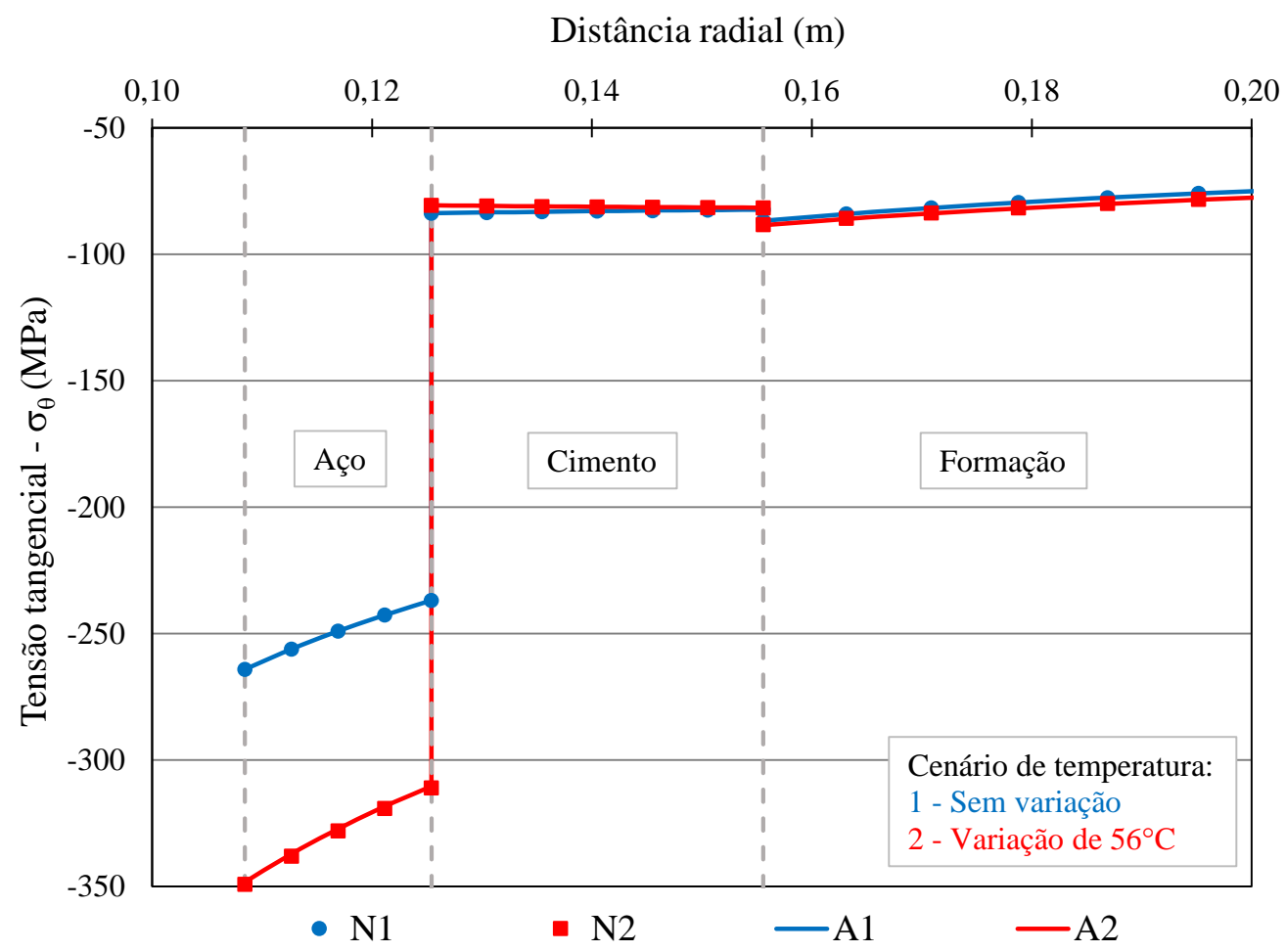

Figura 5.17 - Tensão tangencial no revestimento e no cimento ao final da análise. 
Nota-se que as componentes de tensão no cenário que considera o efeito térmico são superiores aos cenários sem a variação de temperatura. A Figura 5.18 apresenta o índice de plastificação $(I P)$ no revestimento e no cimento, ao final da simulação.

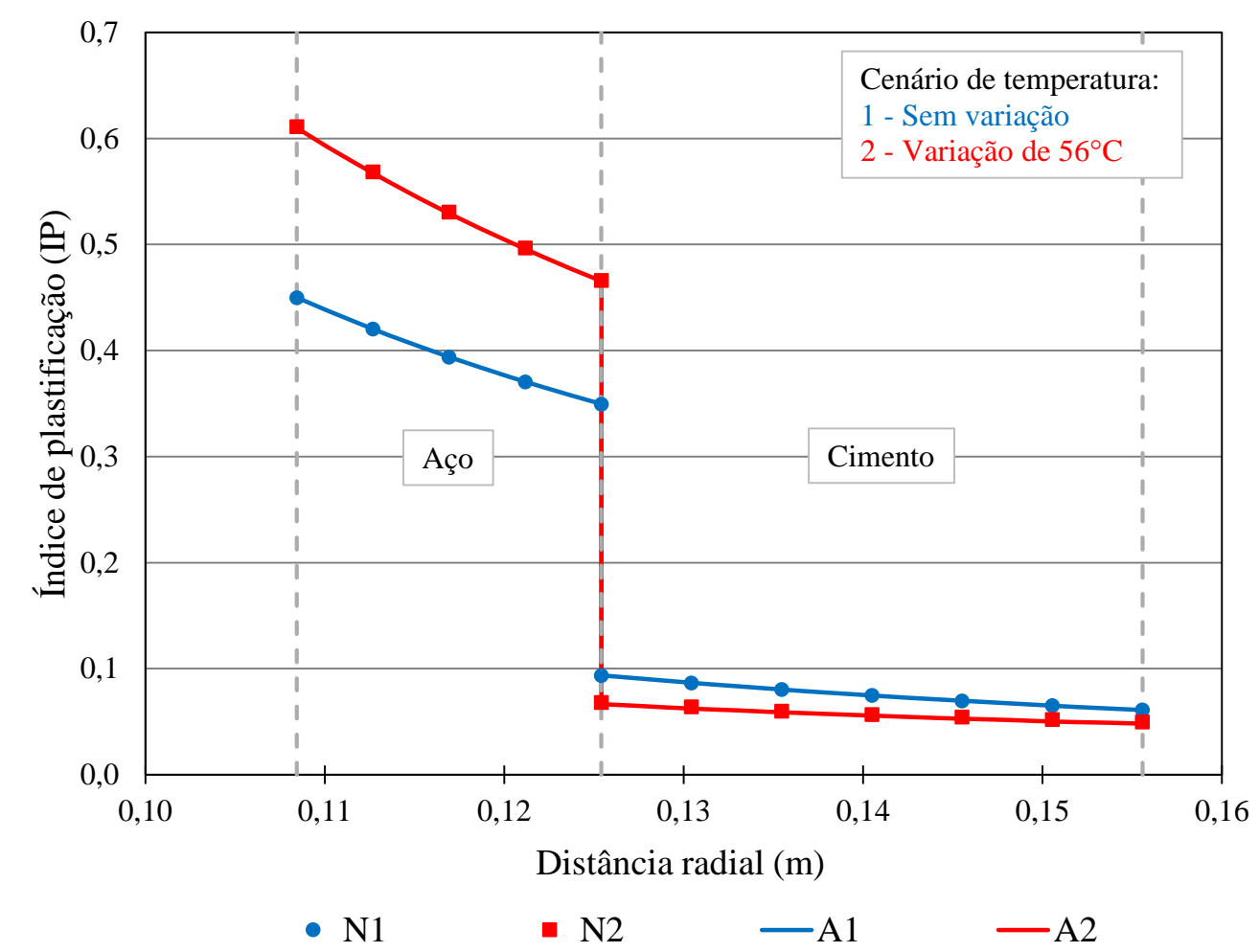

Figura 5.18 - Índice de plastificação no revestimento e no cimento ao final da análise.

Observa-se que o IP na superfície interna do revestimento muda de acordo com o cenário avaliado, apesar da tensão radial nos dois cenários ser a mesma. Essa diferença é devida à tensão tangencial, que possui um valor distinto no ponto interno do revestimento para os dois cenários. Como o IP depende das três componentes de tensão, o cenário 1 possui ao final da análise um $I P$ de 0,61 enquanto o cenário 2, um IP de 0,45. Dessa forma, o pior cenário é o que considera o efeito térmico na simulação.

\section{2.}

\section{Estudo de caso B - Campo da Bacia de Santos, Brasil}

\subsection{1.}

\section{Parâmetros utilizados (Santos em -5130 m)}

Para o segundo estudo de caso, duas análises são feitas em diferentes profundidades. A Tabela 5.5 apresenta as propriedades e os carregamentos 
utilizados na primeira profundidade, em -5130 m (reservatório), tendo como base um poço da Bacia de Santos, no Brasil (Poiate Jr. et al,. 2006).

Tabela 5.5 - Parâmetros do poço.

\begin{tabular}{|l|c|c|}
\hline Parâmetro & Valor & Unidade \\
\hline Diâmetro da parede do poço (14 3/4") & 374,65 & $\mathrm{~mm}$ \\
\hline Diâmetro externo do revestimento externo (10 3/4") & 273,05 & $\mathrm{~mm}$ \\
\hline Diâmetro interno do revestimento externo (9,156") & 232,56 & $\mathrm{~mm}$ \\
\hline Borda externa do modelo & 200,00 & $\mathrm{~m}$ \\
\hline Profundidade & 5130,00 & $\mathrm{~m}$ \\
\hline Lâmina d'água & 2140,00 & $\mathrm{~m}$ \\
\hline Pressão do fluido de perfuração (10,0 lb/gal) & 60277,50 & $\mathrm{kPa}$ \\
\hline Pressão do cimento** (15,8 lb/gal) & $95238,45^{* *}$ & $\mathrm{kPa}$ \\
\hline Tensão in situ da formação (22,56 kN/m $\left.{ }^{3}\right)$ & 88854,40 & $\mathrm{kPa}$ \\
\hline Pressão do fluido de produção (depleção) ${ }^{*}$ & $51960,28^{*}$ & $\mathrm{kPa}$ \\
\hline Pressão do fluido de produção (injeção) & $60277,50^{*}$ & $\mathrm{kPa}$ \\
\hline Poropressão na formação $(9,75$ lb/gal) & 58770,56 & $\mathrm{kPa}$ \\
\hline Variação de temperatura & 5,00 & ${ }^{\circ} \mathrm{C}$ \\
\hline
\end{tabular}

Fonte: Poiate Jr. et al. (2006); "Ravi et al. (2003), **Mackay et al. (2014).

As propriedades da rocha são apresentadas na Tabela 5.6, onde as propriedades elásticas são retiradas de Poiate Jr. et al. (2006) e as propriedades térmicas de Mongelli et al. (1982) e Wong \& Brace (1979).

Tabela 5.6 - Propriedades da rocha.

\begin{tabular}{|l|c|c|}
\hline Propriedade da rocha & Valor & Unidade \\
\hline Módulo de elasticidade $(\mathrm{E})$ & 31,00 & $\mathrm{GPa}$ \\
\hline Coeficiente de Poisson $(v)$ & 0,30 & - \\
\hline Condutividade térmica* $^{*}(\mathrm{k})$ & $1,46^{*}$ & $\mathrm{~W} / \mathrm{m}^{\circ} \mathrm{C}$ \\
\hline Capacidade térmica $^{*}\left(\mathrm{c}_{\mathrm{T}}\right)$ & $740,00^{*}$ & $\mathrm{~J} / \mathrm{kg}^{\circ} \mathrm{C}$ \\
\hline Difusividade térmica* $^{*}(\beta)$ & $7,30 \mathrm{E}-07^{*}$ & $\mathrm{~m}^{2} / \mathrm{s}$ \\
\hline Densidade $^{*}(\rho)$ & $2702,70^{*}$ & $\mathrm{~kg} / \mathrm{m}^{3}$ \\
\hline Coeficiente de dilatação térmica $^{* *}(\alpha)$ & $3,40 \mathrm{E}-6^{* *}$ & $1 /{ }^{\circ} \mathrm{C}$ \\
\hline
\end{tabular}

Fonte: Poiate Jr. et al. (2006); "Mongelli et al. (1982); ${ }^{* *}$ Wong \& Brace (1979).

As propriedades utilizadas no aço nas análises numérica e analítica para este estudo de caso estão apresentadas na Tabela 5.7. As propriedades elásticas são de Poiate Jr. et al. (2006) enquanto as propriedades térmicas são de Kaldal et al. (2015). 
Tabela 5.7 - Propriedades do aço.

\begin{tabular}{|l|c|c|}
\hline Propriedade do aço (revestimento) & Valor & Unidade \\
\hline Módulo de elasticidade $(\mathrm{E})$ & 210,00 & $\mathrm{GPa}$ \\
\hline Coeficiente de Poisson $(v)$ & 0,28 & - \\
\hline Tensão de escoamento* $^{* *}\left(\sigma_{\mathrm{y}}\right)$ & $438,00^{* *}$ & $\mathrm{MPa}$ \\
\hline Condutividade térmica $^{*}(\mathrm{k})$ & $50,00^{*}$ & $\mathrm{~W} / \mathrm{m}^{\circ} \mathrm{C}$ \\
\hline Capacidade térmica* $^{*}\left(\mathrm{c}_{\mathrm{T}}\right)$ & $400,00^{*}$ & $\mathrm{~J} / \mathrm{kg}^{\circ} \mathrm{C}$ \\
\hline Densidade $^{*}(\rho)$ & $7850,00^{*}$ & $\mathrm{~kg} / \mathrm{m}^{3}$ \\
\hline Coeficiente de dilatação térmica $^{*}(\alpha)$ & $12,00 \mathrm{E}-6^{*}$ & $1 /{ }^{\circ} \mathrm{C}$ \\
\hline
\end{tabular}

Fonte: Poiate Jr. et al. (2006); ${ }^{*}$ Kaldal et al. (2015); ${ }^{* *}$ Fossum \& Fredrich (2007).

As propriedades do cimento são apresentadas na Tabela 5.8, onde as propriedades elásticas são de Poiate Jr. et al. (2006).

Tabela 5.8 - Propriedades do cimento.

\begin{tabular}{|l|c|c|}
\hline Propriedade do cimento & Valor & Unidade \\
\hline Módulo de elasticidade $(\mathrm{E})$ & 21,00 & $\mathrm{GPa}$ \\
\hline Coeficiente de Poisson $(v)$ & 0,25 & - \\
\hline Coesão* $^{* *}$ & $21,60^{* *}$ & $\mathrm{MPa}$ \\
\hline Ângulo de atrito $^{* *}$ & $17,10^{* *}$ & ${ }^{\circ}$ \\
\hline Condutividade térmica* $^{*}(\mathrm{k})$ & $0,81^{*}$ & $\mathrm{~W} / \mathrm{m}^{\circ} \mathrm{C}$ \\
\hline Capacidade térmica* $^{*}\left(\mathrm{c}_{\mathrm{T}}\right)$ & $880,00^{*}$ & $\mathrm{~J} / \mathrm{kg}^{\circ} \mathrm{C}$ \\
\hline Densidade* $^{*}(\rho)$ & $1600,00^{*}$ & $\mathrm{~kg} / \mathrm{m}^{3}$ \\
\hline Coeficiente de dilatação térmica* $^{*}(\alpha)$ & $1,00 \mathrm{E}-6^{*}$ & $1 /{ }^{\circ} \mathrm{C}$ \\
\hline
\end{tabular}

Fonte: Poiate Jr. et al. (2006); 'Kaldal et al. (2015); ${ }^{* *}$ Bosma et al. (1999).

\subsection{2.}

\section{Resultados (Santos em -5130 m)}

Para esta análise, como a profundidade avaliada é no reservatório, a variação da temperatura é pequena e, portanto, é adotado o valor de $5^{\circ} \mathrm{C}$. Serão apresentados resultados para as componentes de tensão radial e tangencial e para o índice de plastificação no revestimento e no cimento. Serão apresentados três cenários de variação da poropressão da rocha. O cenário 1 representa o modelo sem variação de poropressão, o 2 representa o caso de injeção de $30 \mathrm{MPa}$ e o cenário 3 simula a depleção de $30 \mathrm{MPa}$. 


\subsubsection{1.}

\section{Produção (com cenários de variação de poropressão - $30 \mathrm{MPa}$ )}

Durante a produção, além da pressão interna e da temperatura no revestimento sofrer uma alteração devido à mudança do fluido, a poropressão na formação sofre uma variação devido à depleção ou a injeção (dependendo da função do poço). As letras $A$ e $N$ se referem à solução analítica e ao modelo numérico, respectivamente.

A Figura 5.19 apresenta a tensão radial ao longo do raio do poço na produção, considerando os três cenários de variação da poropressão e uma variação de temperatura de $5^{\circ} \mathrm{C}$.

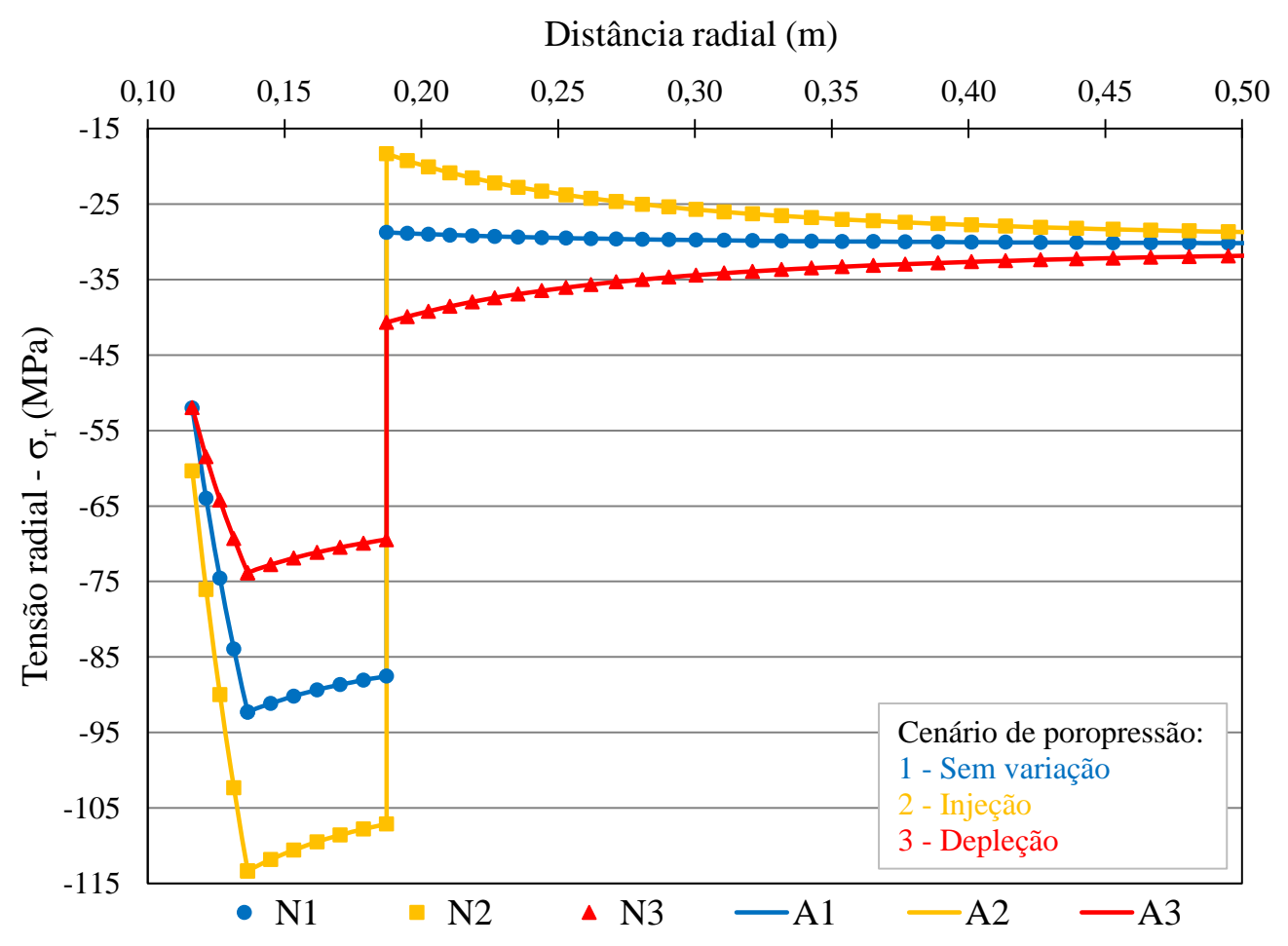

Figura 5.19 - Tensão radial no poço ao longo do raio após o final da análise.

A Figura 5.20 apresenta a tensão radial durante a produção para o revestimento e cimento. Os três cenários de variação da poropressão são simulados e comparados, utilizando as soluções numérica e analítica. 


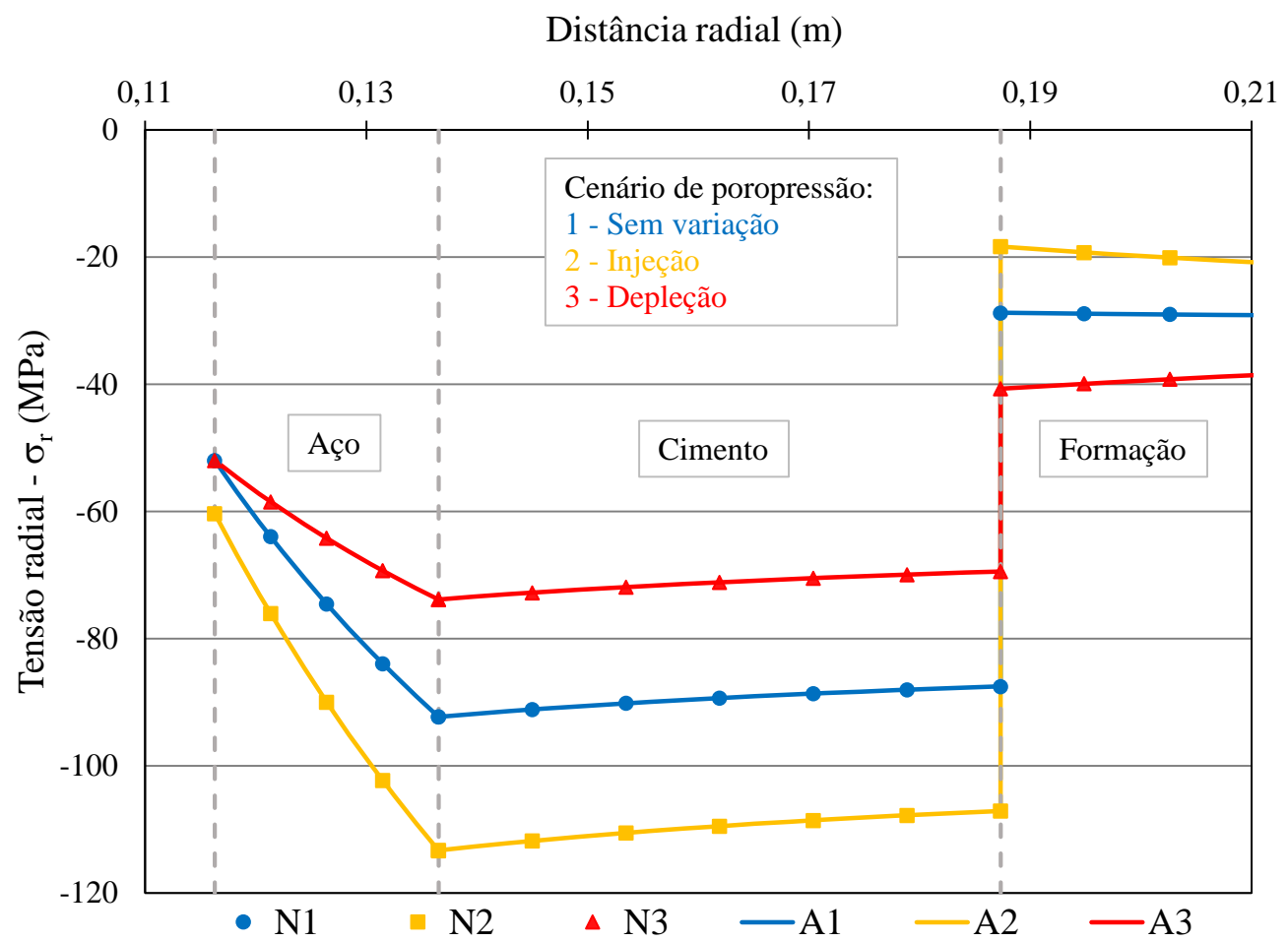

Figura 5.20 - Tensão radial no revestimento (10 3/4”) e no cimento ao longo do raio após o final da análise.

A tensão radial na parede interna do revestimento tem o valor da pressão de produção nos três cenários comparados, de -51,96 MPa nos cenários 1 e 3 e de 60,28 MPa no cenário 2 (injeção). Na interface entre o cimento e a rocha, a descontinuidade no cenário 1 é de $58,77 \mathrm{MPa}$ (valor da poropressão inicial da rocha), no cenário 2 é de 88,77 $\mathrm{MPa}$ (poropressão inicial somada à variação de poropressão de $30 \mathrm{MPa}$ - injeção), enquanto no cenário 3 é de 28,77 $\mathrm{MPa}$ (poropressão inicial subtraída da variação de poropressão de $30 \mathrm{MPa}$ - depleção).

Para a componente de tensão tangencial, a Figura 5.21 mostra o resultado ao longo do raio para o caso sem variação da poropressão, de injeção e de depleção. A Figura 5.22 apresenta a componente de tensão tangencial para o revestimento e o cimento após 20 anos de simulação com variação de temperatura de $5^{\circ} \mathrm{C}$. 


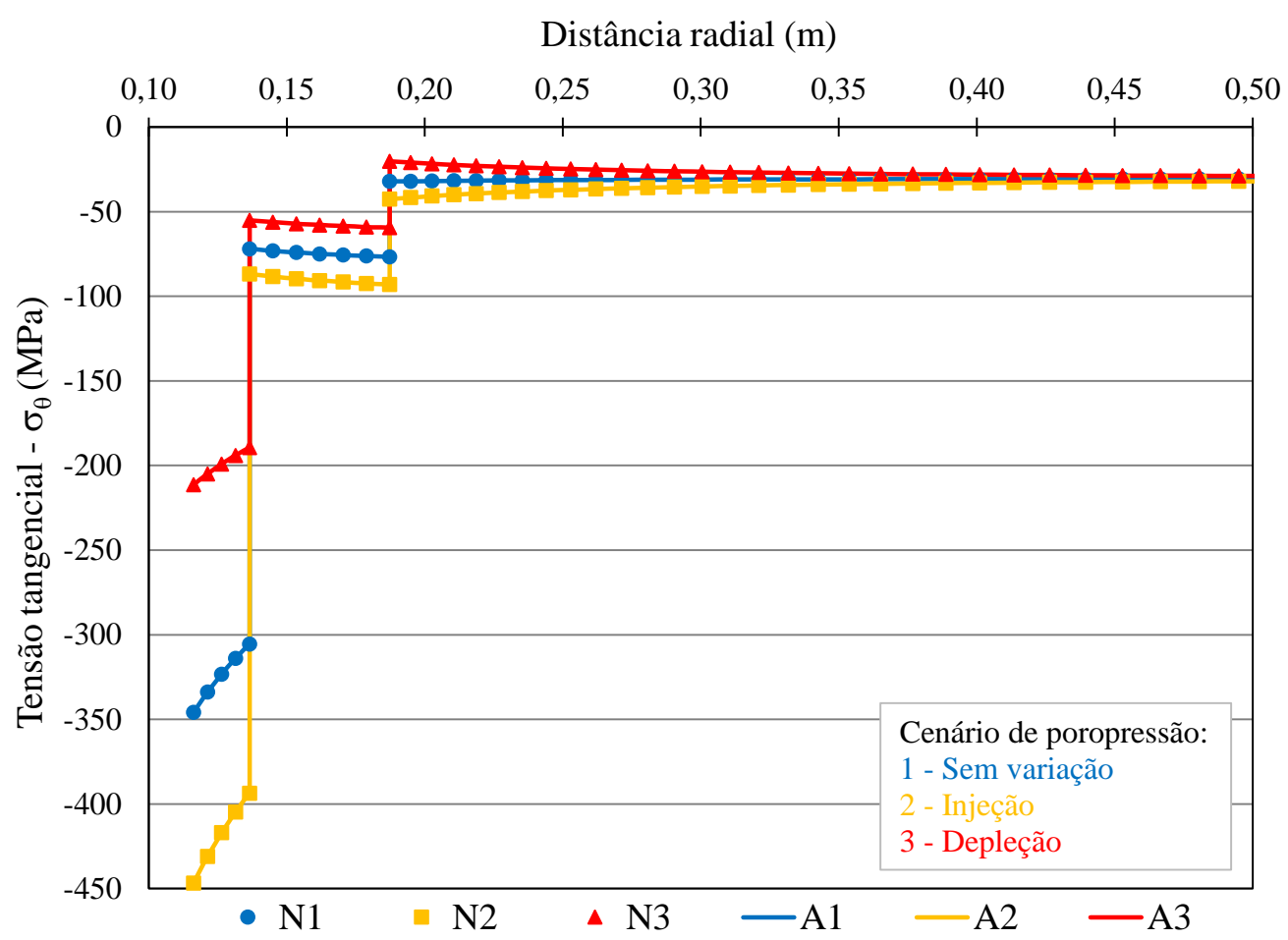

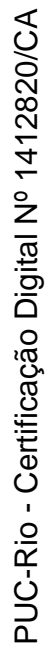

Figura 5.21 - Tensão tangencial no poço ao longo do raio durante a produção.

Distância radial (m)

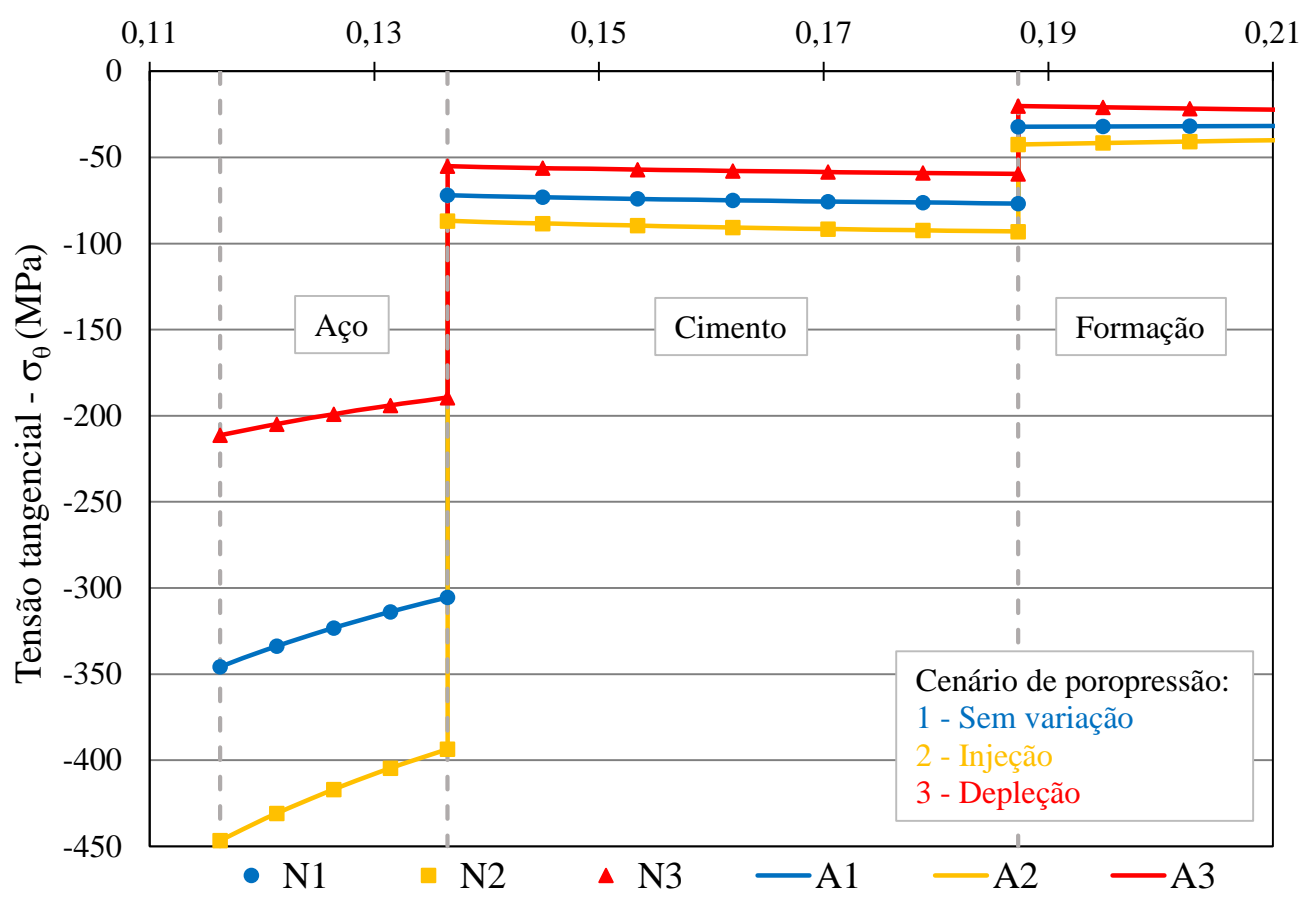

Figura 5.22 - Tensão tangencial no revestimento de 10 3/4" e no cimento ao longo do raio ao final da análise.

O índice de plastificação no revestimento e no cimento considerando os três cenários diferentes de variação da poropressão é apresentado na Figura 5.23. 


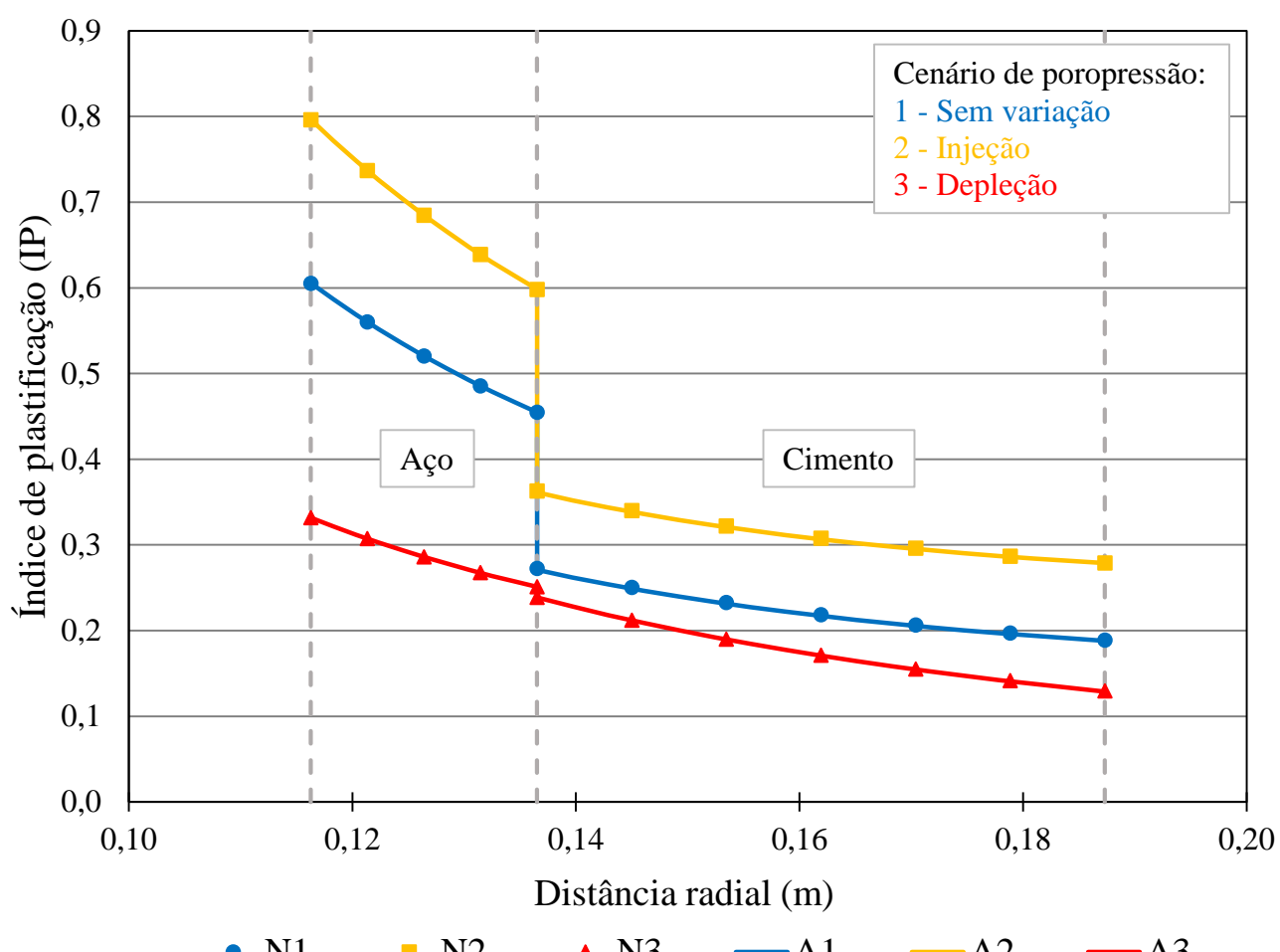

Figura 5.23 - Índice de plastificação no revestimento de 10 3/4" e no cimento ao longo do raio após o final da análise.

O revestimento de 10 3/4" não plastifica ao final da análise para nenhum dos cenários de variação da poropressão. O IP na superfície interna do revestimento, considerando uma variação de temperatura de $5^{\circ} \mathrm{C}$ para os cenários 1,2 e 3 são de 0,61, de 0,80 e de 0,33, respectivamente. Dessa forma, os índices de plastificação nos três cenários de poropressão analisados se apresentam mais críticos na superfície interna do revestimento.

Através dos resultados apresentados neste estudo de caso, observa-se que a variação da poropressão na rocha influencia o estado de tensão do revestimento, do cimento e da rocha. Na Figura 5.24 o IP para o ponto interno do revestimento é apresentado, simulando diferentes cenários de variação da poropressão. 


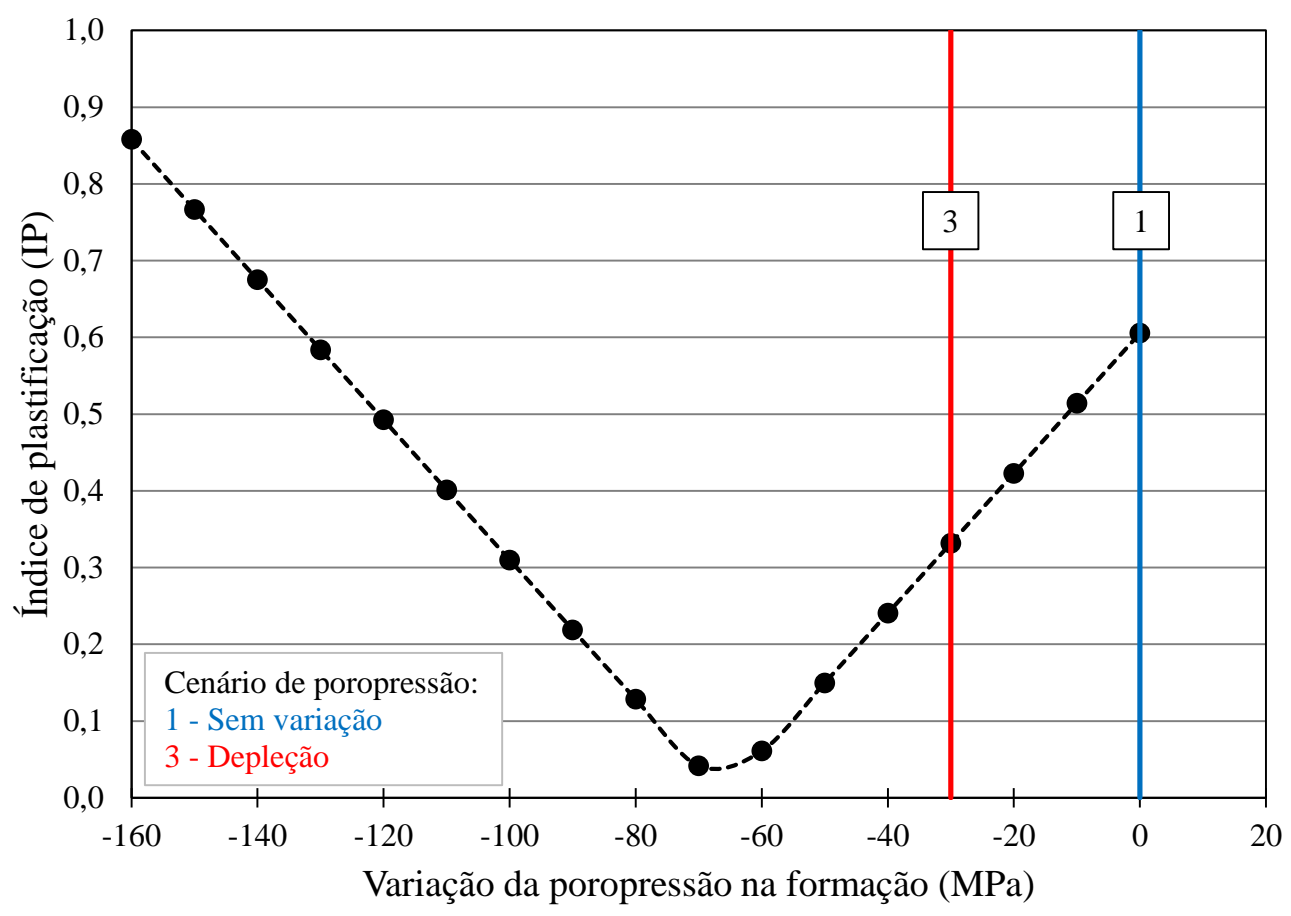

-๑--IP no revestimento —Cenário N1 / A1 Cenário N3 / A3

Figura 5.24 - Índice de plastificação na superfície interna do revestimento de 10 3/4” com diferentes cenários de variação da poropressão.

Os valores de variação da poropressão adotados neste trabalho $(0 \mathrm{MPa}-$ cenário $1,30 \mathrm{MPa}$ - cenário 2 e -30 $\mathrm{MPa}$ - cenário 3) servem para demonstrar o comportamento das tensões nos materiais ao longo do raio. No entanto, de acordo com a Figura 5.24 e a Figura 5.25, é possível observar diversos valores de variação da poropressão com os respectivos valores de $I P$ na superfície interna do revestimento. Dessa forma, é possível ter uma maior sensibilidade em relação à influência da variação da poropressão no estado de tensão final do revestimento.

A Figura 5.25 apresenta uma curva com diferentes valores de variação da poropressão na rocha em caso de injeção, e o IP referente a cada valor. 


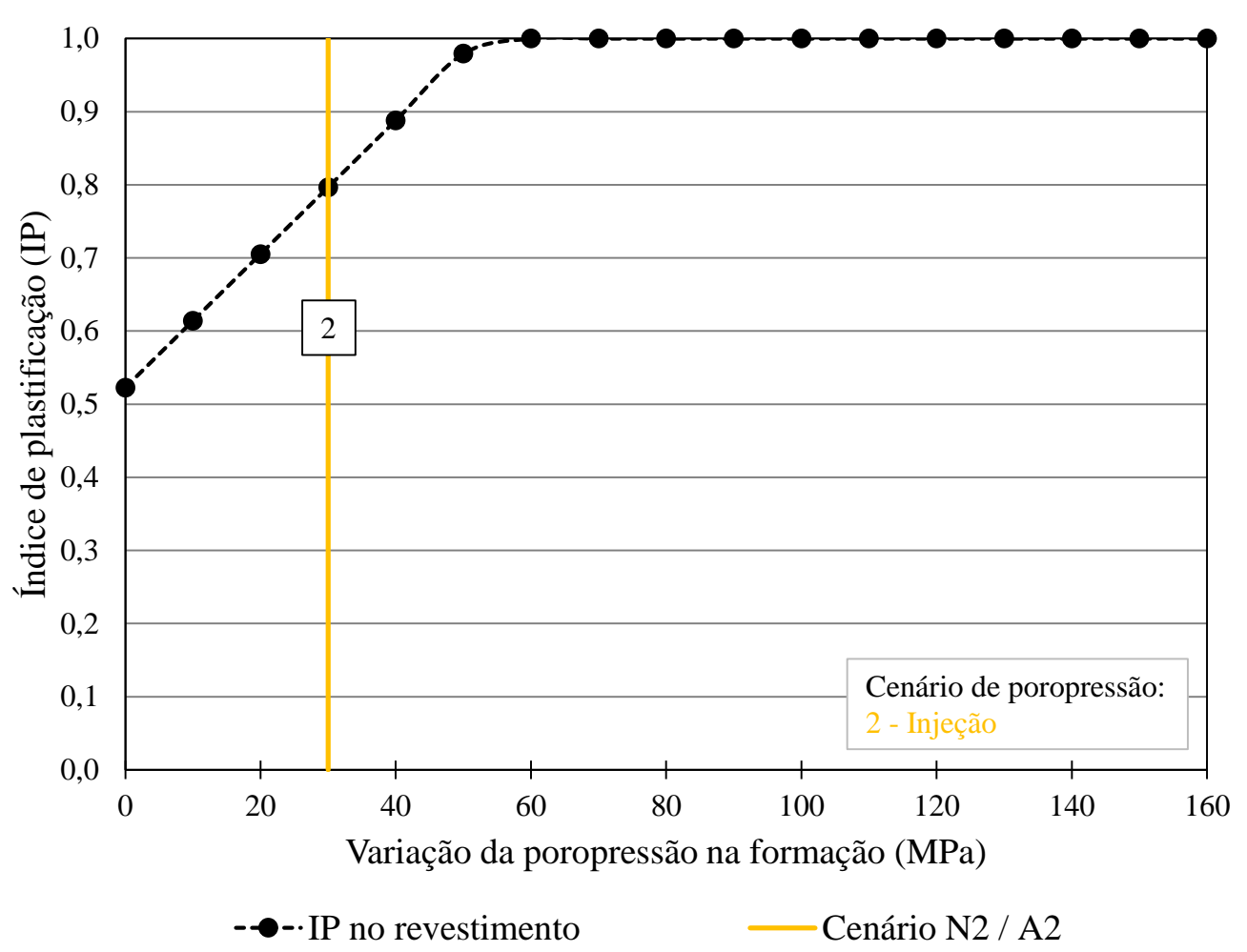

Figura 5.25 - Índice de plastificação na superfície interna do revestimento de 10 3/4” em relação a variação da poropressão da rocha, considerando um cenário de injeção.

Observa-se que ao aumentar a injeção, mais crítico torna-se o cenário para o revestimento. Qualquer valor acima de $60 \mathrm{MPa}$ de injeção levará a superfície interna do revestimento à plastificação.

Apesar de não serem apresentados os resultados para as simulações sem o efeito da temperatura, esses modelos foram analisados. A Figura 5.26 apresenta a comparação entre os modelos com e sem variação de temperatura e com os três cenários de variação de poropressão. 


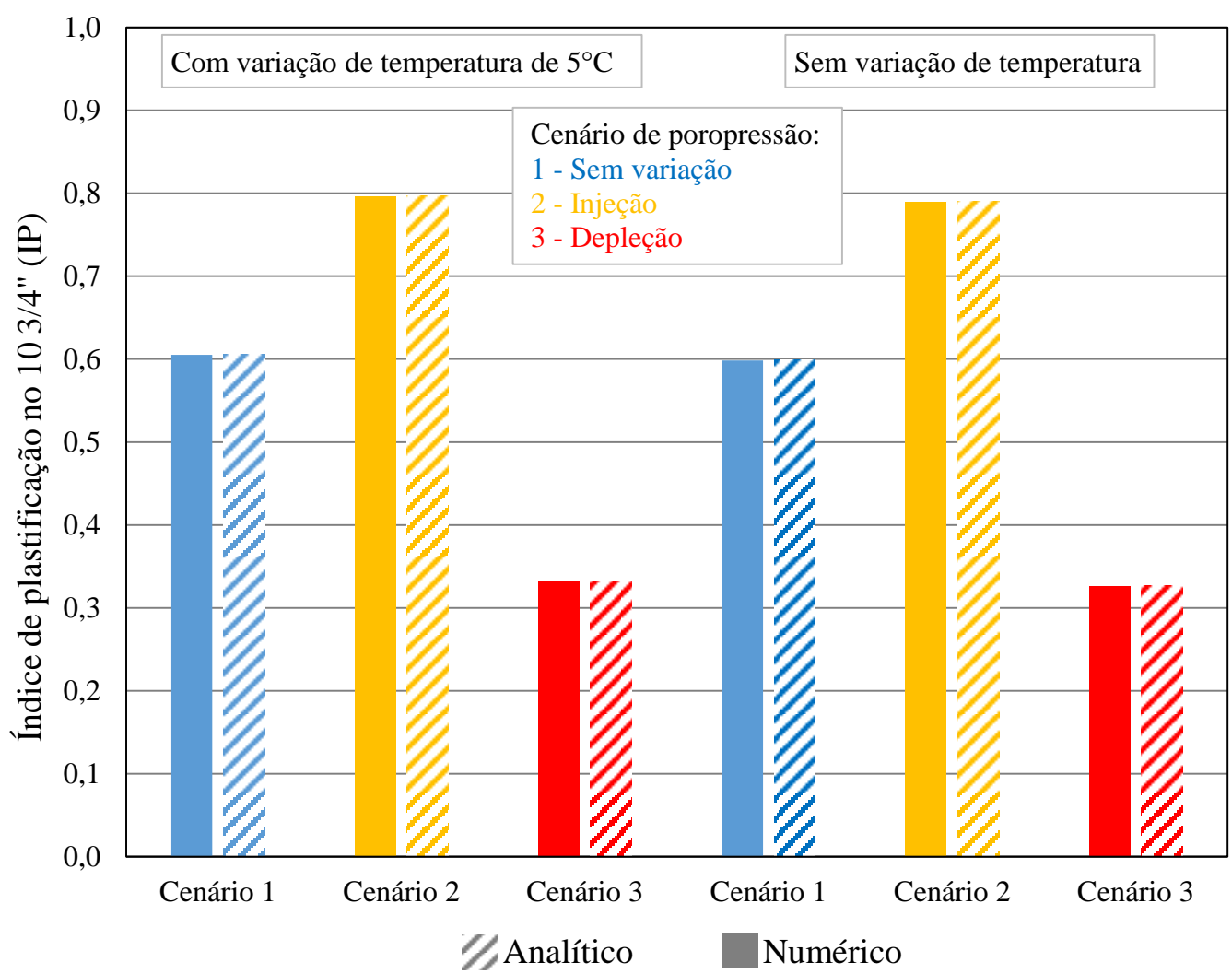

Figura 5.26 - Comparativo do índice de plastificação no revestimento de 10 3/4" entre os cenários de variação de poropressão e de variação de temperatura simulados.

Observa-se que a variação de temperatura de $5^{\circ} \mathrm{C}$ na superfície interna do revestimento pouco altera o IP no ponto interno do revestimento em relação ao modelo sem o efeito térmico. Essa diferença no resultado do índice de plastificação no revestimento é de aproximadamente $1,5 \%$ entre as simulações com e sem variação de temperatura. Nota-se que uma variação pequena de temperatura não gera um grande aumento nas tensões do poço, porém essa pequena variação de temperatura é comum no reservatório, e não nas camadas mais rasas.

\subsection{3.}

\section{Parâmetros utilizados (Santos em -3640 m)}

A segunda profundidade analisada no poço da Bacia de Santos é em -3640 m, onde a Tabela 5.9 apresenta as propriedades e os carregamentos utilizados, tendo como base o poço da Bacia de Santos, no Brasil, apresentado em Poiate Jr. et al. (2006). 
Tabela 5.9 - Parâmetros do poço.

\begin{tabular}{|l|c|c|}
\hline Parâmetro & Valor & Unidade \\
\hline Diâmetro da parede do poço (17 1/2") & 444,50 & $\mathrm{~mm}$ \\
\hline Diâmetro externo do revestimento externo (14") & 355,60 & $\mathrm{~mm}$ \\
\hline Diâmetro interno do revestimento externo (12,376") & 314,35 & $\mathrm{~mm}$ \\
\hline Diâmetro externo do revestimento interno (10 3/4") & 273,05 & $\mathrm{~mm}$ \\
\hline Diâmetro interno do revestimento interno (9,156") & 232,56 & $\mathrm{~mm}$ \\
\hline Borda externa do modelo & 200,00 & $\mathrm{~m}$ \\
\hline Profundidade & 3640,00 & $\mathrm{~m}$ \\
\hline Lâmina d'água & 2140,00 & $\mathrm{~m}$ \\
\hline Pressão do fluido de perfuração (12,0 lb/gal) & 51324,00 & $\mathrm{kPa}$ \\
\hline Pressão do cimento** $(15,8 \mathrm{lb} / \mathrm{gal})$ & $67576,60^{* *}$ & $\mathrm{kPa}$ \\
\hline Tensão in situ da formação $\left(22,56 \mathrm{kN} / \mathrm{m}^{3}\right)$ & 55240,00 & $\mathrm{kPa}$ \\
\hline Pressão do fluido de produção & 36868,47 & $\mathrm{kPa}$ \\
\hline Poropressão inicial da rocha $(9,0 \mathrm{lb} / \mathrm{gal})$ & 38493,00 & $\mathrm{kPa}$ \\
\hline Variação de temperatura & 55,00 & ${ }^{\circ} \mathrm{C}$ \\
\hline
\end{tabular}

\subsection{4.}

\section{Resultados (Santos em -3640 m)}

Para a profundidade analisada $(-3640 \mathrm{~m})$ a variação da temperatura atinge $55^{\circ} \mathrm{C}$ para o caso estudado. São apresentados os resultados para as componentes de tensão radial e tangencial e para o índice de plastificação nos revestimentos e nos cimentos. Os resultados considerando o efeito térmico são comparados com os modelos sem a variação da temperatura. Além disso, todos os modelos são feitos utilizando as soluções analítica e numérica para dois revestimentos.

\subsubsection{1.}

\section{Produção (variação de temperatura de $55^{\circ} \mathrm{C}$ )}

Durante a produção, além da mudança na pressão interna, a temperatura na superfície interna do revestimento sofre uma variação devida ao fluido interno (fluido de produção). A Figura 5.27 mostra o perfil de temperatura ao longo do raio do poço ao final de 20 anos de simulação. 


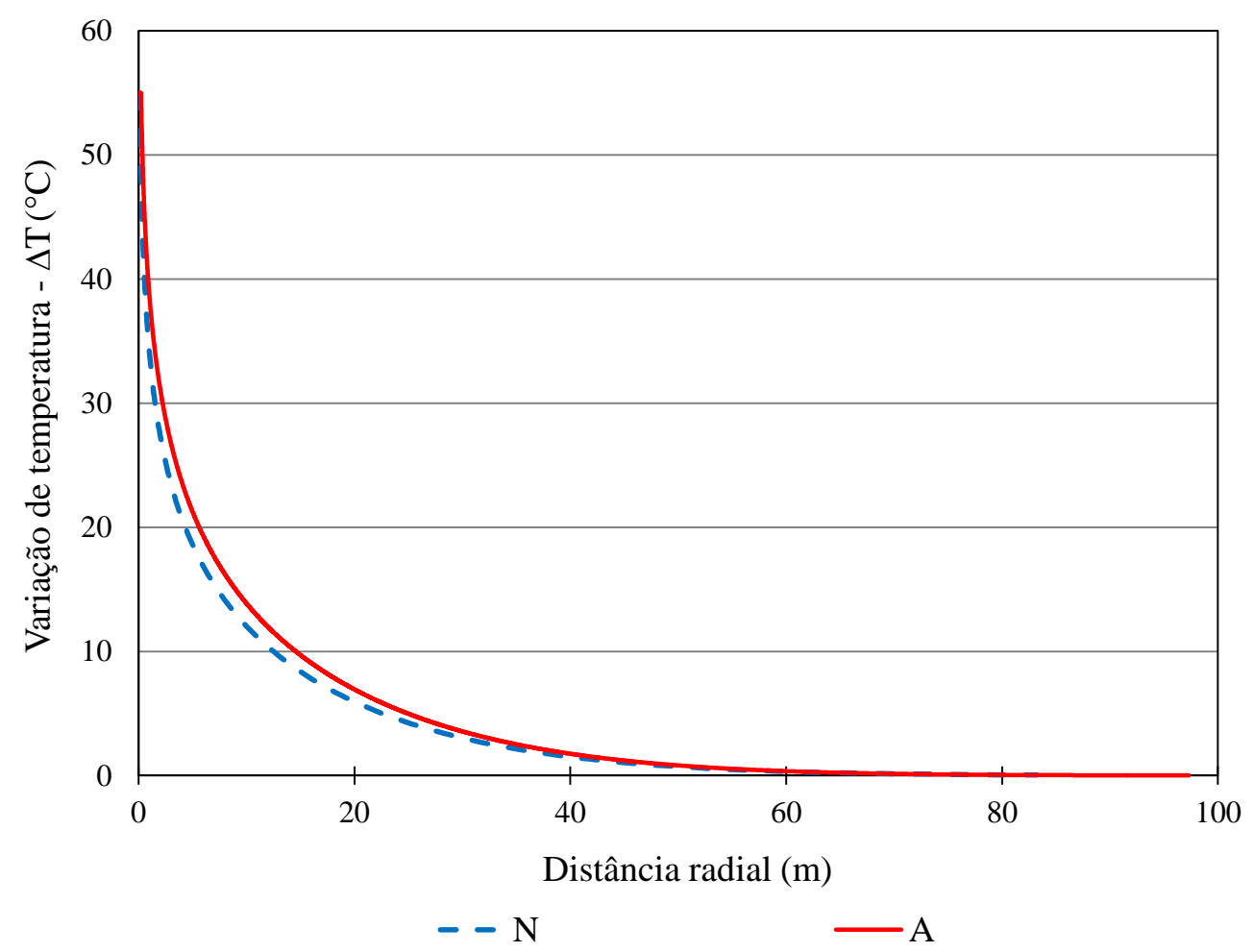

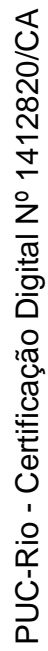

Figura 5.27 - Perfil de variação de temperatura no poço, ao longo do raio, com variação de temperatura de $55^{\circ} \mathrm{C}$ na parede do revestimento após 20 anos.

A Figura 5.28 apresenta o mesmo perfil de temperatura após 20 anos de simulação, porém no revestimento e no cimento.

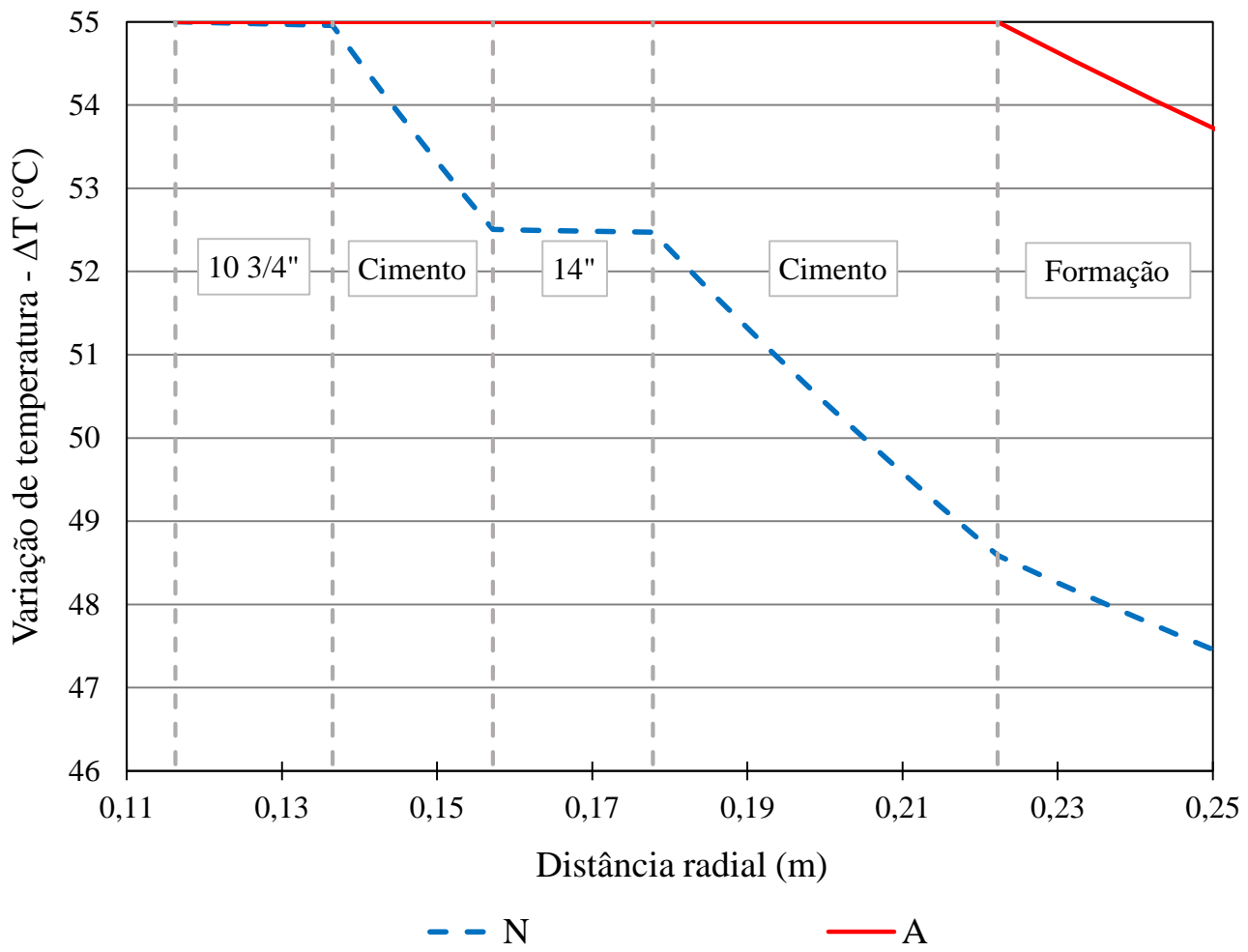

Figura 5.28 - Perfil de variação de temperatura no revestimento e no cimento, com variação de temperatura de $55^{\circ} \mathrm{C}$ na parede do revestimento após 20 anos. 
Na solução analítica, a variação de temperatura é avaliada sendo constante nos revestimentos e nos cimentos, no valor de $55^{\circ} \mathrm{C}$. Na parede da rocha é aplicada $55^{\circ} \mathrm{C}$ de variação de temperatura e a análise é feita de forma transiente. Por outro lado, na modelagem numérica, a variação de temperatura é aplicada na superfície interna do revestimento e então toda a análise térmica é feita em regime transiente. Devido a isso, há uma diferença de $\sim 12 \%$ entre o perfil de temperatura calculado através do modelo numérico e o calculado pelo analítico na parede da formação.

A Figura 5.29 apresenta a tensão radial durante a produção considerando a influência da variação da temperatura nos materiais. Dois cenários são simulados, o primeiro sem o efeito térmico e o segundo com $55^{\circ} \mathrm{C}$ de variação de temperatura. A Figura 5.30 apresenta a tensão radial para os revestimentos e os cimentos.

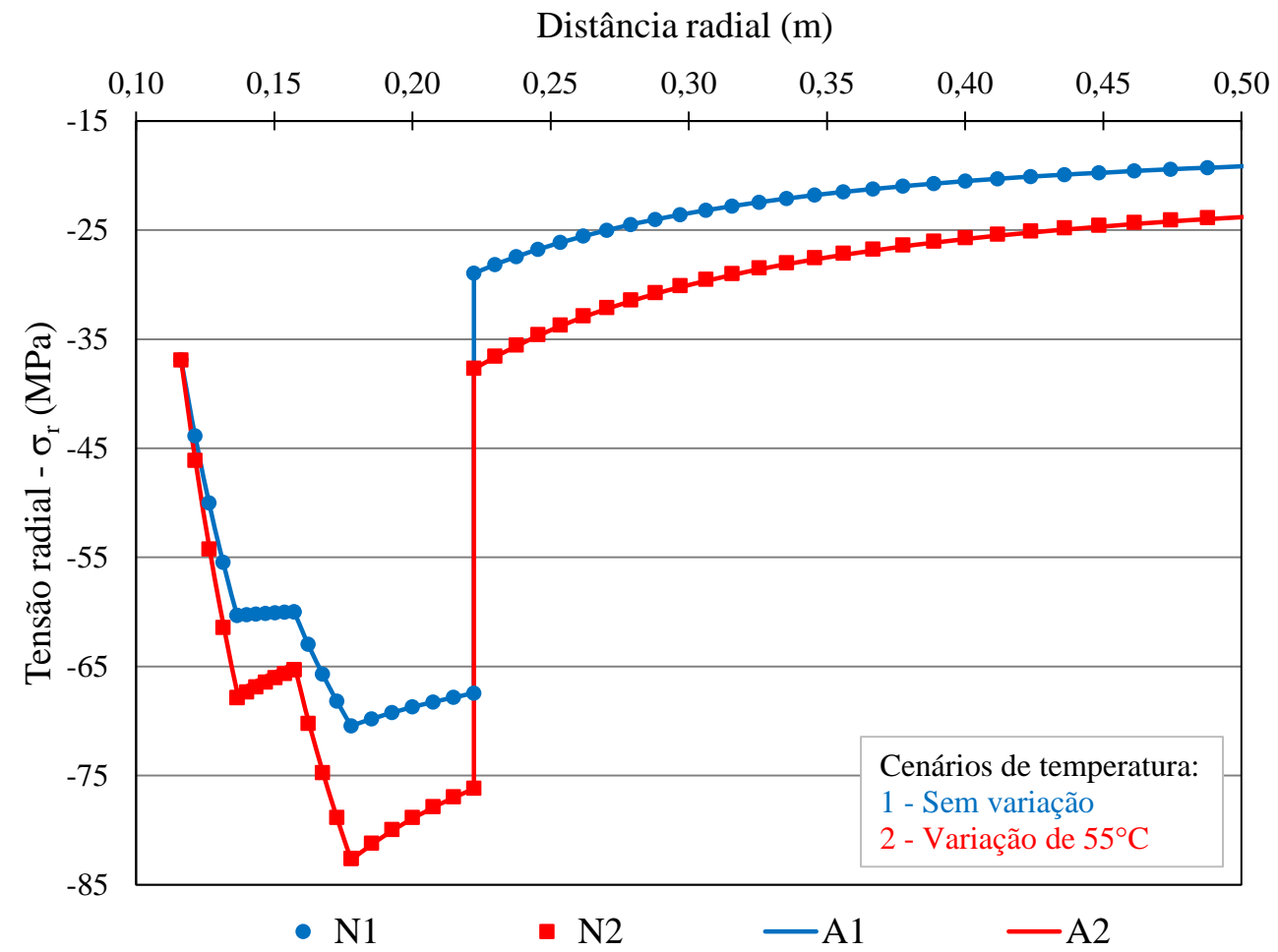

Figura 5.29 - Tensão radial no poço ao longo do raio ao final da análise em poço com dois revestimentos. 
Distância radial (m)

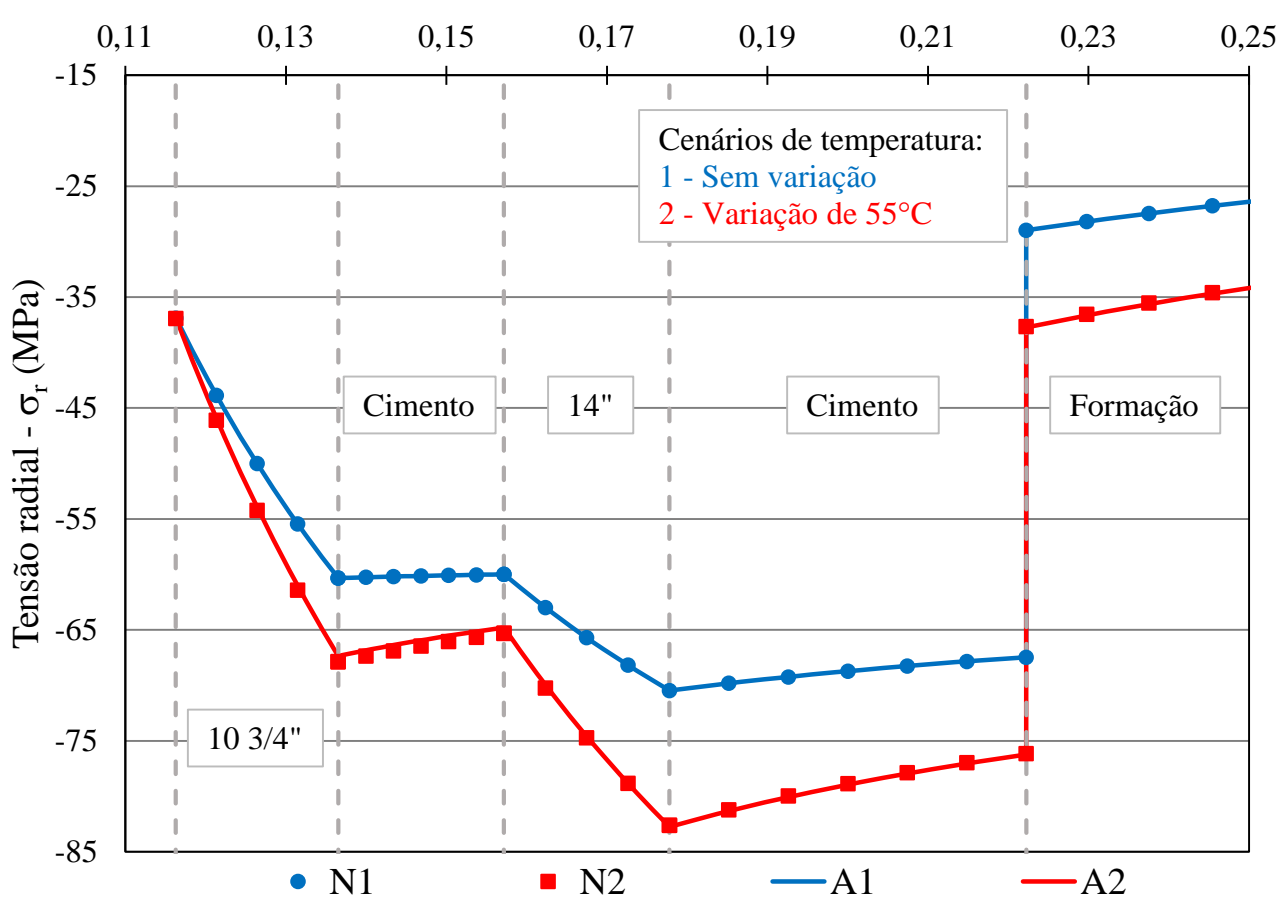

Figura 5.30 - Tensão radial ao longo das espessuras dos revestimentos de 14" e de 10 3/4", e dos cimentos após 20 anos de análise.

Considerando o efeito térmico, as tensões radiais apresentam um cenário mais crítico do que sem a variação da temperatura. Observa-se que o comportamento das tensões está de acordo com o apresentado nos outros cenários, onde na superfície interna do revestimento de 10 3/4", a tensão radial possui o mesmo valor da pressão devido ao fluido de produção, de $-36,87 \mathrm{MPa}$. Nota-se também que há uma descontinuidade nas tensões radiais na interface entre o cimento e a formação. Esse salto na tensão radial na interface cimento-rocha ocorre devido à poropressão inicial da formação, que possui o valor de aproximadamente 38,5 MPa.

Para a componente de tensão tangencial, a Figura 5.31 mostra o resultado ao longo do raio do poço. Os cenários sem variação de temperatura e com variação térmica são avaliados. A Figura 5.32 apresenta a componente de tensão tangencial para o revestimento e o cimento, após 20 anos de análise. 


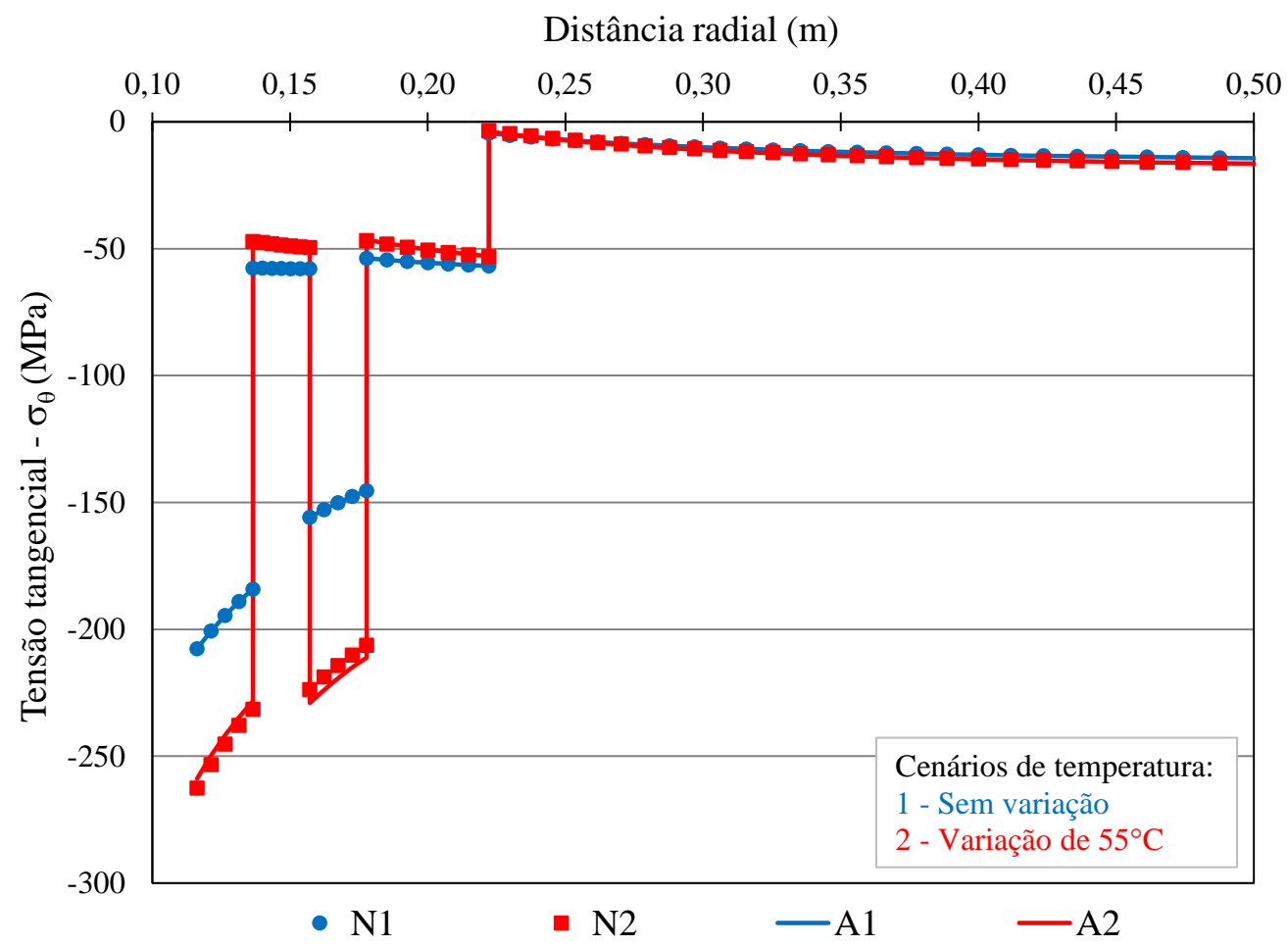

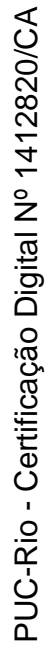

Figura 5.31 - Tensão tangencial no poço ao longo do raio após o final da análise em poço com dois revestimentos.

Distância radial (m)

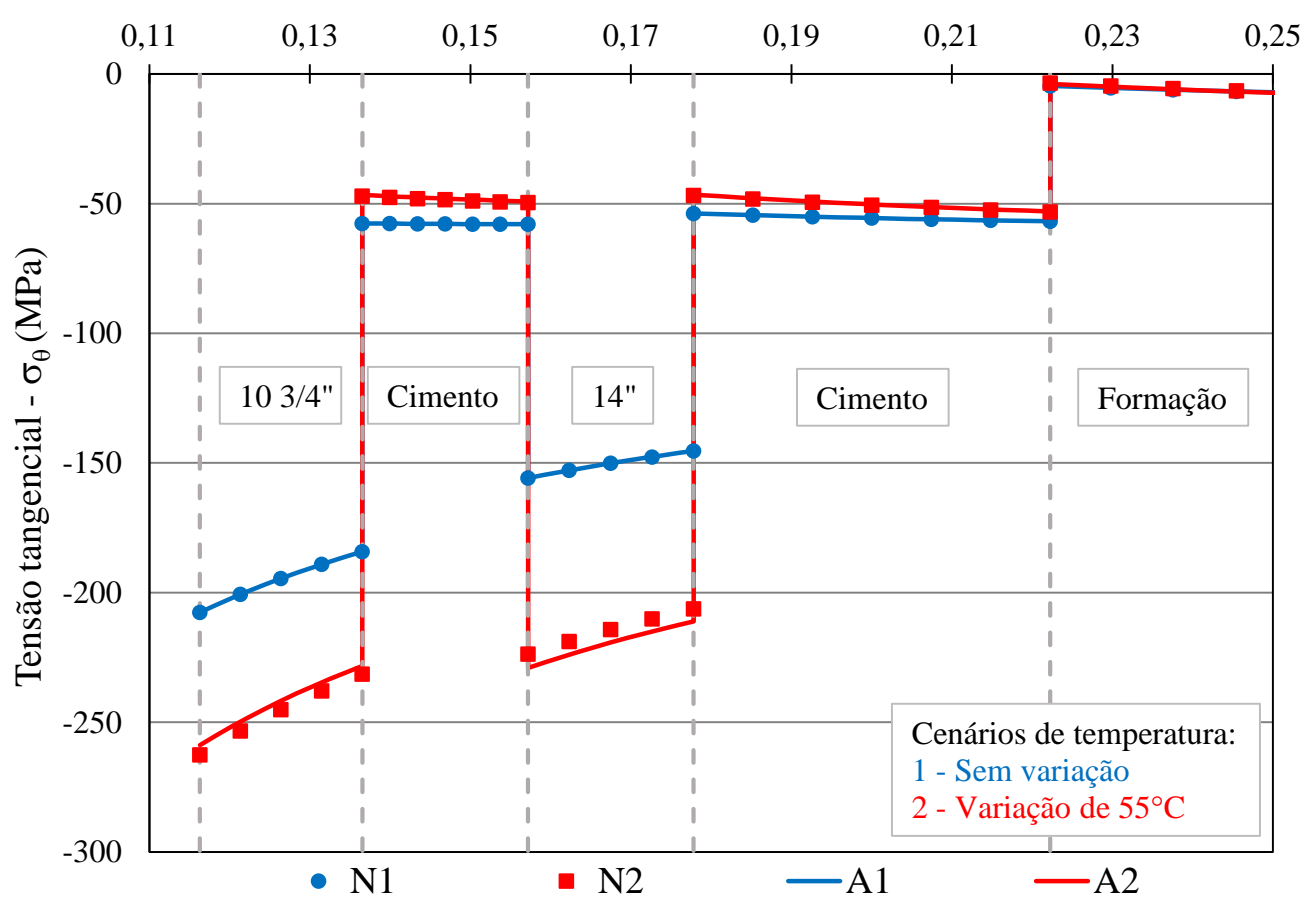

Figura 5.32 - Tensão tangencial nos revestimentos de 14" e de 10 3/4", e nos cimentos após 20 anos de análise. 
Analisando os resultados de tensão tangencial nos revestimentos de 10 3/4" e 14", é possível observar que o cálculo analítico apresenta uma pequena diferença quando comparado com o numérico. Isso ocorre por causa da diferença entre os perfis de temperatura atuando nos modelos após 20 anos, uma vez que as hipóteses adotadas nas soluções numérica e analítica são diferentes. Essa diferença no revestimento é mais acentuada devido ao coeficiente de dilatação térmica do aço, que é muito superior ao do cimento, tornando assim os revestimentos mais sensíveis à variação de temperatura.

O índice de plastificação no revestimento e no cimento é apresentado na Figura 5.33, comparando dois cenários: não levando em conta a temperatura e considerando o efeito térmico.

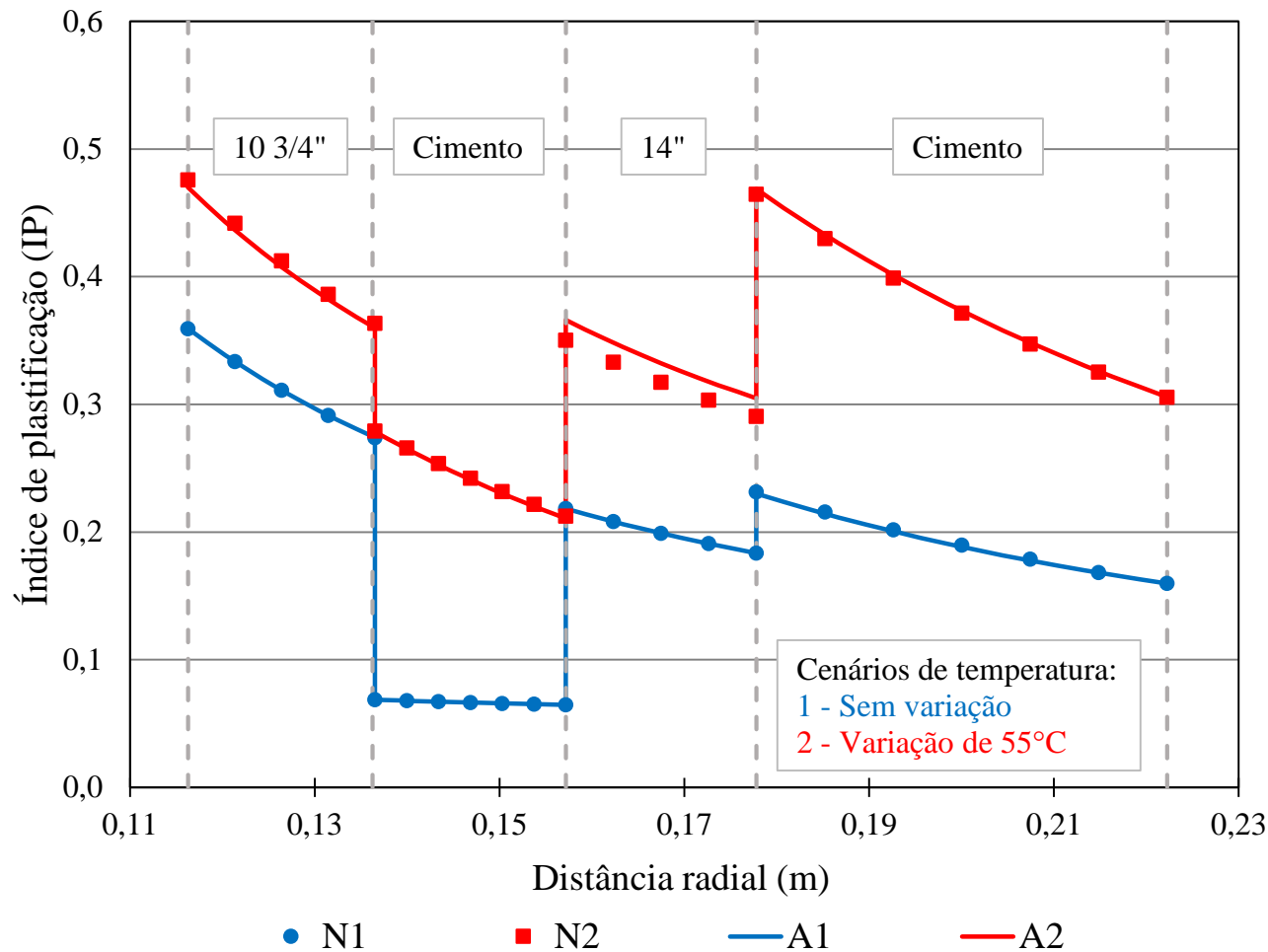

Figura 5.33 - Índice de plastificação ao longo das espessuras dos revestimentos de 14" e de 10 3/4", e dos cimentos após 20 anos de análise.

O IP no revestimento interno é de aproximadamente 0,36 para o cenário 1 , e de 0,47 para o cenário 2 . Observa-se ainda que o IP calculado através da solução analítica possui valores muito próximos aos valores calculados pelos modelos numéricos. Atenta-se que no revestimento de 14" a diferença entre as soluções numérica e analítica se torna mais acentuada, refletindo a diferença entre as soluções da componente de tensão tangencial (Figura 5.32). Essa diferença ocorre 
por causa das hipóteses adotadas em cada uma das soluções. No modelo analítico, a temperatura nos revestimentos e nos cimentos possui o mesmo valor, de $55^{\circ} \mathrm{C}$. No entanto, na solução numérica, a variação da temperatura na superfície interna do revestimento interno é de $55^{\circ} \mathrm{C}$, porém, ao longo do raio, esse valor vai diminuindo, e consequentemente, a tensão devida ao efeito térmico é diferente da tensão calculada através do modelo analítico. Em ambos os cenários simulados, os pontos internos dos revestimentos são os pontos críticos, onde o $I P$ atinge os maiores valores.

\subsubsection{2.}

\section{Produção (com solução mais abrangente para gradientes térmicos)}

Conforme visto na seção anterior, há uma diferença nos valores das tensões encontradas através das soluções analítica e numérica. Dessa forma, esta seção apresenta o cálculo das tensões utilizando uma abordagem mais abrangente para o gradiente de temperatura dos revestimentos e cimentos, conforme explicado na seção 3.4.3.1. Ao invés de adotar uma temperatura imposta e de mesmo valor para os revestimentos e cimentos, essa opção calcula uma temperatura constante, porém diferente, para cada um dos materiais a partir do valor da temperatura definida no interior do poço, $T_{0}$. A Figura 5.34 apresenta o perfil de temperatura para a rocha após 20 anos, enquanto o perfil de temperatura nos revestimentos e cimentos é mostrado na Figura 5.35. A curva $N$ representa a resposta do modelo numérico e a $A$ a resposta do analítico. 


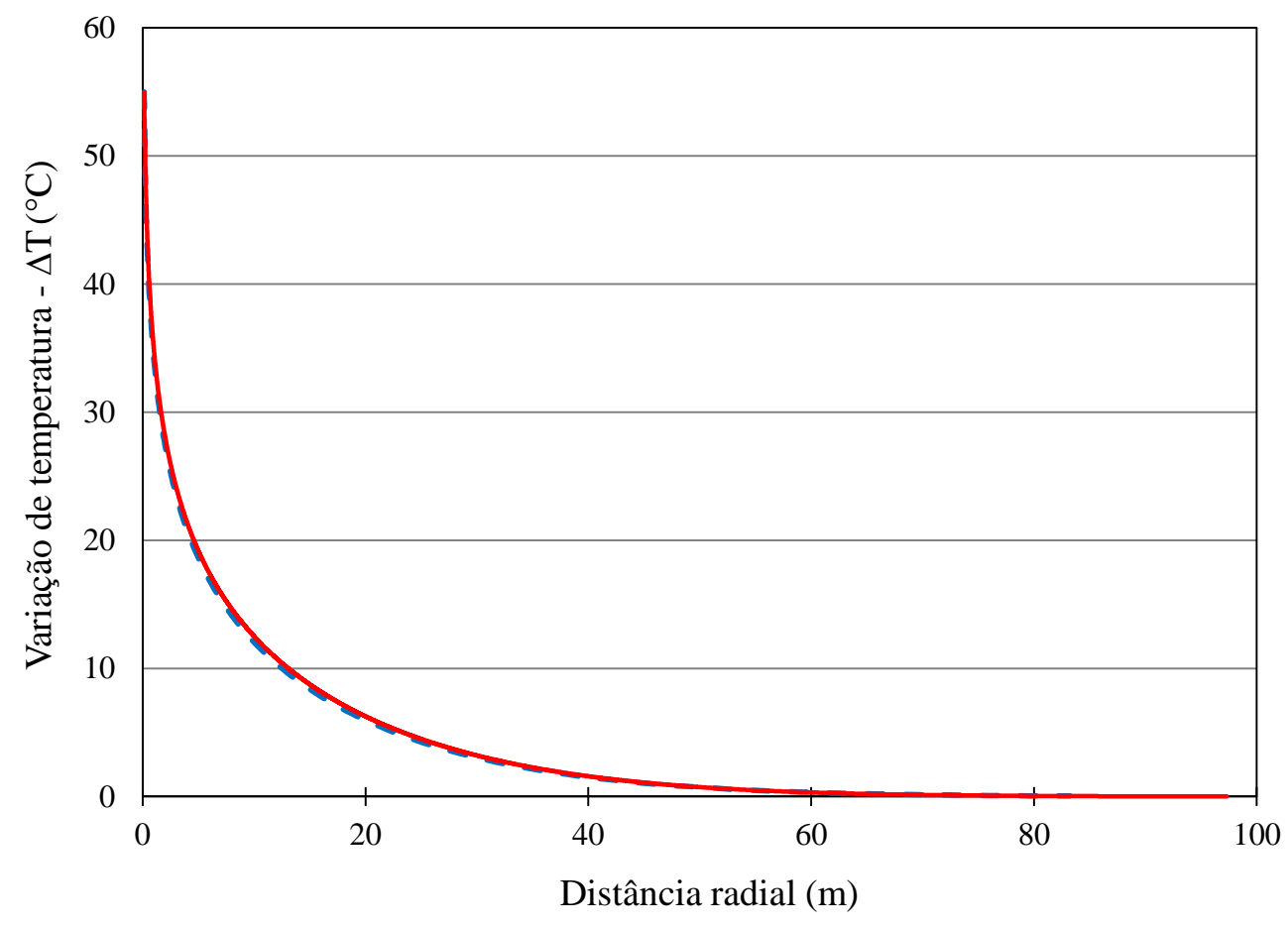

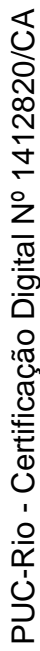
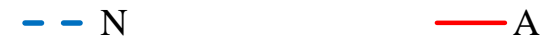

Figura 5.34 - Perfil de temperatura ao longo do modelo após 20 anos de simulação.

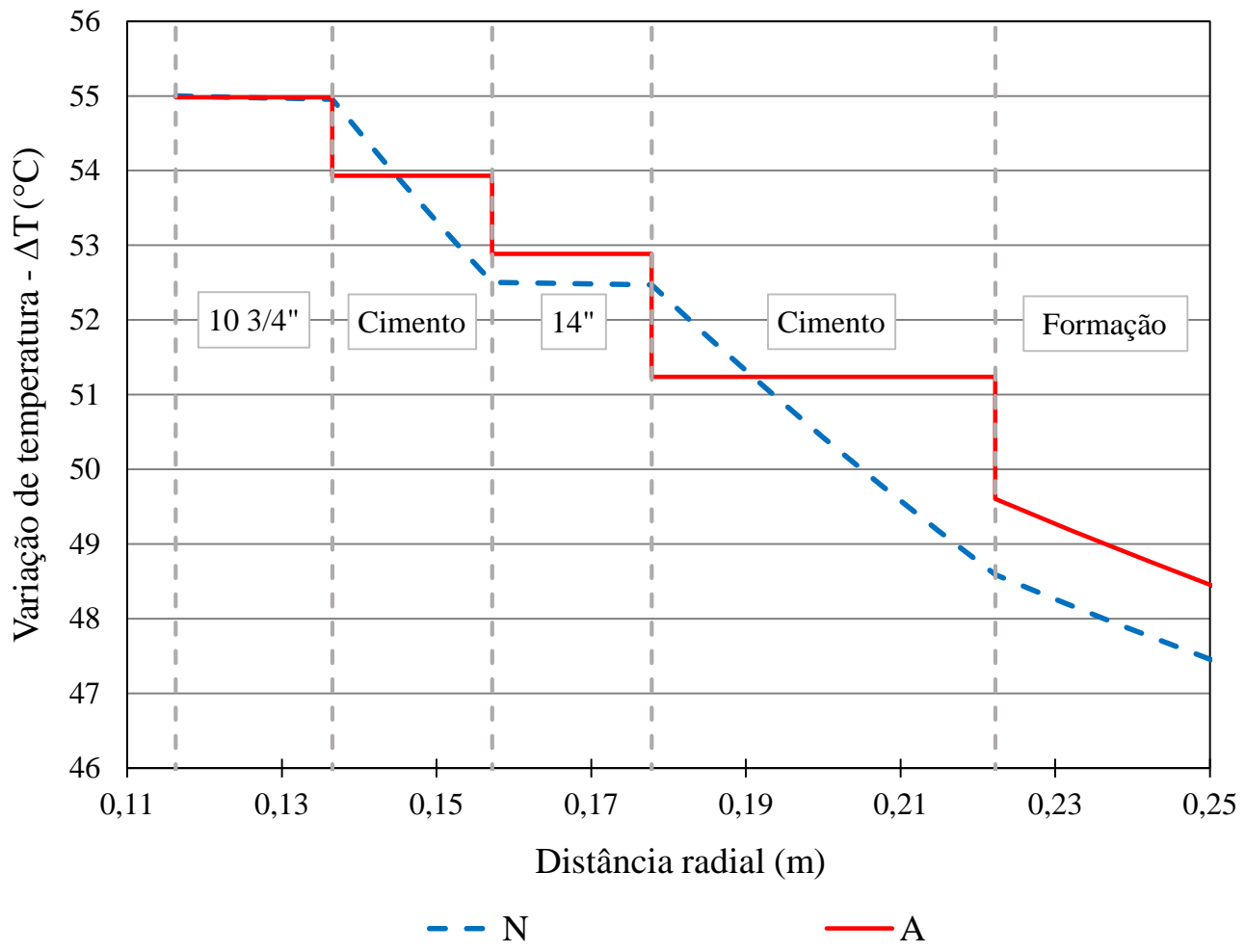

Figura 5.35 - Perfil de temperatura nos revestimentos de 14" e de 10 3/4", e nos cimentos após 20 anos de análise. 
O índice de plastificação ao longo da espessura dos revestimentos e dos cimentos é apresentado na Figura 5.36.

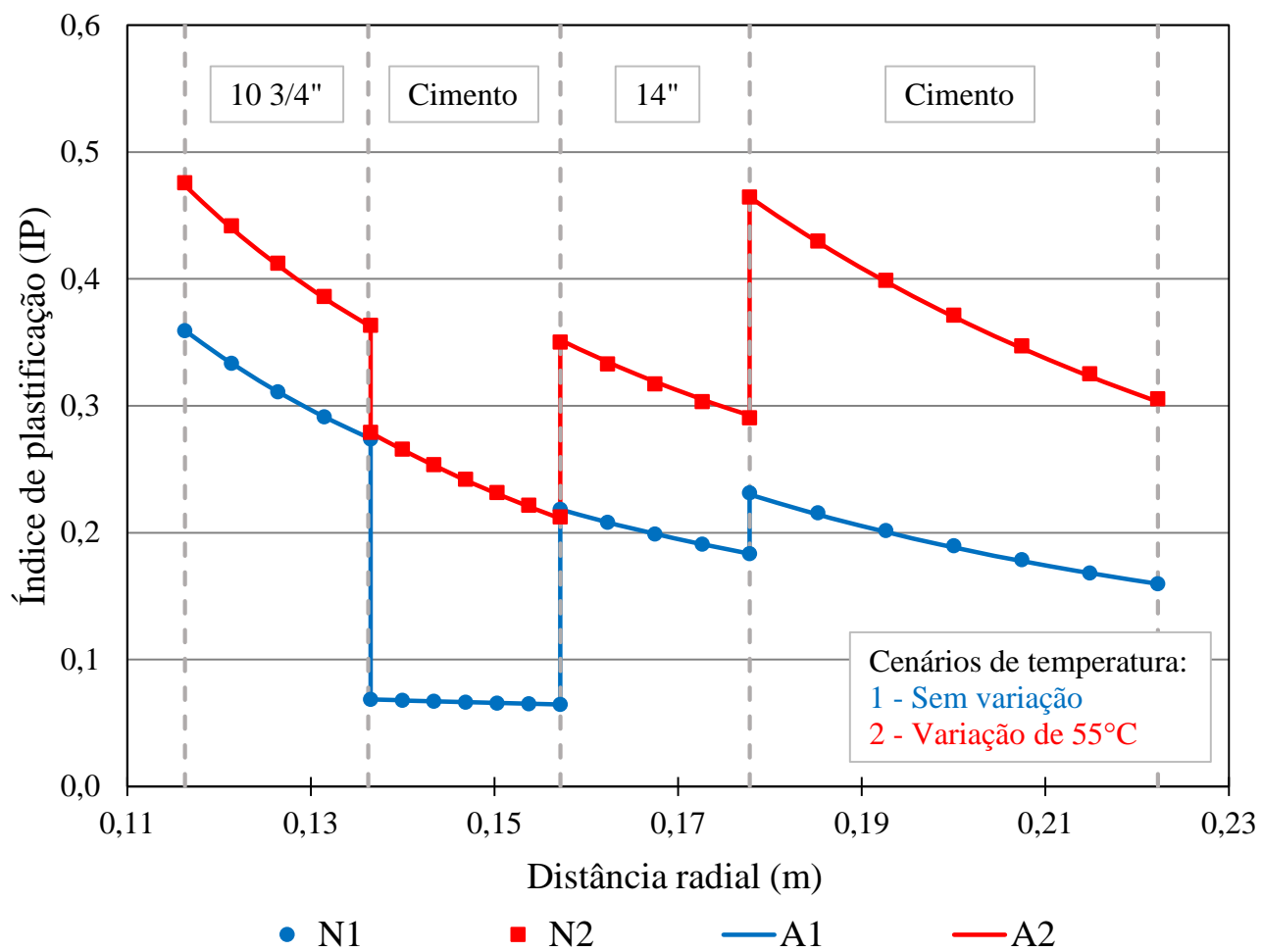

Figura 5.36 - Índice de plastificação nos revestimentos de 14” e 10 3/4”, e cimentos após 20 anos de simulação.

Observa-se que a diferença entre os valores do índice de plastificação obtidos através da solução analítica e da modelagem numérica diminuiu, atingindo um erro de aproximadamente $0,8 \%$. Essa diferença é causada pela hipótese adotada na solução analítica, de que a variação da temperatura nos revestimentos e cimentos é constante ao longo da espessura de cada material. Essa hipótese gera resultados mais próximos aos obtidos pela solução numérica, apesar de não tornar a formulação mais complexa. Nota-se que os valores de IP calculados através da solução analítica se aproximam dos valores obtidos pela simulação numérica. Dessa forma, a solução térmica mais abrangente apresenta um resultado mais satisfatório, aproximando-se da solução por elementos finitos. 


\section{6 Considerações finais}

A seguir são apresentadas as conclusões finais e as sugestões para posteriores trabalhos, com o propósito de ajudar no desenvolvimento científico do tema estudado e fornecer ideias que possam servir de base para futuras pesquisas.

\section{1.}

\section{Conclusões}

São apresentados dois estudos de caso, um representando um poço no Mar do Norte e outro estudo representando um poço na Bacia de Santos, Brasil. São simulados diversos cenários com variações de temperatura na superfície interna do revestimento e de variação de poropressão da rocha, através das soluções analítica e numérica. Analisando esses estudos, é possível notar que os resultados obtidos através da solução analítica e do modelo numérico são iguais para todos os cenários simulados. Esta conclusão é válida ainda para o caso em que são utilizados dois revestimentos. Nesse caso, a variação da temperatura faz com que os resultados das duas soluções não sejam idênticos, uma vez que a solução analítica tem como hipótese temperatura constante ao longo dos revestimentos e dos cimentos. $\mathrm{Na}$ simulação numérica, a variação da temperatura na superfície interna do revestimento é prescrita, calculando em regime transiente o valor da variação da temperatura ao longo do raio do modelo. No entanto, na solução analítica, a variação da temperatura prescrita é aplicada nos revestimentos, nos cimentos e na parede da rocha, calculando em seguida o valor dessa variação na rocha em regime transiente.

Uma abordagem mais abrangente é proposta para o cálculo das tensões devido ao efeito térmico. Nessa abordagem, são calculadas as temperaturas em todas as superfícies dos materiais, e então uma variação de temperatura média é aplicada em cada material. Assim, o resultado da solução analítica se aproxima do resultado da simulação numérica, tornando-se mais satisfatória. Deve-se ressaltar que as soluções analítica e numérica são desenvolvidas a partir das mesmas hipóteses. Para que a metodologia utilizada seja realmente validada, uma 
comparação com resultados obtidos na prática traria maior confiabilidade, porém essas informações são de difícil acesso na literatura.

A importância de se desenvolver uma solução analítica para o cálculo das tensões ao redor do poço, dá-se pela facilidade de obtenção de resultados. Dessa forma, essas soluções servem como um pré-dimensionamento do revestimento do poço, e para a análise de integridade e estabilidade de poços convencionais. Além disso, cálculos analíticos ajudam na avaliação da influência dos parâmetros e facilitam o entendimento da contribuição de cada fase no estado de tensão final do poço. Como exemplo, os gráficos apresentados neste trabalho, em que o índice de plastificação $(I P)$ do revestimento é avaliado em função da variação da poropressão da rocha, são gerados utilizando o resultado da solução analítica, com o IP expresso em função da variável correspondente à variação da poropressão, $P P$. Por último, a solução desenvolvida pode ser facilmente utilizada em estudos probabilísticos em que parâmetros geométricos são utilizados como variável aleatória, sem a necessidade de gerar centenas ou milhares de modelos, como no caso da solução em elementos finitos.

A metodologia apresentada neste trabalho é utilizada na formulação analítica e na modelagem numérica, e é uma representação mais realista dos processos de perfuração e construção do poço e da produção de hidrocarboneto. Essa metodologia consiste em simular a descida do revestimento em etapa anterior à cimentação, e é comparada à metodologia em que o revestimento e o cimento são adicionados simultaneamente. No caso simulado, o índice de plastificação no revestimento apresenta um cenário mais crítico na metodologia adotada neste trabalho em comparação com a metodologia em que o revestimento e o cimento são adicionados no modelo simultaneamente.

Ao avaliar o índice de plastificação nos revestimentos dos modelos analisados, nota-se que os revestimentos utilizados nos dois estudos de caso (baseados em informações do Mar do Norte e da Bacia de Santos) não atingem a plastificação. No estudo feito na Bacia de Santos, Brasil, outra simulação é feita considerando uma profundidade mais rasa, onde um segundo revestimento é inserido no modelo. Percebe-se que os valores das componentes de tensão radial e tangencial são superiores para o caso do Brasil (com variação de poropressão e um revestimento) tanto para o revestimento quanto para o cimento, quando comparados com os valores do Mar do Norte (com variação de temperatura). Essa diferença 
ocorre principalmente por causa dos diferentes valores de pressões, variação de temperatura e variação de poropressão adotado em cada modelo.

Em relação ao efeito térmico, é possível concluir que há uma influência considerável da variação da temperatura nas tensões finais do revestimento, do cimento e da rocha. Essa influência é notada em todos os casos estudados neste trabalho em que a temperatura é considerada. Por fim, ao avaliar a influência da variação da poropressão da rocha no estado de tensão final do poço, conclui-se que para os casos apresentados neste trabalho as tensões finais são mais críticas no caso de injeção. Quando a depleção é considerada, observa-se que as tensões se tornam menos críticas, quando comparadas aos cenários sem variação de poropressão e de injeção. Essa influência do efeito mecânico da variação da poropressão nas tensões finais é visível no caso do campo da Bacia de Santos, considerando um revestimento.

Conclui-se que a solução analítica apresentada é uma boa ferramenta para a análise de tensões em poços convencionais e sob carregamentos uniformes. Por outro lado, caso seja necessário avaliar um poço com falhas na cimentação ou na rocha, e com carregamentos não uniformes, a solução numérica deve ser adotada. Além disso, a metodologia utilizada e a consideração dos efeitos térmicos e dos efeitos mecânicos da variação da poropressão representam um cenário mais realista, sendo mais crítico para a avaliação do estado de tensão final do poço no estudo de caso avaliado.

\section{2.}

\section{Sugestões para trabalhos futuros}

Neste trabalho, todos os materiais utilizados nas simulações são considerados linear elásticos. Adicionar modelos constitutivos plásticos para avaliar o estado de tensão final do poço, considerando todas as fases de construção presentes nesta metodologia, agregaria mais realidade ao comportamento da estrutura.

Em todos os cenários modelados neste trabalho a rocha é considerada elástica, porém, muitas vezes, deve-se simular o comportamento de fluência da rocha, como no caso de rochas salinas. Adicionar modelos constitutivos como o de Duplo Mecanismo na simulação dos poços pode tornar a solução analítica mais completa.

Com a solução analítica desenvolvida neste trabalho pode-se realizar estudos de sensibilidade e probabilísticos. Dessa forma, a geometria do problema pode ser 
alterada facilmente e as propriedades geométricas podem ser consideradas variáveis aleatórias, sem a necessidade de realizar diversos modelos.

A solução analítica é comparada com a modelagem numérica por elementos finitos, através do programa ABAQUS ${ }^{\circledR}$.

A temperatura adotada nos revestimentos e cimentos foi constante, analisada em regime permanente. No caso de poços com múltiplos revestimentos, essa hipótese pode distorcer os resultados. Assim, pode-se adicionar uma solução que adote o regime transiente para a temperatura no revestimento e no cimento. 


\section{Referências bibliográficas}

AL-SHAYEA, N. A. Effects of testing methods and conditions on the elastic properties of limestone rock. Engineering Geology, v. 74, p. 139-156, 2004.

ALVES, I. et al. Pre-salt Santos Basin - Well construction learning curve acceleration. Offshore Technology Conference. Houston: [s.n.]. 2009. p. 12.

ATKINSON, C.; EFTAXIOPOULOS, D. A. A plane model for the stress field around an inclined, cased and cemented wellbore. International Journal for Numerical and Analytical Methods in Geomechanics, 20, 1996. 549-569.

ATKINSON, C.; EFTAXIOPOULOS, D. A. Numerical and analytical solutions for the problem of hydraulic fracturing from a cased and cemented wellbore. International Journal of Solids and Structures , v. 39, p. 1621-1650, 2002.

BERGER, A. et al. Effect of eccentricity, voids, cement channels, and pore pressure decline on collapse resistance of casing. Annual Technical Conference and Exhibition. Houston: Society of Petroleum Engineers Inc. (SPE). 2004. p. 8.

BOSMA, M. et al. Design approach to sealant selection for the life of the well. Annual Technical Conference and Exihibition. Houston: Society of Petroleum Engineers Inc. 1999. p. 14.

BOWMAN, F. Introduction to Bessel Functions. New York: Dover Publications, 1958.

BRANDÃO, N. B. Modelagem da evolução das propriedades mecânicas da pasta de cimento em poços do pré-sal. Rio de Janeiro: Dissertação de Mestrado Departamento de Engenharia Civil - Pontifícia Universidade Católica do Rio de Janeiro (PUC Rio), 2016.

CARRIZO, H.; ORTUÑO, G.; NETO, T. D. Case history: Performance of a drilling campaign in the Santos Basin, Brazil, 2008-2010: A success story. Offshore Technology Conference. Rio de Janeiro: [s.n.]. 2011. p. 8.

CHEN, G.; EWY, R. T. Thermoporoelastic effect on wellbore stability. SPE Journal, p. 121-129, March 2005.

CHEN, Y. et al. Hidden impact of mud loss on wellbore state of stresses disclosed by thermal-poro-elastic modeling. 49th US Rock Mechanics / Geomechanics Symposium. San Francisco: American Rock Mechanics Association (ARMA). 2015. p. 11. 
COOKE JR., C. E.; KLUCK, M. P.; MEDRANO, R. Field measurements of annular pressure and temperature during primary cementing. Journal of Petroleum Technology, p. 1429-1438, 1983.

COSTA, A. M. et al. Triaxial creep tests in salt applied in drilling through thick salt layers in Campos Basin - Brazil. SPE/IADC Drilling Conference. Amsterdam: [s.n.]. 2005. p. 9.

COSTA, A. M. et al. Geomechanics applied to the well design through salt layers in Brazil: A History of success. 44th US Rock Mechanics Symposium and 5th U.S.-Canada Rock Mechanics Symposium. Salt Lake City: American Rock Mechanics Association (ARMA). 2010. p. 13.

COSTA, A. M. et al. Sensitivity study of the finite element modeling applied in the closure analysis of the pre-salt wells in Brazil. Mechanical Behaviour of Salt VIII. [S.1.]: CRC Press 2015. 2015. p. 425-432.

DE MELO, D. D. E. F. et al. Effects of mud compressibility on wellbore closure and annular pressure based on FEM with the incorporation of fluid elements. XXXVI Ibero-Latin American Congress on Computational Methods in Engineering. Rio de Janeiro: CILAMCE 2015. 2015. p. 9.

DE SIMONE, M.; BRANDÃO, N. B.; ROEHL, D. Modelagem numérica de poços de petróleo em zonas de sal com avaliação de efeitos térmicos na fluência. XXXVI Ibero-Latin American Congress on Computational Methods in Engineering. Rio de Janeiro: CILAMCE 2015. 2015. p. 12.

DE SIMONE, M.; PEREIRA, F. L. G.; ROEHL, D. M. Analytical methodology for the wellbore integrity assessment considering the casing-cement-formation interaction (submetido). International Journal of Rock Mechanics and Mining Sciences, p. 16, 2016.

FIRME, P. A. L. P. Modelagem constitutiva e análise probabilística aplicadas a poços em zonas de sal. Rio de Janeiro: Dissertação de Mestrado - Departamento de Engenharia Civil - Pontifícia Universidade Católica do Rio de Janeiro (PUC Rio), 2013.

FIRME, P. A. L. P. et al. Creep constitutive modeling applied to the stability of pre-salt wellbores through salt layers. 48th US Rock Mechanics / Geomechanics Symposium. Minneapolis: American Rock Mechanics Association (ARMA). 2014. p. 10.

FIRME, P. A. L. P. et al. Casing integrity of a typical pre-salt wellbore under local salt dissolution conditions. 13th International Congress of Rock Mechanics. Montreal: ISRM13. 2015. p. 13.

FITZGERALD, B. L.; MCCOURT, A. J.; BRANGETTO, M. Drilling fluid plays key role in developing the extreme HTHP, Elgin/Franklin Field. Drilling Conference. New Orleans: IADC/SPE. 2000. p. 12. 
FJAER, E. et al. Petroleum related rock mechanics. 2nd Edition. ed. [S.1.]: Elsevier, v. 53, 2008.

FLECKENSTEIN, W. W. et al. Cemented casing: The true stress picture. National Technical Conference and Exhibition. Houston: [s.n.]. 2005. p. 8.

FLECKENSTEIN, W. W.; EUSTES, A. W.; MILLER, M. G. Burst induced stresses in cemented wellbores. SPE/AAPG Western Regional Meeting. Long Beach: Society of Petroleum Engineers Inc. (SPE). 2000. p. 16.

FOSSUM, A. F.; FREDRICH, J. T. Probabilistic analysis of borehole closure for through-salt well design. Acta Geotechnica, v. 2, p. 41-51, 2007.

GRAY, K. E.; PODNOS, E.; BECKER, E. Finite element studies of nearwellbore region during cementing operations: Part I. Production and Operations Symposium. Oklahoma City: Society of Petroleum Engineers (SPE). 2007. p. 15.

HEATHMAN, J.; BECK, F. E. Finite element analysis couples casing and cement designs for HP/HT wells in East Texas. IADC/SPE Drilling Conference. Miami: Drilling Conference (SPE). 2006. p. 23.

HENDERSON, D.; HAINSWORTH, D. Elgin G4 gas release: What happened and the lessons to prevent recurrence. International Conference on Health, Safety, and Environment. Long Beach: Society of Petroleum Engineers (SPE). 2014. p. 13.

HUANG, X. et al. Collapse strength analysis of casing design using finite element method. International Journal of Pressure Vessels and Piping, v. 77, p. 359-367, Junho 2000.

JANDHYALA, S. et al. Cement sheath integrity in fast creeping salts: Effect of well operations. Offshore Europe Oil and Gas Conference and Exhibition. Aberdeen: Society of Petroleum Engineers (SPE). 2013. p. 10.

JO, H.; GRAY, K. E. Mechanical behavior of concentric casing, cement, and formation using analytical and numerical methods. 44th US Rock Mechanics Symposium and 5th U.S.-Canada Rock Mechanics Symposium. Salt Lake City: American Rock Mechanics Association (ARMA). 2010. p. 13.

KALDAL, G. S.; JÓNSSON, M.; KARLSDÓTTIR, S. N. Structural analysis of casings in high temperature geothermal wells in Iceland. Proceedings World Geothermal Congress 2015. Melbourne: [s.n.]. 2015. p. 11.

LAO, K.; BRUNO, M. S.; SERAJIAN, V. Analysis of salt creep and well casing damage in high pressure and high temperature environments. Offshore Technology Conference. Houston: [s.n.]. 2012. p. 11.

LAVROV, A.; TODOROVIC, J.; TORSAETER, M. Numerical study of tensile thermal stresses in a casing-cement-rock system with heterogeneities. 49th US Rock Mechanics / Geomechanics Symposium. San Francisco: American Rock Mechanics Association (ARMA). 2015. p. 9. 
LOMBA, R. F. T. et al. Lessons learned in drilling pre-salt wells with water based muds. Offshore Technology Conference. Rio de Janeiro: [s.n.]. 2013. p. 11.

LOMBA, R. F. T. et al. Use of salt dissolution software to evaluate drilling strategies of massive salt layers. Offshore Technology Conference. Rio de Janeiro: [s.n.]. 2013. p. 10.

MACKAY, F. E. Análise geomecânica na perfuração e cimentação de poços de petróleo em zonas de sal. Rio de Janeiro: Tese de Doutorado - Departamento de Engenharia Civil - Pontifícia Universidade Católica do Rio de Janeiro (PUC Rio), 2011.

MACKAY, F. et al. Analysing geomechanical effects while drilling sub salt wells through numerical modeling. Inidian Oil and Gas Technical Conference and Exhibition. Mumbai: Society of Petroleum Engineers (SPE). 2008. p. 12.

MACKAY, F.; FONTOURA, S. A. B. The description of a process for numerical simulations in the casing cementing of petroleum salt wells - Part I: from drilling to cementing. 48th US Rock Mechanics / Geomechanics Symposium. Minneapolis: American Rock Mechanics Association (ARMA). 2014. p. 9.

MACKAY, F.; INOUE, N.; FONTOURA, S. A. B. Geomechanical effects of a 3D vertical salt well drilling by FEA. 42nd US Rock Mechanics Symposium and 2nd U.S.-Canada Rock Mechanics Symposium. San Francisco: American Rock Mechanics Association (ARMA). 2008. p. 10.

MARTINS, A. L. et al. Tools for predicting and avoiding gas migration after casing cementing in Brazilian fields. SPE International. Rio de Janeiro: Society of Petroleum Engineers. 1997. p. 8.

MENDES, R. B. et al. Analytical solution for transient temperature field around a cased and cemented wellbore. Latin American and Caribbean Petroleum Engineering Conference. Rio de Janeiro: Society of Petroleum Engineers. 2005. p. 4.

MONGELLI, F.; LODDO, M.; TRAMACERE, A. Thermal conductivity, difusivity and specific heat variation of some travale field (Tuscany) rocks versus temperature. Tectonophysics, Amsterdam, v. 83, p. 33-43, 1982.

MUELLER, D. T. et al. Characterizing casing-cement-formation interactions under stress conditions: impact on long-term zonal isolation. Annual Technical Conference and Exhibition. Houston: Society of Petroleum Engineers. 2004. p. 7.

NABIPOUR, A.; JOODI, B.; SARMADIVALEH, M. Finite element simulation of downhole stresses in deep gas wells cements. Deep Gas Conference and Exhibition. Bahrain: Society of Petroleum Engineers (SPE). 2010. p. 13.

OSTROWSKI, P.; MICHALAK, B. Non-stationary heat transfer in a hollow cylinder with functionally graded material properties. Journal of Theoretical and Applied Mechanics, Warsaw, v. 49, p. 385-397, 2011. 
OYARHOSSEIN, M.; DUSSEAULT, M. B. Wellbore stress changes and microannulus development because of cement shrinkage. 49th US Rock Mechanics / Geomechanics Symposium. San Francisco: American Rock Mechanics Association (ARMA). 2015. p. 7.

PALCHIK, V.; HATZOR, Y. H. Crack damage stress as a composite function of porosity and elastic matrix stiffness in dolomites and limestones. Engineering Geology, v. 63, p. 233-245, 2002.

PLUCENIO, D. et al. Modelagem numérica de perfuração em formações salinas com fluido a base de água. $V$ Encontro Nacional de Hidráulica de Poços de Petróleo e Gás. Teresópolis: [s.n.]. 2013. p. 9.

POIATE JR., E. Mecânica das rochas e mecânica computacional para projeto de poços de petróleo em zonas de sal. Rio de Janeiro: Tese de Doutorado Departamento de Engenharia Civil - Pontifícia Universidade Católica do Rio de Janeiro (PUC Rio), 2012.

POIATE JR., E.; COSTA, A. M.; FALCAO, J. L. Well design for drilling through thick evaporite layers in Santos Basin - Brazil. IADC/SPE Drilling Conference. Miami: Drilling Conference. 2006. p. 16.

RAVI, K.; BOSMA, M.; GASTEBLED, O. Safe and economic gas wells through cement design for life of the well. Gas Technology Symposium. Calgary: Society of Petroleum Engineers Inc. (SPE). 2002. p. 15.

RAVI, K.; BOSMA, M.; HUNTER, L. Optimizing the cement sheath design in HPHT Shearwater field. Drilling Conference. Amsterdam: Society of Petroleum Engineers (SPE). 2003. p. 9.

RAVI, K.; GRAY, D.; PATTILLO, P. Procedures to optimize cement systems for specific well conditions. Fluids Conference. Houston: AADE Drilling Fluids Technical Conference. 2006. p. 11.

RIGHETTO, G. L. et al. A smart way to build geomechanical models and analyze casing collapse during the petroleum field development. American Rock Mechanics Association (ARMA). Minneapolis: [s.n.]. 2014. p. 8.

ROCHA, L. A. S.; DE AZEVEDO, C. T. Projetos de Poços de Petróleo. Rio de Janeiro: Editora Interciência, 2009.

RODRIGUEZ, W. J.; FLECKENSTEIN, W. W.; EUSTES, A. W. Simulation of collapse loads on cemented casing using finite element analysis. Annual Technical Conference and Exhibition. Denver: Society of Petroleum Engineers Inc. (SPE). 2003. p. 9.

SCHREPPERS, G. A framework for wellbore cement integrity analysis. 49th US Rock Mechanics / Geomechanics Symposium. San Francisco: American Rock Mechanics Association (ARMA). 2015. p. 9. 
SHAHRI, M. A.; SCHUBERT, J. J.; AMANI, M. Detecting and modeling cement failure in high-pressure/high-temperature (HP/HT) wells, using finite element method (FEM). International Petroleum Technology Conference. Doha: International Petroleum Technology Conference (IPTC). 2005. p. 10.

SHAHRI, M. P. et al. An integrated analytical workflow for analysing wellbore stress, stability and strengthening. 49th US Rock Mechanics / Geomechanics Symposium. San Francisco: American Rock Mechanics Association (ARMA). 2015. p. 11.

TEODORIU, C.; UGWU, I.; SCHUBERT, J. Estimation of casing-cementformation interaction using a new analytical model. SPE EUROPEC/EAGE Annual Conference and Exhibition. Barcelona: Society of Petroleum Engineers (SPE). 2010. p. 13.

URIBE, J. D. V. et al. Estabilidade de poços de petróleo em formações evaporíticas - Efeitos de fluência, plasticidade e dano. XXXVI Ibero-Latin American Congress on Computational Methods in Engineering. Rio de Janeiro: CILAMCE 2015. 2015. p. 12.

VULLO, V. Circular cylinders and pressure vessels. 1. ed. [S.1.]: Springer International Publishing, v. 3, 2014.

WILSON, S. M. A Wellbore stability approach for self-killing blowout assessment. Deapwater Drilling and Completions Conference. Galveston: Society of Petroleum Engineers (SPE). 2012. p. 16.

WILSON, S. M.; FOSSUM, A. F.; FREDRICH, J. T. Assessment of salt loading on well casings. IADC/SPE Drilling Conference. Dallas: IADC/SPE Drilling Conference. 2002. p. 10.

WONG, T.-F.; BRACE, W. F. Thermal expansion of rocks - Some measurements at high pressure. Tectonophysics, Amsterdam, v. 57, p. 95-117, 1979.

$\mathrm{XU}, \mathrm{H}$. et al. Influence of the WHCP on cement sheath stress and integrity in HTHP gas well. Journal of Petroleum Science and Engineering, v. 126, p. 174-180, Fevereiro 2015.

ZERVOS, A.; PAPANASTASIOU, P.; COOK, J. Elastoplastic finite element analysis of inclined wellbores. SPE/ISRM Eurock '98. Trondheim: Society of Petroleum Engineers Inc. (SPE). 1998. p. 10. 